\title{
Biomonitoramento intra-urbano da poluição de origem veicular: utilização da casca de árvore na identificação de fontes de poluição atmosférica
}

\author{
Tese apresentada à Faculdade de Medicina da \\ Universidade de São Paulo para obtenção do \\ título de Doutor em Ciências \\ Programa de Patologia \\ Orientadora: Profa Dra Mitiko Saiki \\ (Versão corrigida. Resolução CoPGr 6018, de 13 de Outubro de 2011. A versão \\ original está disponível na biblioteca FMUSP)
}


Dados Internacionais de Catalogação na Publicação (CIP)

Preparada pela Biblioteca da

Faculdade de Medicina da Universidade de São Paulo

Creprodução autorizada pelo autor

Moreira, Tiana Carla Lopes

Biomonitoramento intra-urbano da poluição de origem veicular : utilização da casca de árvore na identificação de fontes de poluição atmosférica / Tiana Carla Lopes Moreira. -- São Paulo, 2015.

Tese(doutorado)--Faculdade de Medicina da Universidade de São Paulo. Programa de Patologia.

Orientadora: Profa Dra Mitiko Saiki.

Descritores: 1.Poluição do ar 2.Saúde ambiental 3.Casca de planta 4.Monitoramento do ar 5.Emissão de veículos

USP/FM/DBD-484/15 


\section{Agradecimentos}

À Minha orientadora, Profa. Dra Mitiko Saiki;

Ao Prof. Paulo Hilário Nascimento Saldiva;

Minha família, Elza Maria Lopes, Camila Lopes Moreira, Elza Costa Lopes, Everaldo Ramos Moreira, Estela Ramos Moreira e Tomaz Bernardo Moreira;

Aos Colegas do Laboratório de poluição atmosférica experimental Luís Fernando, Regiani e Mariângela;

Às minhas 'roomates" durante o período de doutorado sanduiche em Harvard, Ana Laura Ricci Vitor, Carine Hartmann e Nívea Ferreira;

Ao Coordenador do Programa de Pós graduação em Patologia da FMUSP, Prof. Raymundo Soares Azevedo;

A professora Carmem Diva Saldiva;

Ao secretário do Programa de Pós graduação em Patologia Thiago Resende;

À Profa. Dra. Thais Mauad;

Ao Prof Petros Koutrakis, Harvard School of Public Health;

Ao Choong Ming Kang, Harvard School of Public Health;

A todos meus amigos;

Ao Toddy e a Dara;

A todos aqueles que de alguma forma contribuíram para o desenvolvimento e elaboração desta tese;

À Universidade de São Paulo (USP), Faculdade de Medicina (FMUSP) e a Faculdade de Saúde Pública da Universidade de Harvard (HSPH);

A Capes pela bolsa de Doutorado e Bolsa de doutorado sanduiche (PDSE). 

Esta dissertação ou tese está de acordo com as seguintes normas, em vigor no momento desta publicação:

Referências: adaptado de International Committee of Medical Journals Editors (Vancouver).

Universidade de São Paulo. Faculdade de Medicina. Divisão de Biblioteca e Documentação. Guia de apresentação de dissertações, teses e monografias. Elaborado por Anneliese Carneiro da Cunha, Maria Julia de A. L. Freddi, Maria F. Crestana, Marinalva de Souza Aragão, Suely Campos Cardoso, Valéria Vilhena. 3a ed. São Paulo: Divisão de Biblioteca e Documentação; 2011.

Abreviaturas dos títulos dos periódicos de acordo com List of Journals Indexed in Index Medicus. 



\section{Sumário}

Lista de tabelas

Lista de figuras

Resumo

Summary

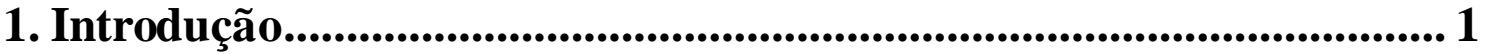

1.1 Objetivos ................................................................................................................ 5

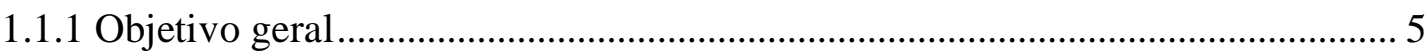

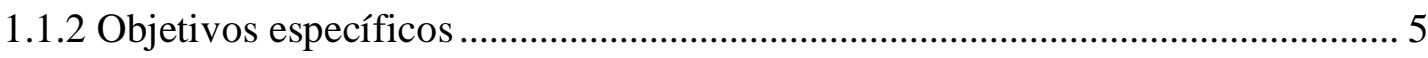

1.2 Revisão da literatura ........................................................................... 7

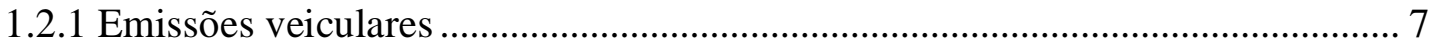

1.2.3 Poluição do ar e tráfego de veículos na cidade de São Paulo .............................. 9

1.2.3 Monitoramento da poluição do ar .................................................................... 13

1.2.4 Biomonitoramento de poluentes atmosféricos ............................................... 18

1.2.5 Espectrômetria de fluorescência de raios X (EDXRF) aplicada na análise do

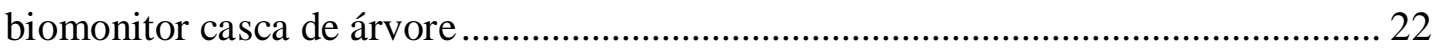

1.2.6 Impacto do material particulado na saúde humana........................................ 23

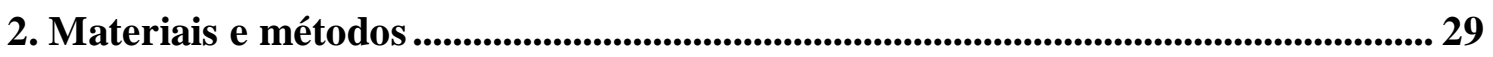

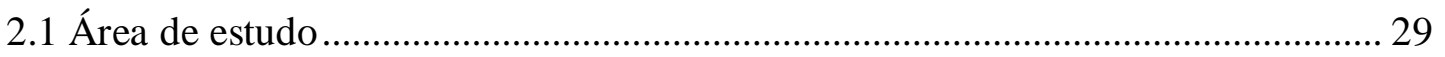

2.2 Anatomia e morfologia das espécies arbóreas utilizadas no estudo de biomonitoramento da poluição do ar ....................................................................... 31

2.3 Procedimento de coleta das cascas das árvores................................................... 31

2.4 Tratamento das amostras de cascas de árvore para análise ................................. 33

2.5 Análises das amostras pelo método de EDXRF.................................................... 34

2.6 Análise dos dados de cascas de árvores..................................................................... 36

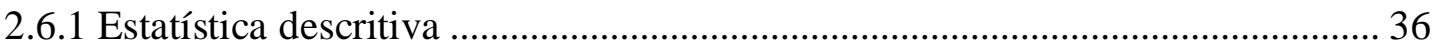

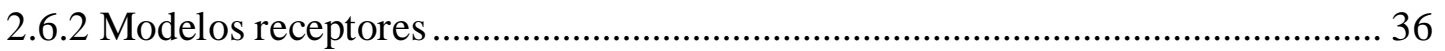

2.6.2.1 Análise de componentes principais .................................................................... 36

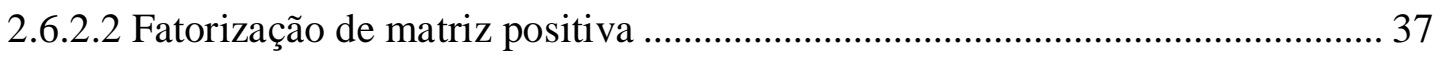

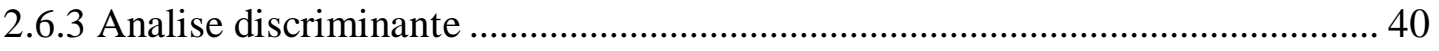

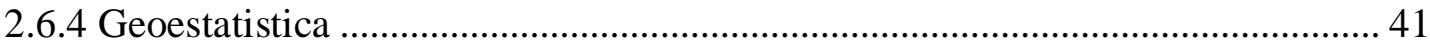

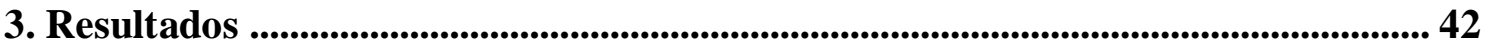




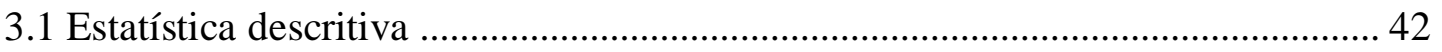

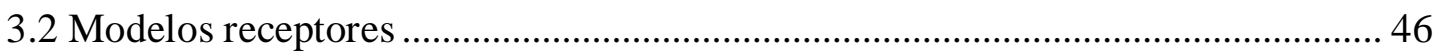

3.2.1 Análise de componentes principais .................................................................... 46

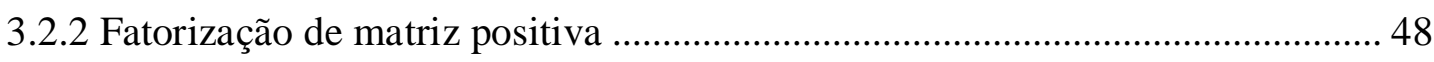

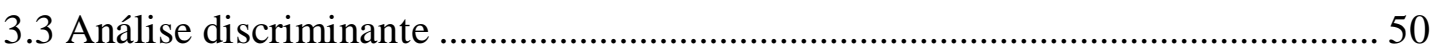

3.4 Geoestatistica - Mapas de distribuição das concentrações de elementos nas cascas de árvores no centro expandido de São Paulo ................................................................... 50

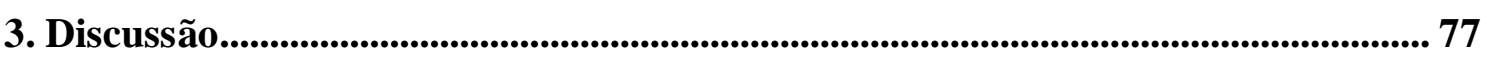

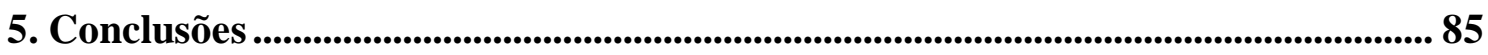

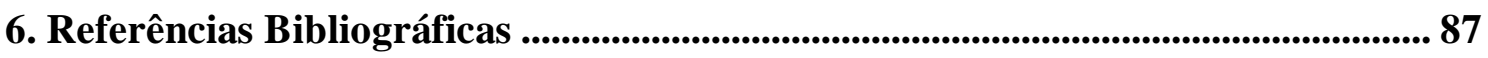




\section{Lista de Tabelas}

Tabela 1. Classificação das vias de tráfego segundo a Companhia de Engenharia de Tráfego (CET, 2013) e o Código de Trânsito Brasileiro (CTB Brasil, 1997)

Tabela 2 - Padrões de qualidade do ar (CONAMA - Brasil, EPA- EUA, Europa, CETESB- São Paulo).

Tabela 3 - Dados das espécies arbóreas cujas cascas foram coletadas na área de estudo.

Tabela 4 - Número de amostras (N), Mediana das concentrações de elementos (em ppm), 1ํ e 3ำ quartil, valor mínimo, valor máximo

Tabela 5 - Número de amostras $(\mathrm{N})$, Mediana das concentrações de elementos (em ppm), 1ㅇ e 3ㅇquartil, valor mínimo, valor máximo por tipo de via

Tabela 6-Resultados da Análise dos Componentes Principais- Rotação ortogonal Varimax (Varimax method with Kaiser Normalization)

Tabela 7- Composição das fontes segundo o resultado obtido no programa PMF

Tabela 8 - Nova classificação das vias da área de estudo obtida por meio da aplicação na análise discriminante 


\section{Lista de Figuras}

Figura 1 - Composição da frota de veículos na cidade de São Paulo. Fonte: Departamento Estadual de Trânsito de São Paulo - Detran (DETRAN, 2013)...

Figura 2 - Mapa de distribuição das estações de monitoramento da qualidade do ar da CETESB na Região Metropolitana de São Paulo. (CETESB, 2014)

Figura 3 - Estações automáticas da CETESB no centro expandido e estações manuais para monitoramento de $\mathrm{MP}_{2,5}$

Figura 4. Área de estudo e localização das árvores cujas cascas amostradas no centro expandido de São Paulo.

Figura 5. Localização da Mata da Câmara em São Roque-SP (Google Earth).....

Figura 6 - Seção transversal do tronco de uma árvore.

Figura 7 - Foto mostrando a remoção da casca do tronco da espécie Sibipiruna..

Figura 8 - Foto da casca e do saco de papel para armazenagem da casca da espécie Sibipiruna.

Figura 9 - Materiais utilizados na remoção da camada superficial da casca de árvore e sua transformação em pó para análise.

Figura 10 - Foto do equipamento EDX- 700

Figura 11 - Interface da página de inserção das planilhas de concentração dos elementos e incertezas analíticas.

Figura 12- Classificação dos elementos.

Figura 13 (time series concentration- time-series plot)

Figura 14 - Soma da concentração de todos os elementos $\left(\mu \mathrm{g} / \mathrm{m}^{3}\right)$ em função do tipo de via e na área controle.

Figura 15 - Gráfico de radar mostrando a distribuição dos elementos nas diferentes vias de tráfego

Figura 16- Gráfico Scree-Plot da análise de componentes principais.

Figura 17- Composição das fontes obtidas pela aplicação da PMF.

Figura 18 - Mapa da distribuição das concentrações de $\mathrm{Al}$ na região do centro expandido de São Paulo. (Mapa de contorno de isolinhas, no sistema UTM, datum Sade 69, latitude 23, gerado partir da concentração média do elemento Al, utilizando a metodologia de Krigagem Ordinária) 
Figura 19 - Mapa de erros da distribuição das concentrações de Al na região do centro expandido de São Paulo. (Mapa de contorno de isolinhas, no sistema UTM, datum Sade 69, latitude 23, gerado partir da concentração média do elemento Al, utilizando a metodologia de Krigagem Ordinária).

Figura 20 - Mapa da distribuição da concentração de Ba na região do centro expandido de São Paulo. (Mapa de contorno de isolinhas, no sistema UTM, datum Sade 69, latitude 23, gerado partir da concentração média do elemento Ba, utilizando a metodologia de Krigagem Ordinária).

Figura 21 - Mapa de erros da distribuição das concentrações de Ba na região do centro expandido de São Paulo. (Mapa de contorno de isolinhas, no sistema UTM, datum Sade 69, latitude 23, gerado partir da concentração média do elemento Ba, utilizando a metodologia de Krigagem Ordinária).

Figura 22- Mapa da distribuição da concentração de Ca na região do centro expandido de São Paulo. (Mapa de contorno de isolinhas, no sistema UTM, datum Sade 69, latitude 23, gerado partir da concentração média do elemento $\mathrm{Ca}$, utilizando a metodologia de Krigagem Ordinária).

Figura 23 - Mapa de erros da distribuição das concentrações de Ca na região do centro expandido de São Paulo. (Mapa de contorno de isolinhas, no sistema UTM, datum Sade 69, latitude 23, gerado partir da concentração média do elemento $\mathrm{Ca}$, utilizando a metodologia de Krigagem Ordinária)....

Figura 24 - Mapa da distribuição da concentração de $\mathrm{Cu}$ na região do centro expandido de São Paulo. (Mapa de contorno de isolinhas, no sistema UTM, datum Sade 69, latitude 23, gerado partir da concentração média do elemento $\mathrm{Cu}$, utilizando a metodologia de Krigagem Ordinária)

Figura 25 - Mapa de erros da distribuição das concentrações de $\mathrm{Cu}$ na região do centro expandido de São Paulo. (Mapa de contorno de isolinhas, no sistema UTM, datum Sade 69, latitude 23, gerado partir da concentração média do elemento $\mathrm{Cu}$, utilizando a metodologia de Krigagem Ordinária)

Figura 26 - Mapa da distribuição da concentração de Fe na região do centro expandido de São Paulo. (Mapa de contorno de isolinhas, no sistema UTM, datum Sade 69, latitude 23, gerado partir da concentração média do elementoFe, utilizando a metodologia de Krigagem Ordinária).

Figura 27 - Mapa de erros da distribuição das concentrações de Fe na região do centro expandido de São Paulo. (Mapa de contorno de isolinhas, no sistema UTM, datum Sade 69, latitude 23, gerado partir da concentração média do elemento Fe, utilizando a metodologia de Krigagem Ordinária)

Figura 28 - Mapa da distribuição da concentração de K na região do centro expandido de São Paulo. (Mapa de contorno de isolinhas, no sistema UTM, datum Sade 69, latitude 23, gerado partir da concentração média do elemento $\mathrm{K}$, utilizando a metodologia de Krigagem Ordinária) 
Figura 29 - Mapa de erros da distribuição das concentrações de K na região do centro expandido de São Paulo. (Mapa de contorno de isolinhas, no sistema UTM, datum Sade 69, latitude 23, gerado partir da concentração média do elemento K, utilizando a metodologia de Krigagem Ordinária).

Figura 30 - Mapa da distribuição da concentração de Mg na região do centro expandido de São Paulo. (Mapa de contorno de isolinhas, no sistema UTM, datum Sade 69, latitude 23, gerado partir da concentração média do elemento Mg, utilizando a metodologia de Krigagem Ordinária).

Figura 31- Mapa de erros da distribuição das concentrações de $\mathrm{Mg}$ na região do centro expandido de São Paulo. (Mapa de contorno de isolinhas, no sistema UTM, datum Sade 69, latitude 23, gerado partir da concentração média do elemento Mg, utilizando a metodologia de Krigagem Ordinária).

Figura 32- Mapa da distribuição da concentração de Mn na região do centro expandido de São Paulo. (Mapa de contorno de isolinhas, no sistema UTM, datum Sade 69, latitude 23, gerado partir da concentração média do elemento Mn, utilizando a metodologia de Krigagem Ordinária).

Figura 33- Mapa de erros da distribuição das concentrações de Mn na região do centro expandido de São Paulo. (Mapa de contorno de isolinhas, no sistema UTM, datum Sade 69, latitude 23, gerado partir da concentração média do elemento Mn, utilizando a metodologia de Krigagem Ordinária).

Figura 34- Mapa da distribuição da concentração de $\mathrm{P}$ na região do centro expandido de São Paulo. (Mapa de contorno de isolinhas, no sistema UTM, datum Sade 69, latitude 23, gerado partir da concentração média do elemento $P$, utilizando a metodologia de Krigagem Ordinária)....

Figura 35 - Mapa de erros da distribuição das concentrações de $\mathrm{P}$ na região do centro expandido de São Paulo. (Mapa de contorno de isolinhas, no sistema UTM, datum Sade 69, latitude 23, gerado partir da concentração média do elemento P, utilizando a metodologia de Krigagem Ordinária)

Figura 36- Mapa da distribuição da concentração de Rb na região do centro expandido de São Paulo. (Mapa de contorno de isolinhas, no sistema UTM, datum Sade 69, latitude 23, gerado partir da concentração média do elemento $\mathrm{Rb}$, utilizando a metodologia de Krigagem Ordinária).

Figura 37 - Mapa de erros da distribuição das concentrações de $\mathrm{Rb}$ na região do centro expandido de São Paulo. (Mapa de contorno de isolinhas, no sistema UTM, datum Sade 69, latitude 23, gerado partir da concentração média do elemento Rb, utilizando a metodologia de Krigagem Ordinária)

Figura 38- Mapa da distribuição da concentração de $S$ na região do centro expandido de São Paulo. (Mapa de contorno de isolinhas, no sistema UTM, datum Sade 69, latitude 23, gerado partir da concentração média do elemento $S$, utilizando a metodologia de Krigagem Ordinária). 
Figura 39- Mapa de erros da distribuição das concentrações de S na região do centro expandido de São Paulo. (Mapa de contorno de isolinhas, no sistema UTM, datum Sade 69, latitude 23, gerado partir da concentração média do elemento S, utilizando a metodologia de Krigagem Ordinária)......

Figura 40- Mapa da distribuição da concentração de $\mathrm{Sr}$ na região do centro expandido de São Paulo. (Mapa de contorno de isolinhas, no sistema UTM, datum Sade 69, latitude 23, gerado partir da concentração média do elemento Sr, utilizando a metodologia de Krigagem Ordinária)

Figura 41 - Mapa de erros da distribuição das concentrações de $\mathrm{Sr}$ na região do centro expandido de São Paulo. (Mapa de contorno de isolinhas, no sistema UTM, datum Sade 69, latitude 23, gerado partir da concentração média do elemento Sr, utilizando a metodologia de Krigagem Ordinária).

Figura 42 - Mapa da distribuição da concentração de Zn na região do centro expandido de São Paulo. (Mapa de contorno de isolinhas, no sistema UTM, datum Sade 69, latitude 23, gerado partir da concentração média do elemento Zn, utilizando a metodologia de Krigagem Ordinária).

Figura 43 - Mapa de erros da distribuição das concentrações de Zn na região do centro expandido de São Paulo. (Mapa de contorno de isolinhas, no sistema UTM, datum Sade 69, latitude 23, gerado partir da concentração média do elemento Zn, utilizando a metodologia de Krigagem Ordinária).... 
Moreira TCL. Biomonitoramento intra-urbano da poluição de origem veicular: utilização da casca de árvore na identificação de fontes de poluição atmosférica [Tese]. São Paulo: Faculdade de Medicina, Universidade de São Paulo; 2015

Devido à dispersão heterogênea da poluição do ar, é importante compreender as fontes de poluição local para avaliar os impactos sobre a saúde humana. Os elementos químicos, especialmente metais, podem afetar a saúde humana, causando efeitos genotóxicos, indução de câncer e danos nos sistemas imunes e neurológicos. Alguns elementos são considerados marcadores de emissões veiculares. Por conseguinte, é de grande interesse avaliar se existe uma relação entre o fluxo de tráfego de veículos e a deposição de elementos usando a técnica biomonitoramento. Neste estudo, casca de árvore de 171 diferentes pontos de amostragens coletados no centro expandido da cidade de São Paulo foi utilizada como biomonitora. As concentrações dos elementos químicos ( $\mathrm{Al}, \mathrm{Ba}, \mathrm{Ca}, \mathrm{Cl}, \mathrm{Cu}, \mathrm{Fe}, \mathrm{K}, \mathrm{Mg}, \mathrm{Mn}, \mathrm{Na}, \mathrm{P}, \mathrm{Pb}, \mathrm{Rb}, \mathrm{S}, \mathrm{Sr}$ e $\mathrm{Zn}$ ) foram determinadas por meio da espectrometria de fluorescência de raios x por dispersão de energia (EDXRF). A técnica estatística da análise de componentes principais (PCA) foi aplicada aos resultados analíticos obtidos para identificar as fontes de poluentes de elementos químicos. A principal fonte de poluentes do ar encontrada no Centro expandido da cidade de São Paulo pôde ser atribuída à emissão veicular principalmente de processos de desgastes de suas peças e da ressuspensão das poeiras das vias (caracterizados por $\mathrm{Al}, \mathrm{Ba}, \mathrm{Cu}, \mathrm{Fe}, \mathrm{Mn}$ e $\mathrm{Zn}$ ), explicando $27,1 \%$ da variância, seguida de cimento das construções $(14,8 \%)$, sal marinho $(11,6 \%)$ e queima de madeira $(10 \%)$ O modelo receptor conhecido como fatoração de matriz positiva utilizado para identificação das fontes de poluição do ar mostrou também que a emissão veicular é a principal fonte de origem dos poluentes na área de estudo. Foi verificado ainda que os elementos relacionados à emissão veicular apresentaram diferentes concentrações em uma mesma rua, e estes resultados permitiram obter uma nova classificação das ruas de acordo com a concentração dos elementos. Os mapas de distribuição espacial das concentrações dos elementos foram obtidos para avaliar os diferentes níveis de poluição em ruas e avenidas. Os resultados indicaram que a técnica de biomonitoramento pode ser aplicada para avaliar a dispersão da poluição do ar.

Descritores: poluição do ar; saúde ambiental; casca de planta; monitoramento do ar; emissões de veículos.

Moreira TCL. Intraurban biomonitoring of air pollution from vehicular sources: source apportionment using tree barks [Thesis]. São Paulo: "Faculdade de Medicina, Universidade de São Paulo"; 2015 
Due to the heterogeneous dispersion of air pollution, it is important to understand sources of local pollution to assess impacts on human health. Chemical elements, especially metals, can affect human health, causing genotoxic effects, cancer induction, and damage in the immune and neurological systems. Some elements are considered markers of vehicle emissions. Consequently it is of great interest to evaluate if there is a relationship between the vehicular traffic flow and deposition of elements measured using the biomonitoring technique. In this study, tree barks from 171 sampling sites in the inner city of São Paulo were collected. The chemical elements ( $\mathrm{Al}, \mathrm{Ba}, \mathrm{Ca}, \mathrm{Cl}, \mathrm{Cu}$, $\mathrm{Fe}, \mathrm{K}, \mathrm{Mg}, \mathrm{Mn}, \mathrm{Na}, \mathrm{P}, \mathrm{Pb}, \mathrm{Rb}, \mathrm{S}, \mathrm{Sr}$ and $\mathrm{Zn}$ ) were determined by the energy dispersive $\mathrm{x}$-ray fluorescence (EDXRF) spectrometry. The principal component analysis (PCA) statistical technique was applied to the analytical results in order to identify the origin of element pollutants. The results indicated that major source of air pollution is due to vehicular emission derived mainly from wear processes and road dust resuspension (characterized by $\mathrm{Al}, \mathrm{Ba}, \mathrm{Cu}, \mathrm{Fe}, \mathrm{Mn}$ and $\mathrm{Zn}$ ), which was explained by $27.1 \%$ of the variance, followed by cement from building constructions and road pavements (14.8 $\%$ ), sea salt (11.6\%) and wood burning (10\%) at São Paulo inner city. The algorithm called positive matrix factorization (PMF) likewise used to identify the air pollution sources showed that the vehicular emission is also the main source of atmospheric pollution. We also verified that the elements related to vehicular emission presented different concentrations at different sampling sites of the same street, which might be possible to identify a new street classification according to the elemental concentration. The spatial distribution maps of element concentrations were obtained to evaluate the different levels of pollution on streets and avenues. Results indicated that biomonitoring technique can be applied to evaluate dispersion of air pollution.

Descriptors: air pollution; environmental health; plant bark; air monitoring; vehicle emissions 


\section{Introdução}

A poluição atmosférica é definida como uma complexa mistura de componentes gasosos e de material particulado, proveniente de fontes móveis e estacionárias, sendo estas constituídas por veículos automotores e aquelas por indústrias, incineradores, entre outros. No último século, a principal fonte de poluição atmosférica nos centros urbanos mudou de industrial para veicular, e isto pode ser atribuído a vários fatores, tais como: o maior controle legislativo de emissões, melhorias nos processos industriais e aumento da frota veicular.

Esse monitoramento da poluição é realizado por meio da aplicação de métodos analíticos instrumentais ou de biomonitoramento. Nos métodos analíticos instrumentais são utilizadas técnicas de amostragem sofisticadas e dispendiosas, devido à necessidade de alimentação contínua de energia elétrica, à natureza dos equipamentos e à necessidade de técnicos capacitados na operação desses equipamentos.

Ainda em relação ao ônus, a aplicação dessas técnicas seria pouco eficaz no que diz respeito a monitorar os diferentes gradientes de exposição nos quais a principal fonte emissora é a automotiva (Dos Cruz e Campos, 2002). Isso devido ao alto custo das estações para o monitoramento da qualidade do ar, o que leva à distribuição espacial inadequada das estações, bem como faz com que vastas áreas urbanizadas fiquem desprovidas de informações da qualidade do ar, de modo que a estimativa do risco para a saúde da população relativo à exposição aos poluentes fique propensa ao erro.

Para sanar essas dificuldades, surge a necessidade de desenvolver métodos alternativos que possibilitem conhecer a distribuição da poluição do ar em micro-escala espacial com baixo custo. Habermann e Gouveia (2012) afirmam que as estações de monitoramento são capazes de atingir uma distância de até $250 \mathrm{~m}$ ao redor de uma mesma estação, subestimando as concentrações em áreas mais afastadas. 
Adicionalmente, segundo a Companhia Ambiental do Estado de São Paulo (CETESB, 2013), os dados das estações de monitoramento são significativos apenas em $100 \mathrm{~m}$ de seu entorno para estudos de microescala, justificando a necessidade de desenvolvimento de metodologias que permitam detectar a heterogeneidade a poucas distâncias da fonte geradora e obter uma melhor distribuição espacial dos poluentes. Essas metodologias também podem empregar técnicas determinação da composição elementar do material particulado, algo que as redes automáticas de monitoramento da CETESB não fazem. Outro aspecto das redes automáticas de monitoramento da CETESB é que medem em sua maioria apenas $\mathrm{MP}_{10}$ e não elementos químicos.

Dois exemplos dessas metodologias seriam a modelagem e a geoestatística que permitem estimar os níveis de poluentes. No método de modelagem, são utilizados diversos dados que contêm parâmetros que afetam a dispersão de poluentes, tais como: uso e ocupação de solo, tipo de frota e combustível predominante na região, dados climáticos, entre outros. Na geoestatística, são utilizados dados coletados em diversos pontos da área de estudo. Quanto maior o número de pontos coletados, melhor é a predição. Essas coletas dos dados podem ser feitas usando amostradores de biomonitoramento e monitoramentos ativos e passivos.

Markert et al. (2003) definiram biomonitoramento como a utilização da resposta dos indivíduos, em diferentes níveis de organização biológica, de forma a detectar ou prevenir os efeitos adversos da contaminação sobre a saúde humana. Para o biomonitoramento, podem ser utilizadas diferentes espécies vegetais que permitem obter dados da composição da poluição em microescala.

A casca de árvore muitas vezes apresenta vantagens para uso na técnica de biomonitoramento em relação a outros organismos como os liquens ou as folhas. Apesar de bem estabelecida, a utilização de liquens como biomonitores estes organismos 
apresentam desvantagens como as descritas por Upreti et al. (2015) isto é em locais poluídos a ocorrência liquens pode ser baixa uma vez que a poluição pode afetar o seu crescimento. Já as folhas das árvores apresentam restrições devido à sua interação com o solo. Nas folhas são encontrados os poluentes provenientes do solo assim como do ar atmosférico.

O biomonitoramento possui algumas limitações como organismos que se adaptam e respondem menos, respostas temporais imprecisas e alta variabilidade nas respostas.

A aplicação da técnica de biomonitoramento usando cascas de árvores seria de grande valia permitindo complementar os dados obtidos da rede monitoramento da CETESB provendo de informações da composição elementar do material particulado (MP) que é interceptado e aderido pelas cascas das árvores.

O biomonitoramento de poluentes permite avaliar, em geral, a qualidade do ar de forma rápida e simples, e cujos dados obtidos poderão contribuir para buscas alternativas para a adoção de políticas públicas adequadas em áreas de interesse para o estudo da poluição. O biomonitoramento pode ser ativo, quando o biomonitor é introduzido no local ou passivo com a análise de biomonitores já existentes no local. Com a utilização da técnica de biomonitoramento passivo, é possível avaliar a poluição integral de um período de tempo mais longo, além de ser menos custosa, e mais rápida que o biomonitoramento ativo uma vez que as árvores comumente já estão nas áreas de estudo e não há a etapa de transplante das cascas para exposição.

Aliando técnicas de biomonitoramento com a geoestatística e ferramentas estatísticas de análise multivariada, é possível determinar a distribuição espacial dos elementos químicos, de suas concentrações e ainda a identificação de possíveis fontes emissoras. Os dados da determinação da composição elementar do material particulado 
retido na casca e os dados da contribuição das suas fontes emissoras podem estar relacionados com o tipo de via de tráfego e ainda com os padrões na forma de conduzir os veículos.

A utilização da casca de árvore como monitora da poluição de elementos químicos é de grande importância para verificar se o biomonitoramento permite diferenciar a intensidade de emissão dos elementos químicos dependendo do tipo de vias de tráfego.

Face ao que foi exposto, julgou se de grande interesse estudar nesta pesquisa, para a cidade de São Paulo, a distribuição espacial da poluição atmosférica de elementos químicos proveniente do tráfego veicular em microescala por meio do biomonitoramento vegetal. Para tanto, foram determinadas as concentrações de elementos cujas fontes de origem estejam relacionadas ao tráfego veicular, em cascas de árvores coletadas na região do município de São Paulo, na área denominada de centro expandido. Essa área refere-se àquela circunscrita às grandes avenidas da Cidade de São Paulo que possuem restrições ao tráfego veicular conforme será descrito no capitulo Materiais e Métodos. 


\subsection{Objetivos}

\subsubsection{Objetivo geral}

O objetivo desta pesquisa foi avaliar a poluição aérea de origem veicular por elementos químicos utilizando como biomonitor cascas de árvores das vias da região do centro expandido do município de São Paulo.

\subsubsection{Objetivos específicos}

Os objetivos específicos desta pesquisa são:

- determinação, por biomonitoramento, das concentrações dos elementos químicos presentes nas cascas de árvores coletadas em distintos tipos de vias de tráfego;

- identificação das fontes de poluição na cidade de São Paulo;

- obtenção da distribuição espacial de elementos químicos poluentes provenientes do tráfego veicular em microescala por meio do biomonitoramento. 


\subsection{Revisão da literatura}

\subsubsection{Emissões veiculares}

Os veículos são responsáveis pela grande parte das emissões de poluentes atmosféricos em centros urbanos. A emissão dos poluentes veiculares está relacionada ao tipo de veículo (leve ou pesado), tipo de combustível utilizado, idade do veículo, condições de sua manutenção, velocidade de deslocamento, entre outros (Toledo e Nardocci, 2013).

A Agência de Proteção Ambiental Americana (EPA) elaborou um relatório informando que as emissões veiculares são responsáveis pela liberação de mais de mil compostos químicos na atmosfera (EPA, 2006).

Relativamente aos principais poluentes oriundos da emissão veicular, podem ser citados: monóxido de carbono $(\mathrm{CO})$, hidrocarbonetos $(\mathrm{HC})$, dióxido de enxofre $\left(\mathrm{SO}_{2}\right)$, aldeídos $(\mathrm{CHO})$, dióxido de carbono $\left(\mathrm{CO}_{2}\right)$ e os óxidos de nitrogênio $\left(\mathrm{NO}_{\mathrm{x}}\right)$, além de material particulado (MP) . O MP pode ser separado em grosso $\left(\mathrm{MP}_{10}\right)$, fino $\left(\mathrm{MP}_{2,5}\right)$ e ainda o ultrafino $\left(\mathrm{MP}_{1,0}\right)$. A maioria dos elementos químicos estão presentes no $\mathrm{MP}_{2,5} \mathrm{e}$ no $\mathrm{MP}_{1,0}$ (Assunção, 2004).

Segundo o Relatório Emissões Veiculares no Estado de São Paulo - 2012, da Companhia Ambiental do Estado de São Paulo (CETESB, 2013), os veículos são responsáveis por lançar mais de $1000 \mathrm{t}$ de material particulado anualmente na atmosfera da Região Metropolitana de São Paulo, além de outros poluentes.

Segundo Silva (2007), os veículos a diesel emitem uma concentração média da emissão de partículas $\left(\mathrm{PM}_{10}\right)$ de aproximadamente $20,166 \mathrm{mg} / \mathrm{m}^{3}$ de ar; os a gasolina, de $0,411 \mathrm{mg} / \mathrm{m}^{3}$ e aqueles a álcool, de $0,142 \mathrm{mg} / \mathrm{m}^{3}$. 
Estudos também têm demonstrado que existem diferenças na emissão, não apenas pelo tipo de veículo, mas também pela idade deles (Toledo, 2010).

Entre elementos, normalmente estudados e apresentam relação com o tráfego veicular, são: bário $(\mathrm{Ba})$, cádmio $(\mathrm{Cd})$, cromo $(\mathrm{Cr})$, cobre $(\mathrm{Cu})$, ferro $(\mathrm{Fe})$, manganês $(\mathrm{Mn})$, níquel $(\mathrm{Ni})$, chumbo $(\mathrm{Pb})$, enxofre $(\mathrm{S})$ e zinco $(\mathrm{Zn})$ (Samara e Voutsa, 2005; Laschober et al., 2003; Martins, 2009; Maher et al. 2007; Silva, 2007).

De acordo com Silva (2007), as emissões de metais dos veículos a diesel se devem principalmente ao combustível. Seus estudos têm mostrado que Al, $\mathrm{Ca}, \mathrm{Fe}, \mathrm{Mg}$ e Si representam mais de $80 \%$ dos teores de elementos existentes no combustível diesel e o restante está distribuído entre teores de $\mathrm{Ag}, \mathrm{Ba}, \mathrm{Cd}, \mathrm{Co}, \mathrm{Cr}, \mathrm{Cu}, \mathrm{Mn}, \mathrm{Mo}, \mathrm{Ni}, \mathrm{Pb}, \mathrm{Sb}$, Sr, Ti, V e Zn. Os veículos a gasolina emitem quantidades traço de vários elementos, como $\mathrm{Mn}, \mathrm{Zn}, \mathrm{Cu}, \mathrm{Fe}, \mathrm{Mg}$ e $\mathrm{Pb}$ e, nos casos de álcool, tem sido observada a presença de $\mathrm{Zn}, \mathrm{Cu}, \mathrm{Pb}$ e $\mathrm{Cd}$.

A emissão de elementos relacionados ao tráfego veicular tem sua origem na queima incompleta do combustível ( $\mathrm{Ba}$ e $\mathrm{Pb}$ ), pneus, freios, motores e desgaste de peças ( $\mathrm{Cd}, \mathrm{Cr}, \mathrm{Cu}, \mathrm{Fe}, \mathrm{Mn}, \mathrm{Ni}, \mathrm{Sb}, \mathrm{V}$ e $\mathrm{Zn}$ ) e ainda a ressuspensão da poeira do solo ( $\mathrm{Al}$ e Fe) (Schauer et al, 2006).

Nas áreas urbanas, as fontes potenciais são os veículos e as emissões de $\mathrm{Cd}$ e $\mathrm{Pb}$ são as características. A maioria dos estudos revela que a principal fonte de poluição em grandes centros urbanos é a veicular, já que muitas indústrias não se encontram mais instaladas nas áreas urbanas (Olowoyo et al., 2009).

Também Santos et al. (2015) encontraram altas concentrações dos elementos Fe, $\mathrm{Pb}$ e $\mathrm{Zn}$ em áreas com o tráfego intenso utilizando a planta Tradescantia pallida na cidade de Ribeirão Preto. 
Pandian et al. (2009) observaram que veículos pesados emitem maior quantidade de MP que veículos leves sendo que altas densidades de tráfego aumentam as concentrações dos poluentes e o peso e tamanho do veículo aumentam o consumo de combustível elevando assim, a emissão de MP e $\mathrm{NO}_{x}$.

Consequentemente, os diferentes tipos de vias de tráfego também podem influenciar no tipo de emissão. Uma via com poucos pontos de parada e redução de velocidade apresentará emissão relacionada ao escapamento veicular, enquanto numa via com muitas paradas poderá ocorrer a emissão de mais elementos relacionados ao desgaste de peças do veículo.

Segundo Ericsson (2000) o padrão de condução de um veículo também é responsável por diferentes níveis de emissão. E esse padrão é influenciado por fatores, como o tipo de rua, número de faixas na via, condições meteorológicas e ainda das condições de tráfego e o tipo de motorista.

\subsubsection{Poluição do ar e tráfego de veículos na cidade de São Paulo}

O município de São Paulo possui frota veicular registrada de 7.529.208 (DETRAN, 2013) somada a veículos que circulam pela cidade, mas que possuem registros em outros municípios. Em São Paulo, o crescimento da frota veicular foi superior ao crescimento da população. Em quatro anos, a população da cidade permaneceu praticamente estável, crescendo pouco mais de 250.000 habitantes (IBGE, 2012), ao passo que, nesse mesmo período, foram licenciados mais de 1.100.000 veículos (DETRAN, 2013). 
São os automóveis, considerados veículos leves, que fazem parte da maioria da composição da frota veicular na cidade de São Paulo, conforme mostrado na Figura 1, apresentada pelo DETRAN.

\section{Frota veícular 09/ 2013}

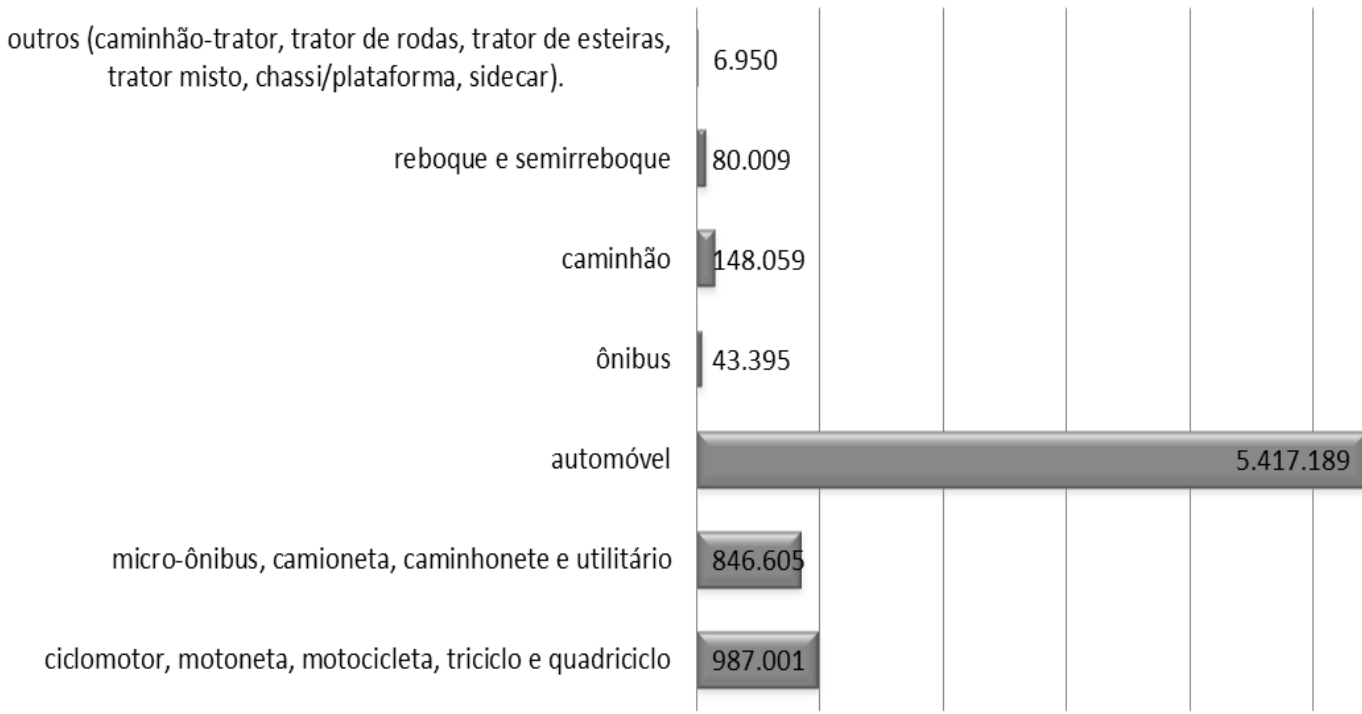

Figura 1 - Composição da frota de veículos na cidade de São Paulo. Fonte: Departamento Estadual de Trânsito de São Paulo - Detran (DETRAN, 2013)

A Companhia de Engenharia de Tráfego (CET) realiza o monitoramento diário do fluxo de veículos nas principais vias da cidade. Desse monitoramento, são disponíveis dados referentes ao tipo e número de veículos circulantes, que permitem classificar as vias segundo o fluxo veicular. As vias de tráfego, por sua vez, possuem classificação em função do tráfego, da geometria e do uso do solo do entorno como mostra a Tabela 1. Assim, as vias são classificadas em expressa, arterial, coletora e local. Essa classificação possibilita a determinação da emissão pelo tipo de via. 
Tabela 1. Classificação das vias de tráfego segundo a Companhia de Engenharia de Tráfego (CET, 2013) e o Código de Trânsito Brasileiro (CTB - Brasil, 1997).

\begin{tabular}{|c|c|c|c|c|c|}
\hline \multirow{2}{*}{ Classificação das vias } & \multirow{2}{*}{ Descrição } & \multirow{2}{*}{ Tráfego previsto } & \multicolumn{2}{|c|}{ Volume inicial - faixa mais carregada } & \multirow{2}{*}{ Limite de velocidade (km/h) } \\
\hline & & & Veículo leve & veículo pesado & \\
\hline Expressa & $\begin{array}{l}\text { Via que serve os maiores centros e possui } \\
\text { os maiores tráfegos e distância percorrida. }\end{array}$ & $\begin{array}{l}\text { pesado e muito } \\
\text { pesado }\end{array}$ & $>5000$ & $>300$ & 80 \\
\hline Arterial & $\begin{array}{l}\text { Via com tráfego moderado e menor que nas } \\
\text { vias expressas. Permite algum acesso aos } \\
\text { lotes. Possui rotas de ônibus e liga um bairro } \\
\text { ao outro. Não entra nos bairros. }\end{array}$ & $\begin{array}{l}\text { médio, meio } \\
\text { pesado e } \\
\text { pesado }\end{array}$ & 1500 a 5000 & 101 a 300 & 60 \\
\hline \multirow{2}{*}{ Coletora } & $\begin{array}{l}\text { Via que dá acesso aos lotes e onde há } \\
\text { tráfego de véculos. }\end{array}$ & \multirow{2}{*}{$\begin{array}{l}\text { médio e meio } \\
\text { pesado }\end{array}$} & \multirow{2}{*}{401 a 1500} & \multirow{2}{*}{21 a 100} & \multirow{2}{*}{40} \\
\hline & Entra nos bairros e distribui o tráfego nestes. & & & & \\
\hline Local & $\begin{array}{l}\text { Via que permite acesso aos lotes, em que há } \\
\text { baixo nível de mobilidade e que raramente } \\
\text { possui tráfego pesado. }\end{array}$ & leve e médio & 100 a 400 & 4 a 20 & 30 \\
\hline
\end{tabular}

Na cidade de São Paulo, existe uma restrição referente à circulação dos veículos com o objetivo de diminuir as emissões veiculares e a consequente diminuição do tráfego veicular. Essa restrição começou a vigorar em 1997 e a área é delimitada pelo chamado "centro expandido", onde os veículos, conforme o número final de suas placas fica proibido de circular entre $7 \mathrm{~h}$ e $10 \mathrm{~h}$ da manhã e entre $17 \mathrm{~h}$ e $20 \mathrm{~h}$ no período da noite (CET, 2015).

Em 1986 foi criado o Programa de Controle da Poluição do Ar por Veículos Automotores (Proconve) pelo Conselho Nacional do Meio Ambiente (CONAMA) como uma forma de controle da qualidade do ar nos centros urbanos. Este programa garante que as emissões de veículos novos e de motores nacionais e importados funcionem dentro dos limites de emissões permitidos. Atualmente o programa encontra-se em sua sétima fase na qual foi verificada uma diminuição significativa nos níveis de emissões permitidos para a linha de veículos pesados produzidos a partir de $1^{\circ}$ de janeiro de 2012 (CETESB, 2015).

No caso, as montadoras de veículos automotores devem produzir os veículos com limites de emissão de poluentes tanto para veículos leves como pesados, conforme 
os limites estabelecidos pelo Proconve em vigência desde 2012, exigindo a adequação dos combustíveis com a finalidade de reduzir os teores da massa de enxofre na gasolina para 50 partes por milhão (ppm) e para 10 partes por milhão (ppm ) no óleo diesel (CETESB, 2015) .

Relativamente à emissão de poluentes oriundos da emissão de tráfego veicular, em um estudo de biomonitoramento utilizando Tillandsia usneoides na cidade de São Paulo, foram encontradas as mais altas concentrações de $\mathrm{Zn}$ e Ba próximo de avenidas com tráfego pesado (carro, ônibus e caminhões), indicando que esses elementos provavelmente se originam de tráfego veicular (Figueiredo et al., 2007).

A poluição veicular também tem sido responsável pelas altas concentrações de hidrocarbonetos na cidade de São Paulo. De acordo com Vasconcellos et al. (2011), os n-alcanos encontrados no material particulado menor que $10 \mu \mathrm{m}\left(\mathrm{PM}_{10}\right)$ são provenientes de resíduos da queima de diesel, ou seja, das emissões veiculares.

Tem se estimado que a emissão de poluentes pelas fontes móveis na RMSP representam cerca de 128260 t de $\mathrm{CO}, 33550 \mathrm{t}$ de $\mathrm{HC}, 61250$ de $\mathrm{NO}_{\mathrm{x}}, 1380 \mathrm{t}$ de $\mathrm{MP}$ e 5090 t de $\mathrm{SO}_{x}$ em um ano. Os veículos automotores são responsáveis por $97 \%$ das emissões de CO, $81 \%$ de $\mathrm{HC}, 80 \%$ de $\mathrm{NO}_{\mathrm{x}}, 48 \%$ de $\mathrm{SO}_{\mathrm{x}}$ e $40 \% \mathrm{MP}$ (CETESB, 2014).

De acordo com o relatório da CETESB (CETESB, 2009) sobre a evolução das concentrações de chumbo na atmosfera da Região Metropolitana de São Paulo, as regiões de tráfego pesado ainda apresentam altas concentrações de chumbo no solo e na poeira mesmo após a proibição da adição de chumbo na gasolina. Porem desde a proibição da adição de chumbo nos combustíveis, os níveis médios deste elemento na atmosfera caíram consideravelmente. Fato digno de nota é que as estações da rede de monitoramento que se encontram próximas a vias de tráfego apresentarem 
concentrações mais elevadas de $\mathrm{Pb}$ que a estação Ibirapuera que se encontra no interior do parque conforme apresentado no relatório da CETESB de 2009.

\subsubsection{Monitoramento da poluição do ar}

A poluição atmosférica pode ser monitorada ou estudada por meio de métodos instrumentais analíticos e de biomonitoramento. Os métodos instrumentais podem ser automáticos, mecânicos ou passivos. E o monitoramento pode ser dividido entre gases e material particulado.

Diversos tipos de equipamentos podem ser usados para a coleta do material particulado. O material particulado pode estar presente na fase líquida ou gasosa tornando-se necessário que mais de um tipo de coletor seja utilizado. Posteriormente a coleta, a determinação da concentração do material particulado e sua análise elementar são realizadas separadamente. Os coletores mais comumente utilizados são os filtros dispostos dentro de impactadores (Kenneth e Warner, 1981).

Os gases podem ser coletados e serem analisados de várias formas tais como o método de colorimetria, detecção eletroquímica, espectrometria de infravermelho não dispersiva, cromatografia gasosa, método de detector de chama ionizante, quimiluminescência e espectrometria de massa (Kenneth e Warner, 1981).

Os padrões de qualidade do ar são determinados de acordo com as concentrações de poluentes atmosféricos que se ultrapassadas, poderão afetar a saúde, a segurança e o bem-estar da população, assim como ocasionar danos à flora e à fauna, aos materiais e ao meio ambiente em geral. Esses padrões são denominados de primários quando as concentrações de poluentes ultrapassadas afetam a saúde da população, ou de secundários quando as concentrações preveem um mínimo efeito adverso sobre o bem- 
estar da população e um mínimo dano à fauna, à flora, aos materiais e ao meio ambiente.

No Brasil, a Resolução CONAMA número 003 de 28 de junho de 1990 estabelece sobre os poluentes a serem monitorados, os padrões de qualidade do ar no país, assim como a metodologia a ser aplicada para o monitoramento. No ano de 1981, foi iniciado o monitoramento automático da poluição do ar na cidade de São Paulo, porém, desde a década de 1970, a CETESB já se efetuava monitoramento manual da qualidade do ar (CETESB, 2015).

Em 2013, com o Decreto Estadual 59113 de 23/4/2013 foram estabelecidos novos padrões de qualidade do ar com base nas diretrizes de 2005 da Organização Mundial de Saúde, utilizando metas progressivas e gradativas. Também foram estabelecidos novos padrões da qualidade do ar para parâmetros como as partículas inaláveis e o chumbo. Esses padrões de qualidade do ar podem ser comparados com os padrões adotados pelos Estados Unidos da América (EUA) e pela Europa, como mostra a Tabela 2 . 


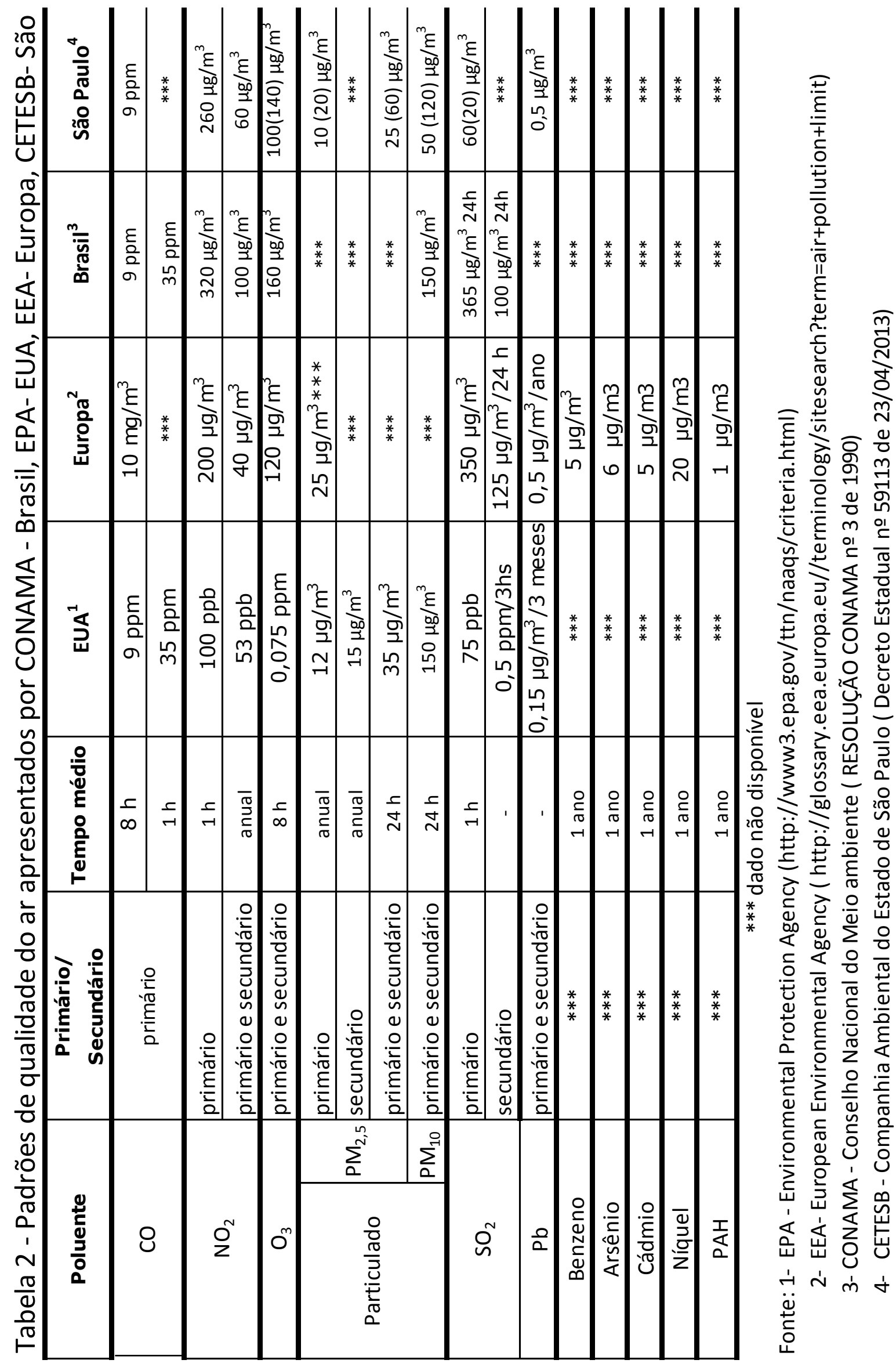


Em São Paulo, a CETESB dispõe de rede automática e rede manual de monitoramento com as mesmas configurações estabelecidas pela Resolução 003 do CONAMA. A rede automática se configura da seguinte forma: Partículas inaláveis devem ser medidas por meio da radiação beta; o dióxido de enxofre deve ser determinado pela fluorescência de pulso (ultravioleta); o óxido de nitrogênio pelo método de quimioluminescência; o monóxido de carbono por meio do infravermelho não dispersivo; o enxofre reduzido total pela oxidação térmica - fluorescência de pulso e o ozônio por meio do método ultravioleta. A rede manual, por sua vez, monitora o $\mathrm{PM}_{2,5}$ pelo método da gravimetria, utilizando amostrador, assim como o $\mathrm{PM}_{10}$ e as partículas totais em suspensão (PTS). Para análise de fumaça é utilizado o método de refletância e para o dióxido de enxofre, a cromatografia iônica.

Na Região Metropolitana de São Paulo (RMSP), estão instaladas as estações das redes de monitoramento automático distribuídas como as mostradas na Figura 2 e estações móveis nas quais a Companhia Ambiental do Estado de São Paulo (CETESB) mede os níveis de poluição do ar. Entretanto, essas redes não fornecem obter as concentrações de poluentes aéreos em microescala $(0-100 \mathrm{~m})$ e com alta resolução espacial. Além disso, a região circunscrita no centro expandido com uma área de 143 $\mathrm{km}^{2}$ possui apenas sete estações automáticas de monitoramento, das quais somente quatro para as medidas do $\mathrm{MP}_{2,5}$, o qual permite a determinação da composição elementar. Na Figura 3 é apresentado o mapa de distribuição das estações de monitoramento da CETESB no centro expandido de São Paulo. 


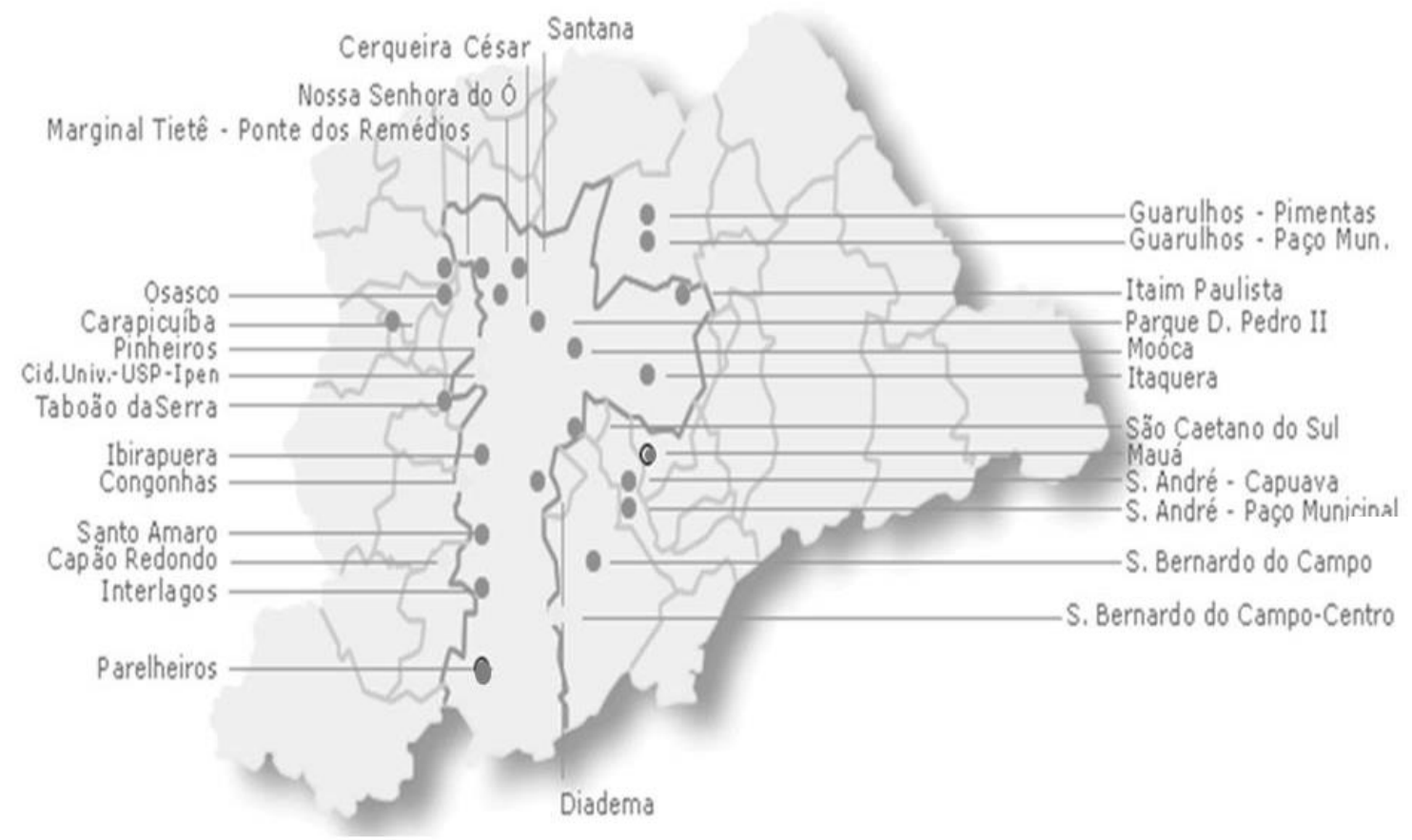

Figura 2 - Mapa de distribuição das estações de monitoramento da qualidade do ar da CETESB na Região Metropolitana de São Paulo. (CETESB, 2014)

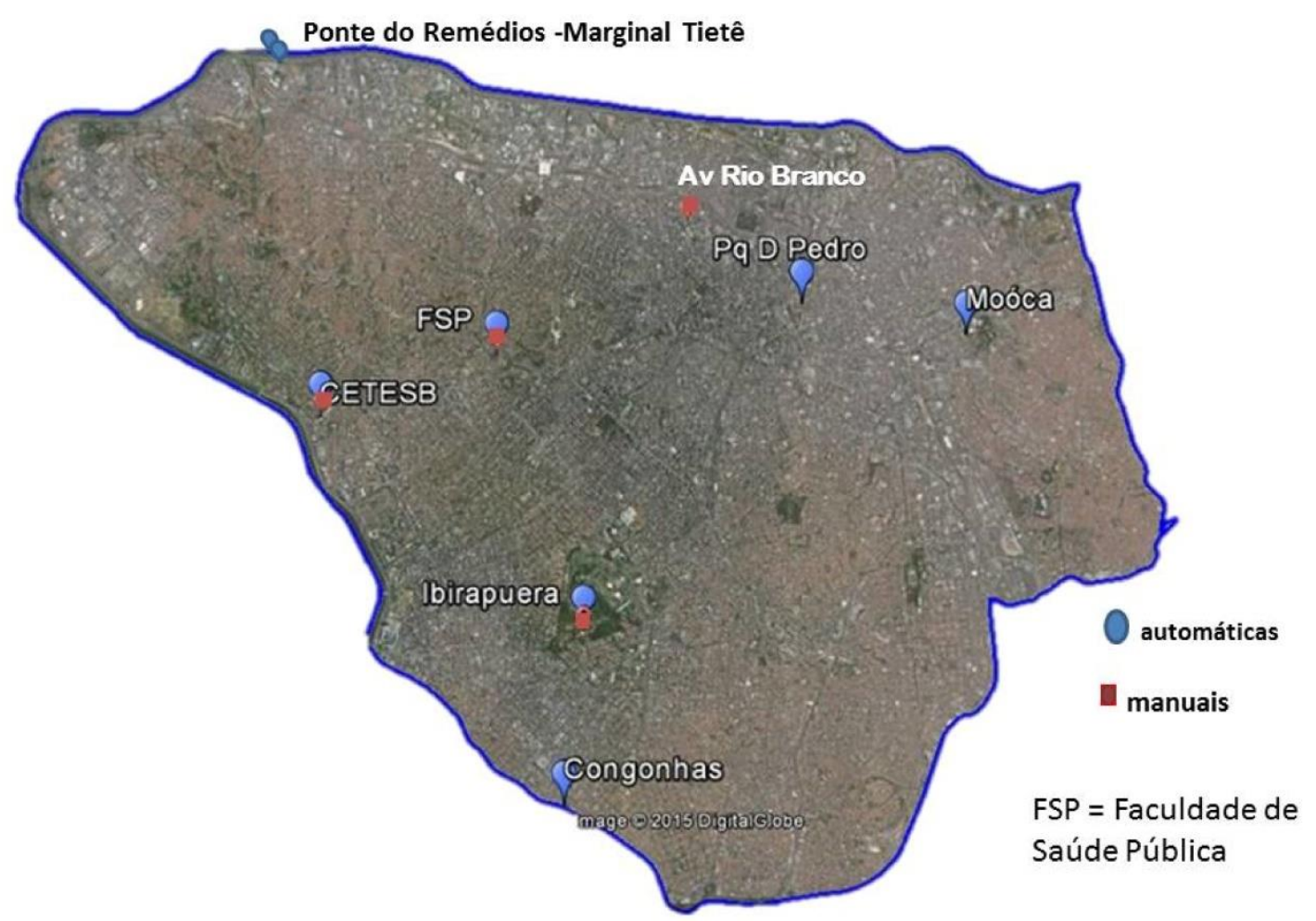

Figura 3 - Estações automáticas da CETESB no centro expandido da cidade de São Paulo e estações manuais para monitoramento de $\mathrm{MP}_{2,5}$. 
O Relatório de Qualidade do Ar no Estado de São Paulo referente ao ano de 2012 (CETESB, 2013) apresenta os dados dos padrões de qualidade e indica as estações de monitoramento que ultrapassaram esses valores na Região Metropolitana de São Paulo. Para as partículas inaláveis finas, os valores padrões diários foram ultrapassados nas estações de Congonhas, Parelheiros e Marginal Tietê pelo menos uma vez no ano.. O padrão anual foi atingido na estação de Osasco, mas não foi ultrapassado o limite estipulado pela CETESB.

O padrão diário de fumaça foi ultrapassado na estação de Pinheiros. O valor anual e diário de partículas totais em suspensão foi ultrapassado na estação de Osasco. O padrão estadual de $\mathrm{O}_{3}$ (8h) foi ultrapassado em 13 dias e o nacional (1h), em 55 dias. O padrão horário de $\mathrm{NO}_{2}$ foi ultrapassado uma única vez em Cerqueira César e o padrão anual na Marginal Tietê. Não ocorreram ultrapassagens do padrão para os dados de CO e $\mathrm{SO}_{2}$ na RMSP no ano de 2012.

\subsubsection{Biomonitoramento de poluentes atmosféricos}

De acordo com o Dicionário de Meio Ambiente e Conservação, de Oxford (Alaby e Park, 2013), biomonitoramento (monitoramento biológico) pode ser definido como a medida dos níveis de determinados elementos químicos que estão presentes no material biológico (como: sangue e urina) para determinar qual foi a exposição química.

Wolterbeek et al. (2010) definiram biomonitoramento como uso de bioorganismos/materiais para obter informações de certas características da biosfera. A informação relevante em biomonitoramento (por exemplo: uso de plantas ou animais) é comumente deduzida de mudanças no comportamento do organismo monitor (impacto: 
composições das espécies e ou riqueza, fisiológica e ou desempenho ecológico, morfologia) ou das concentrações de substância específicas nos tecidos monitores.

Os organismos podem ser bioindicadores e /ou biomonitores. Bioindicador é um organismo ou parte dele, ou ainda uma comunidade de organismos, que possui informação sobre a qualidade do ambiente (ou parte dele). Biomonitor, por outro lado, é um organismo que contém informações sobre aspectos quantitativos da qualidade do ambiente (Markert et al., 2003).

O biomonitoramento pode ser ativo ou passivo. O biomonitoramento ativo ocorre quando o biomonitor é criado em laboratório e é exposto em uma forma padronizada no campo por um período definido de tempo e no final da exposição, as reações que aconteceram no organismo são analisadas. Os biomonitores passivos são aqueles que já existem naturalmente no ambiente e que serão analisados.

Quando são utilizadas, as plantas bioindicadoras de poluição respondem ao ambiente de diversas formas, podendo apresentar cloroses, perda de cor nas folhas, pontos necróticos, queda avançada de folhas, mutagenicidade, entre outros sintomas visíveis ou de nível celular (Powell, 1997).

Já o uso de técnicas de biomonitoramento permite estimar as mudanças de deposição de poluentes do ar por meio de coletas frequentes de material e análises regulares (Lodenius, 2014).

O biomonitoramento utilizando vegetais e liquens iniciou-se em 1866, segundo um trabalho conduzido por William Nylander (1886) ${ }^{1}$ apud Wolterbeek et al. (2010), quando foi observada a sensibilidade dos liquens à poluição.

\footnotetext{
${ }^{1}$ Nylander W. Les lichens Du Jardin du Luxembourg. Paris: Bulletin de la Societé Botanique de France 13:364, 1886.
} 
De acordo com Bargagli (1998), plantas para serem biomonitoras ou bioindicadoras de poluição devem apresentar determinadas características, a saber:

- Ampla distribuição e presença durante todo o ano na área de pesquisa (biomonitoramento passivo).

- Resposta clara, reprodutibilidade e sensibilidade específica aos poluentes ou capacidade de acumulá-los refletindo as concentrações desses poluentes no ar ou no solo.

- Sensibilidade alta aos poluentes (bioindicadores) para que os efeitos ocorram até mesmo em baixos níveis de poluição ambiental.

Um dos trabalhos pioneiros sobre o uso de cascas de árvore como biomonitor da poluição do ar foi realizado em Frankfurt por Lötschert e Köhm (1977) e, desde então, muitos outros foram desenvolvidos.

Relativamente ao uso da vegetação como amostrador passivo de biomonitoramento de poluentes, convém ressaltar que ela apresenta a vantagem de possibilitar o mapeamento com uma alta resolução espacial, excelente disponibilidade de espécies arbóreas e também o baixo custo de amostragem (Sawidis et al., 2011). Entretanto, apesar da ampla distribuição e facilidade na coleta das amostras, as espécies arbóreas sofrem, principalmente as folhas, influência direta dos componentes do solo onde são cultivadas.

Os poluentes podem ser translocados às cascas de duas formas diferentes: pelo sistema radicular e pelo ciclo biológico das árvores, ou ainda no processo de deposição do ar e de água na superfície das cascas (Narewski et al., 2000).

As árvores também são consideradas mais adequadas que musgos e comunidades de liquens para uso em biomonitoramento em regiões secas quando existe a necessidade de intensa e frequente amostragem que pode ocasionar diminuição do 
estoque e, até mesmo, a condução do processo de extinção do biomonitor (Pacheco et al., 2001).

Além disso, a casca de árvore tem mostrado ser uma alternativa viável tanto para o monitoramento de poluentes orgânicos quanto inorgânicos (Zhao et al., 2006).

Cascas também são eficientes ferramentas para a determinação da origem da poluição e para a construção de mapas da distribuição espacial dos metais. É possível estimar a deposição dos metais quantitativamente ou semiquantitativamente.

A deposição dos poluentes nas cascas ocorre principalmente pela deposição seca, quando as partículas são impactadas no tronco. O transporte de elementos pelas raízes ou a assimilação de nutrientes para as cascas mais externas podem ser considerados nulos, o que é explicado levando-se em conta o tamanho ou a solubilidade das partículas, elas podem ser grandes para serem translocadas ou ainda não serem solúveis no solo.

As cascas são usadas para determinar a contaminação por amônia (Spangenberg et al., 2002) e também elementos químicos, tais como Fe, $\mathrm{Mg}, \mathrm{Al}, \mathrm{Mn}, \mathrm{Zn}, \mathrm{Pb}, \mathrm{Ba}, \mathrm{Cr}$, Cu, Ni e Sb (Guéguen et al. 2012; Perelman et al., 2010; Catinon et al., 2009).

Segundo Kabata-Pendias (2011), as plantas respondem diretamente ao estado do ar. A parte superior das plantas acumula os poluentes, e seus componentes químicos podem ser eficazes indicadores de áreas contaminadas quando comparados com valores de áreas mais limpas ou não poluídas.

Estudos da poluição em grande escala geográfica necessitam, em geral, de mais de uma espécie biomonitora, pois uma única espécie pode não ser encontrada em toda a área de estudo. E, nesse caso, é realizada uma calibração entre as espécies e adaptação das condições e variações de vitalidade, morfologia e fisiologia. Essas variações entre as 
espécies acabam introduzindo uma grande flutuação de dados nos estudos de biomonitoramento (Wolterbeek et al., 2010).

O efeito da poluição atmosférica urbana da qual consequentemente significa o acúmulo de metais pesados difere entre as espécies de árvores ou partes dessas árvores. Um dos fatores principais para essa ocorrência é a diferença das estruturas da superfície tanto foliar quanto das cascas das árvores (Sawidis et al., 2011).

Diversos estudos foram realizados na cidade de São Paulo, tanto de biomonitoramento ativo como passivo (por ex. Sant'Anna et al. 2008, Ferreira et al. 2007, Figueiredo et al. 2007), porém não se tem conhecimento de nenhum estudo utilizando cascas de árvores para monitorar o tecido intra-urbano da região do centro expandido.

\subsubsection{Espectrômetria de fluorescência de raios $X$ (EDXRF) aplicada na análise do biomonitor casca de árvore}

A técnica EDXRF consiste na irradiação da amostra com raios X. Os átomos absorvem essa energia e se tornam excitados liberando espectros característicos para cada elemento. Os comprimentos de onda que são detectados indicam quais elementos estão presentes, e a quantidade de cada elemento é determinada a partir da intensidade dos raios X em cada comprimento de onda característico.

Um átomo, ao receber uma descarga de raios $\mathrm{X}$, possibilita a entrada de fótons de raios $\mathrm{X}$ que atingem um elétron, esse elétron é retirado da camada atômica de menor energia, deixando um vazio e esse vazio é preenchido por um elétron de maior energia. No processo, há liberação de energia (fluorescência), desprendida na forma de um fóton de raios X (Bona et al. 2007). 
Existem alguns estudos, apresentados a seguir, comprovando que a técnica de EDXRF possui resultados significativos para a análise de material vegetal e sua utilização em biomonitoramento.

Richardson et al. (1995) utilizaram a técnica de EDXRF para avaliar os seguintes elementos $\mathrm{S}, \mathrm{Cl}, \mathrm{K}, \mathrm{Ca}, \mathrm{Fe}, \mathrm{Ni}, \mathrm{Cu}, \mathrm{Zn}$ e $\mathrm{Pb}$ em liquens.

A técnica de EDXRF também foi empregada para determinação dos elementos químicos presentes nas cascas de árvore por Schelle et al. (2008).

Carneiro et al. (2011) utilizaram a técnica de EDXRF para avaliar a concentração de elementos relacionados ao tráfego veicular, presentes em cascas de árvore, coletadas em diferentes distâncias da via. Seus resultados indicaram que os elementos $\mathrm{Al}, \mathrm{S}, \mathrm{Cl}, \mathrm{V}, \mathrm{Fe}, \mathrm{Cu}$ e $\mathrm{Zn}$ estão em altas concentrações em locais mais próximas da via de tráfego de veículos pesados.

Senhou et al. (2002) compararam as técnicas de análise por ativação com nêutrons (NAA) e EDXRF para a determinação de elementos químicos presentes em musgos, liquens e cascas de árvore. Seus resultados obtidos indicaram que o método de EDXRF é uma técnica mais flexível, mais rápida e que requer equipamentos mais baratos, porém com valores de limites de detecção mais altos. Dessa forma, verifica-se que a técnica de EDXRF possui qualidades adequadas para determinação de elementos de interesse ambiental como o $\mathrm{Pb}$ e $\mathrm{S}$ que não podem ser determinados por NAA.

\subsubsection{Impacto do material particulado na saúde humana}

Em abril de 2014, a Organização Mundial de Saúde divulgou a estimativa de óbitos cujas causas estão relacionadas à poluição do ar do ano de 2012. O trabalho relata 
sobre a mortalidade de 3,7 milhões de pessoas com idade inferior a 60 anos que foi causada pela poluição (OMS, 2012).

O Health Effects Institute (HEI, 2010) apresentou por meio de uma revisão de literatura sobre emissões que existe uma relação entre a poluição do ar gerada pelo tráfego e os mais variados efeitos na saúde humana, tais como, ocorrência de asma e suas exacerbações, diminuição da função pulmonar bem como da morbidade e mortalidade devido doença cardiovascular.

Os poluentes do ar são uma mistura complexa de gases e partículas, o que torna difícil a compreensão dos efeitos de cada elemento na saúde. Além disso, alguns elementos são capazes de causar efeitos negativos à saúde mesmo em concentrações consideradas normais no ambiente (Austin et al., 2013).

Segundo Mills et al. (2009), a exposição à poluição do ar está associada com o aumento da morbidade cardiovascular e mortes devido a arritmias cardíacas, insuficiência cardíaca e isquemia do miocárdio.

A exposição aos poluentes atmosféricos pode ser considerada um fator de risco à saúde humana em todas as fases da vida (Arbex et al., 2012).

$\mathrm{Na}$ cidade de São Paulo, a concentração de poluentes como $\mathrm{MP}_{10}, \mathrm{NO}_{2}, \mathrm{CO}$ e $\mathrm{O}_{3}$ estão associados ao aumento do risco da mortalidade de causas cardiovasculares, não acidentais e respiratórias. Somente para o poluente $\mathrm{O}_{3}$ o risco de mortalidade de causas cardiovasculares não aumenta (Bravo et al., 2015).

$\mathrm{O}$ material particulado $\left(\mathrm{MP}_{10}, \mathrm{MP}_{2,5}, \mathrm{MP}_{1,0}\right)$ é um dos componentes da poluição do ar, e os veículos são um dos responsáveis pela emissão desse material, conforme descrito no item 1.2.1 desta tese.

Os $\mathrm{MP}_{2,5}$ que são constituídos de partículas respiráveis com diâmetro menor que $2,5 \mu \mathrm{m}$ penetram até a área de troca de gases dos pulmões. As partículas ultrafinas 
são as menores que $100 \mathrm{~nm}$, esse material particulado $\mathrm{MP}_{1,0}$ contribui pouco com a sua massa do MP, mas são muito abundantes em número e portanto apresentam uma extensa área de contato e alta penetração nos pulmões.

Em 2000, a Agência Americana de Proteção Ambiental (EPA) estabeleceu uma rede de estudos sobre a caracterização do material particulado devido à preocupação com a toxicidade dos seus elementos que fazem parte da sua composição (EPA, 2000).

Relativamente ao material particulado (MP) originário de fontes veiculares convém salientar que ele é composto principalmente por $\mathrm{MP}_{2,5}$ e $\mathrm{MP}_{1,0}$, os quais têm um potencial de penetrar mais profundamente nos tecidos do pulmão e do coração podendo causar danos de maior gravidade (Nel, 2005).

As investigações sobre associação entre o material particulado e a mortalidade tem mostrado que diversos componentes da atmosfera são responsáveis pela toxicidade das partículas, entre eles o carbono elementar; o carbono orgânico, sulfatos, nitratos, além de metais como o zinco, níquel, ferro, potássio e cromo (Dai et al. 2014).

Segundo POPE III et al. (2009), uma redução da concentração material particulado fino de $10 \mu \mathrm{g} / \mathrm{m}^{3}$ de ar está associada com o aumento da expectativa de vida de $0,61 \pm 0,2$ anos.

Maynard et al. (2007) relacionaram um aumento de 2,3\% de óbitos nos dias seguintes a um aumento de tráfico veicular, o que pode ser explicado pelo aumento da exposição ao material particulado devido sua maior concentração.

As medidas do $\mathrm{MP}_{2,5}$ são consideradas o melhor indicador do nível do risco de exposição à poluição para a saúde humana uma vez que suas concentrações podem ser fortemente associadas tanto com as doenças cardiovasculares como as respiratórias e também ao câncer (OMS, 2015). 
Vários estudos vêm mostrando, por meio da determinação da composição do material particulado e da identificação de fontes emissoras de poluentes, a correlação entre tipo de fonte com a morbidade e mortalidade. A concentração do $\mathrm{MP}_{2,5}$ apresenta uma forte relação com a exacerbação de algumas doenças, como câncer de pulmão e de doenças cardiovasculares (Lepeule et al. 2012), asma (Guarnieri e Balmes, 2014), além de baixo peso ao nascer (Ebisu and Bell, 2012).

A composição do $\mathrm{MP}_{2,5}$ está relacionada com a fonte de emissão, e alguns componentes podem ser mais perigosos que outros. Geralmente é possível utilizar um ou múltiplos elementos como traçadores de materiais particulados MP de fontes específicas. É possível identificar um elemento único no MP com efeitos específicos na saúde, porém não é muito comum. As categorias de fontes que mais contribuem para a massa do $\mathrm{MP}_{2.5}$ são a combustão de carvão, do óleo residual, da movimentação do tráfego, ressuspensão de solo, processamento e refinaria de metais e ainda o $\mathrm{MP}_{2.5}$ formado na atmosfera. Estas fontes apresentam diferentes composições de poluentes que podem ser analiticamente separadas utilizando modelos para a sua separação (Lippmann, 2009).

Zanobetti et al. (2014) apontaram que a mortalidade na cidade de Boston é significativamente afetada pela concentração de $\mathrm{MP}_{2,5}$, sendo que dias caracterizados por altas concentrações de elementos decorrentes da poluição de tráfego primário e queima de combustível possuem maior risco de mortalidade associado.

Bell et al. (2011) correlacionando número de internações hospitalares com os componentes do $\mathrm{MP}_{2,5}$, observaram que aquelas realizadas devido a causas cardiovasculares estão mais fortemente correlacionados com Black Carbon (BC), Ca, V e Zn, e que outras internações de causa respiratória apresentam maior correlação com $\mathrm{Al}, \mathrm{Ca}, \mathrm{Cl}, \mathrm{BC}, \mathrm{Ni}$, Si e Ti. 
A distribuição espacial das fontes de poluição atmosférica e a ocupação do solo afetam na exposição da população à poluição. Isso pode ocorrer devido estas áreas apresentarem maior densidade populacional e vias com alta densidade de tráfego ( $\mathrm{Su}$ et al., 2015). Porém áreas com alta densidade populacional podem estar associadas com a redução de gases de efeito estufa, $\mathrm{NO}_{2}$, precursor de $\mathrm{O}_{3}$; e material particulado, principalmente em razão de menores deslocamentos e, portanto, menor emissão veicular. No entanto há um aumento da exposição da população aos poluentes ao se concentrar mais pessoas numa mesma área, ou seja, em uma área de alta densidade populacional (Bereitschaft e Debbage, 2013).

Os impactos dos poluentes atmosféricos na saúde humana dependem de fatores como, tipo do poluente e de sua concentração bem como do tempo de exposição e da susceptibilidade do indivíduo. 


\section{Materiais e métodos}

Os materiais utilizados neste trabalho foram as cascas de árvores coletadas na área de estudo descrita no item a seguir.

\section{1 Área de estudo}

A área de estudo engloba ruas e avenidas da cidade de São Paulo, capital do estado de São Paulo - Brasil, localizada no perímetro do centro expandido, também chamado de minianel viário e com uma área de $149,84 \mathrm{~km}^{2}$. As coordenadas geográficas são $23^{\circ} 32^{\prime} 51^{\prime \prime}$ S e 46³8'10" W e clima CWA segundo a classificação de Koppen.

Para o presente estudo, o centro expandido foi dividido em quadrantes de $3 \mathrm{~km}^{2}$ visando facilitar a amostragem e cobrir a área de estudo com melhor distribuição espacial. As cascas de 171 árvores foram amostradas nas principais avenidas e, a partir destas avenidas, foi realizada a amostragem das ruas em suas adjacências. Essa distribuição de pontos de coleta pode ser visualizada na Figura 4. 


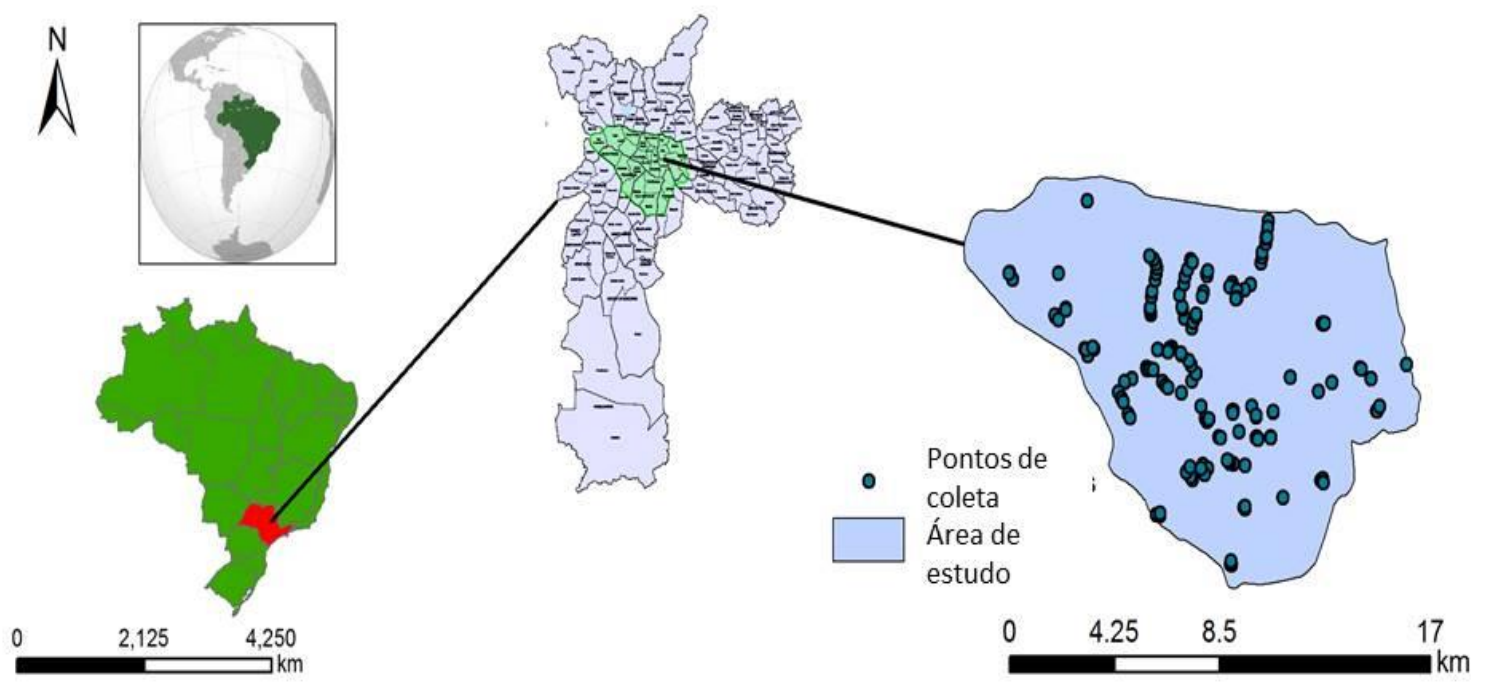

Figura 4. Área de estudo e localização das árvores cujas cascas foram amostradas no centro expandido de São Paulo.

As cascas de 5 árvores totalizando 22 amostras controle foram coletadas na Mata da Câmara localizada na cidade de São Roque, SP nas latitude $23^{\circ} 31^{\prime} 41.71$ "S e longitude $47^{\circ} 6^{\prime 2} 23.81$ "O. Trata-se de uma área de mata preservada e ausência de tráfego veicular em seu interior. Na Figura 5 é apresentada a localização do ponto de amostragem das amostras de controle situada cerca de $0,87 \mathrm{~km}$ da via de tráfego mais próximo e 2,03 km do centro urbano mais próximo, na cidade de São Roque.

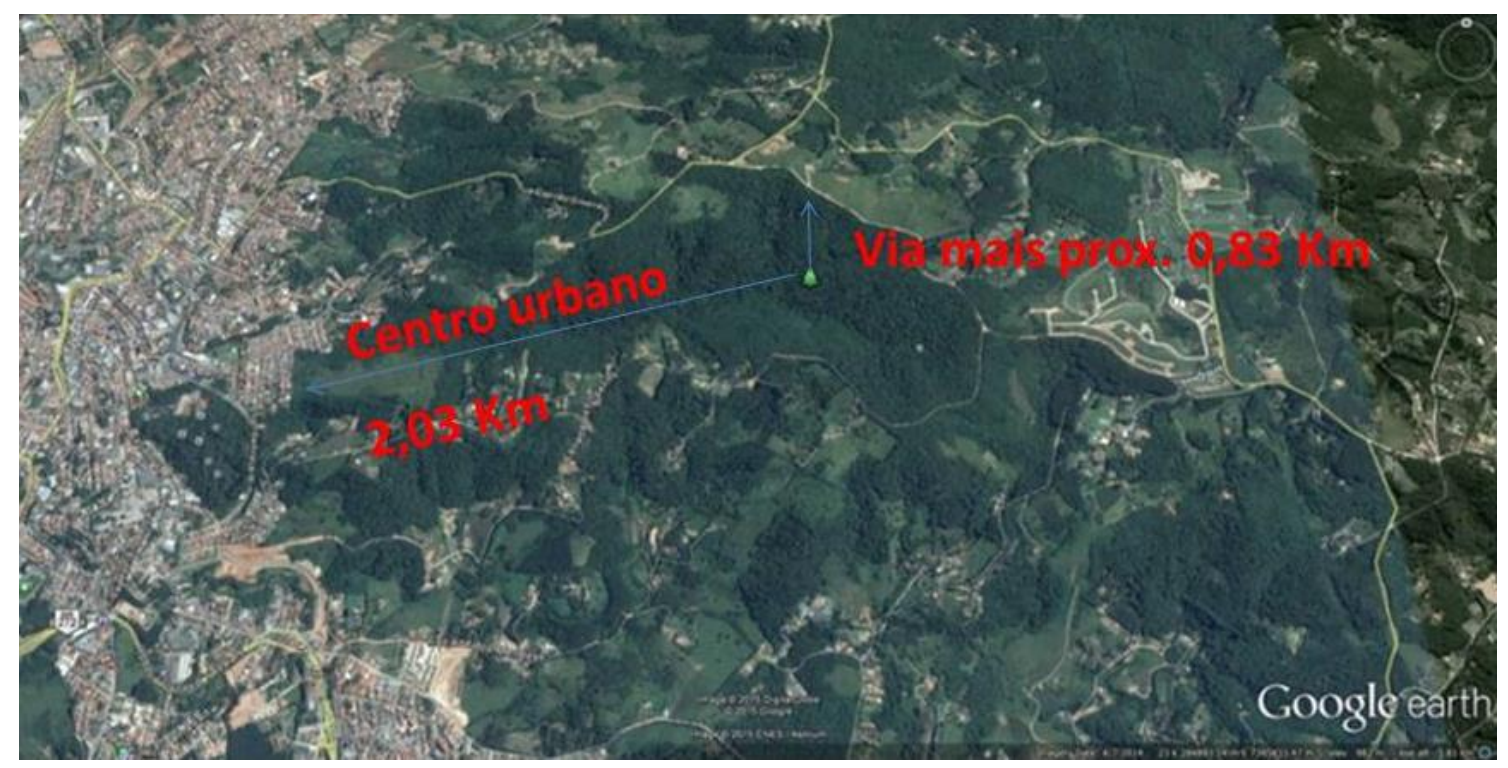

Figura 5. Localização da Mata da Câmara em São Roque-SP (Google Earth). 


\subsection{Anatomia e morfologia das espécies arbóreas utilizadas no estudo de biomonitoramento da poluição do ar}

A anatomia do tronco da árvore, sua casca e a configuração na planta irão influenciar a forma como ocorrerá a deposição e absorção dos poluentes nas cascas das árvores.

A casca da árvore é separada em duas partes, uma mais interna e outra mais externa como mostra a Figura 6. A parte utilizada para o uso no biomonitoramento é a chamada de ritidoma ou periderme, a camada mais externa do tronco. Essa parte é diretamente influenciada pela altura e ou idade da árvore (Ritcher et al., 1996).

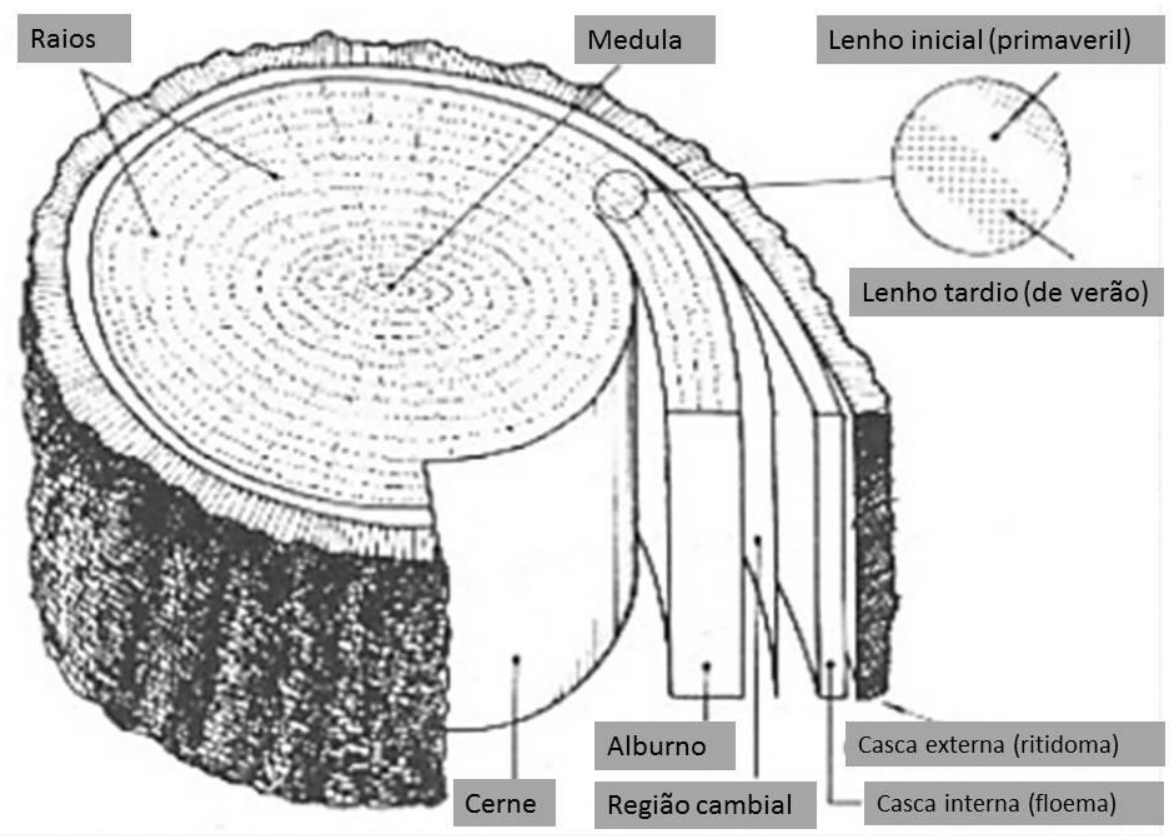

Figura 6 - Seção transversal do tronco de uma árvore (Lepage, 1986).

\subsection{Procedimento de coleta das cascas das árvores}

As cascas de quatro espécies arbóreas diferentes foram coletadas. Na Tabela 3, são apresentados o nome comum, o científico, a origem, a família das espécies e as características das cascas dessas espécies. Todas as cascas foram coletadas a uma altura 
de cerca de 1,5 metros do solo e ao redor de todo seu tronco para obtenção de uma amostra representativa, evitando que a predominância da direção de ventos pudesse interferir no acumulo do material particulado pela casca. As árvores coletadas possuem em média $2 \mathrm{~m}$ de circunferência e no mínimo 2,5 $\mathrm{m}$ de altura. As cascas foram coletadas no período de seca, entre os meses de abril e outubro de 2012.

Tabela 3 - Dados das espécies arbóreas cujas cascas foram coletadas na área de estudo

\begin{tabular}{|c|c|c|c|c|}
\hline Nome comum & $\begin{array}{l}\text { Nome } \\
\text { científico }\end{array}$ & Origem & Família & Cascas \\
\hline Quaresmeira & $\begin{array}{l}\text { Tibouchina } \\
\text { granulosa }\end{array}$ & Brasil & Melastomacea & Perenes \\
\hline Alfeneiro & Ligustrum $s p$ & Ásia & Oleraceae & Perenes \\
\hline Tipuana & Tipuana tipu & $\begin{array}{l}\text { América } \\
\text { do Sul }\end{array}$ & Fabaceae & Decíduas \\
\hline Sibipiruna & $\begin{array}{l}\text { Caesalpinia } \\
\text { pluviosa }\end{array}$ & Brasil & Fabaceae & Deiscentes \\
\hline
\end{tabular}

A casca foi removida com as mãos, quando possuía tipo de deiscência que se soltasse facilmente, ou com auxílio de uma pá de jardinagem, nos casos em que se encontrava com maior aderência ao tronco da árvore. Essas cascas foram armazenadas em sacos de papel conforme mostrado nas Figuras 7 e 8 .

Cada amostra da casca de árvore foi identificada com um código, e durante a coleta foram registrados os seguintes dado a saber, coordenadas geográficas, endereço do ponto de coleta, circunferência do tronco da árvore na altura do peito e observações como a proximidade de pontos de ônibus ou de táxi, a presença de algum tipo de 
material como liquens, insetos e outras impurezas não provenientes da árvore e ainda a condição do clima no dia da coleta.

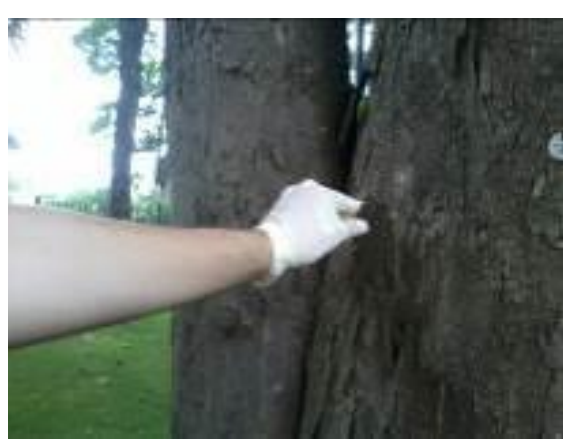

Figura 7 - Foto mostrando a remoção da casca do tronco da espécie Sibipiruna.

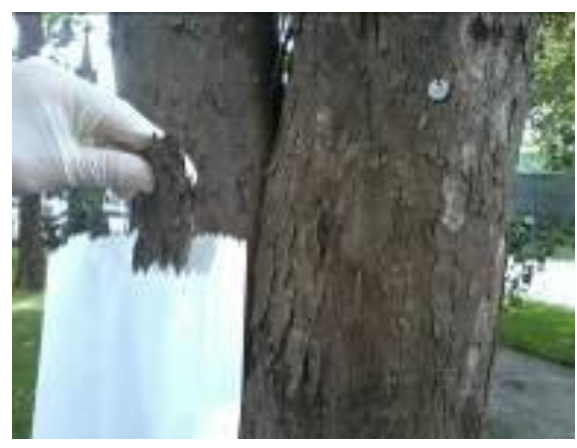

Figura 8 - Foto da casca e do saco de papel para armazenagem da casca da espécie Sibipiruna.

\subsection{Tratamento das amostras de cascas de árvore para análise}

As cascas foram secas na estufa de ventilação forçada durante 48 h, a uma temperatura de $40 \pm 2{ }^{\circ} \mathrm{C}$. A seguir, essas cascas foram limpas com auxílio de uma escova dental com cerdas de nylon duras para remoção de eventual presença de liquens, musgos, poeiras superficiais e insetos.

Cerca de $3 \mathrm{~mm}$ de espessura da camada superficial da casca externa (ritidoma ou periderme) foram removidos com o auxílio de um ralador de titânio para a análise sobre uma folha de papel impermeável. Esse material foi passado em um coador de plástico e depois foi moído com almofariz de bola de ágata da marca Fritsch modelo Pulverizette 0 com o objetivo de obter uma amostra na forma de pó fino e homogêneo. Na Figura 9 estão apresentados os materiais utilizados na remoção da camada superficial da casca para análise. 


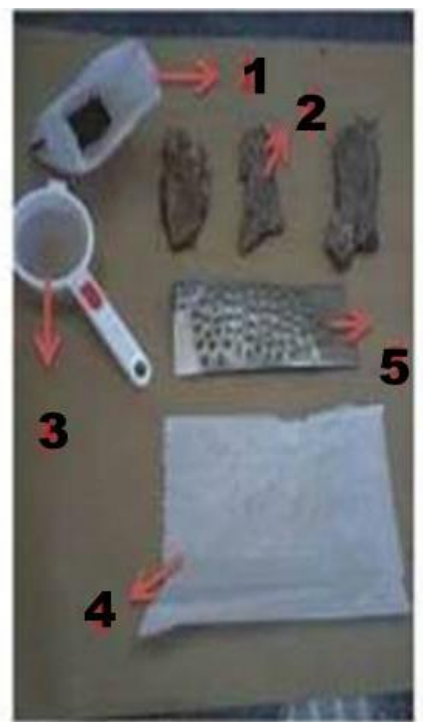

1- pó de casca de árvore

2- casca de árvore

3- peneira de plástico

4- papel impermeável

5- ralador de titânio

Figura 9 - Materiais utilizados na remoção da camada superficial da casca de àrvore.

Para análise pela técnica de fluorescência de raios X por dispersão de energia (EDXRF) as amostras foram preparadas na forma de pastilhas. Para isso uma massa de 0,5 g dessa amostra na forma de pó foi adicionado a 1,5 g de ácido bórico p.a da Merck e a seguir compactados com numa prensa manual a uma pressão de $100 \mathrm{MPa}$. Essa pastilha de duas camadas de espessura de aproximadamente $0,4 \mathrm{~cm}$ e diâmetro de 0,22 $\mathrm{cm}$ foi utilizada para a leitura no equipamento espectrômetro de fluorescência de raios $\mathrm{X}$ por energia dispersiva.

\subsection{Análises das amostras pelo método de EDXRF}

As amostras foram analisadas na forma de pastilha de dupla camada pela técnica EDXRF para determinar os seguintes elementos: $\mathrm{Al}, \mathrm{As}, \mathrm{Ba}, \mathrm{Ca}, \mathrm{Cl}, \mathrm{Cd}, \mathrm{Cu}, \mathrm{Fe}, \mathrm{Hg}, \mathrm{K}$, $\mathrm{Mg}, \mathrm{Mn}, \mathrm{Mo}, \mathrm{Na}, \mathrm{Ni}, \mathrm{P}, \mathrm{Pb}, \mathrm{Rb}, \mathrm{S}, \mathrm{Se}, \mathrm{Sr}, \mathrm{V}$ e $\mathrm{Zn} . \mathrm{O}$ equipamento utilizado para estas análises foi o EDXRF-700 da marca Shimadzu Corporation. A Figura 10 apresenta a foto do equipamento. As condições instrumentais de medidas foram: tempo de medição 
240 s, tensão $5-50 \mathrm{kV}$, corrente de 1-1000 A em atmosfera de vácuo e cada amostra foi lida duas vezes.

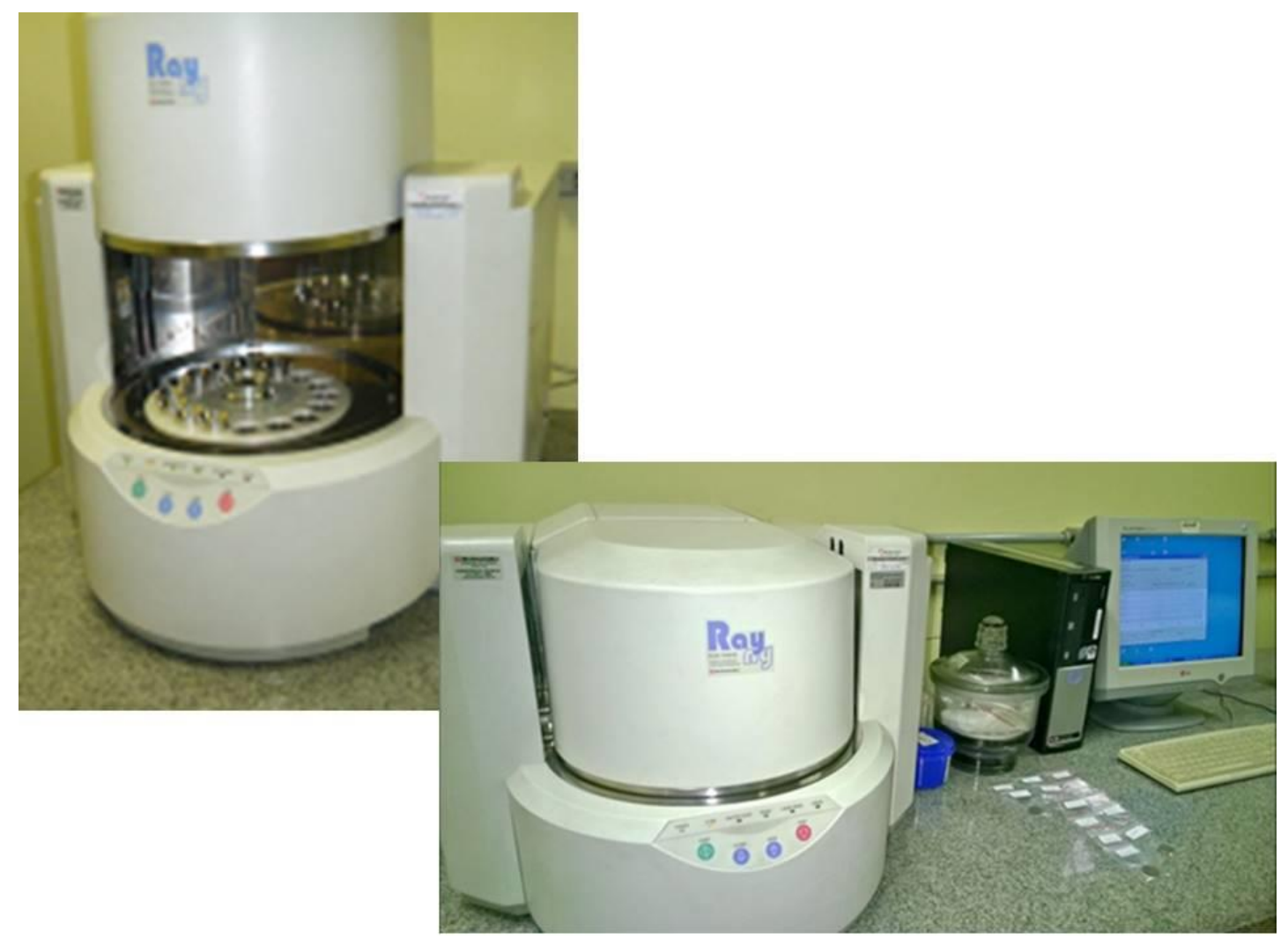

Figura 10 - Foto do equipamento EDXRF- 700

Para a obtenção da concentração do elemento foi utilizado o método de calibrações dos parâmetros fundamentais (PF). Esse método baseia-se na obtenção da curva de calibração do equipamento de cada elemento de interesse usando uma amostra de composição conhecida como o material de referência certificado, NIST 1547 Peach Leaves. Essa curva de calibração relaciona a intensidade de fluorescência calculada com a que foi medida pelo equipamento, para determinar a composição do material analisado (Bona et al., 2007).

O material de referência utilizado foi o NIST 1547 Peach Leaves fornecido pelo National Institute of Standards and Technology, dos Estados Unidos uma vez que não está disponível para aquisição material de referência de casca de árvore. 


\subsection{Análise dos dados de cascas de árvores}

\subsubsection{Estatística descritiva}

Foi elaborado o resumo descritivo das concentrações dos elementos geral e por tipo de via e para isto foi realizado o cálculo da mediana, 1 e 3 quartis e os valores máximos e mínimos.

Para verificar se existe diferença significava das concentrações de elementos entre as vias de diferentes classificações foi utilizado o teste não paramétrico de Kruskal-Wallis. Foi feita a comparação entre médias das concentrações dos elementos de cada classificação de vias, a um nível de significância de 0,05.

\subsubsection{Modelos receptores}

Dois modelos receptores foram empregados, o da análise de componentes principais (ACP) e da Fatorização de matriz positiva (Positive Matrix Factorization$P M F$ 5.0). Os modelos receptores foram utilizados para verificar a possibilidade de separar os poluentes atmosféricos por fontes de emissão, relacionando propriedades físicas e químicas do material na fonte com as propriedades observadas em um receptor.

\subsubsection{Análise de componentes principais}

A análise de componentes principais (ACP) foi aplicada para resumir a estrutura de correlação dos elementos e identificação das fontes emissoras. 
O scree plot é uma ajuda visual útil para determinar o número apropriado de componentes principais. Para determinar o número apropriado de componentes, observa-se um "cotovelo" no gráfico scree. O número de componente é considerado como sendo o ponto em que a curva apresenta esta flexão e a partir deste ponto o número de componentes não explica os componentes.

\subsubsection{Fatorização de matriz positiva}

A técnica de fatorização de matriz positiva foi aplicada aos resultados das analises utilizando-se o programa de PMF 5.0, software este desenvolvido pela EPA.

O PMF 5.0 é uma ferramenta de análise de fatores multivariada que nos fornece a contribuição dos fatores e o perfil deles, utilizando o arquivo contento as concentrações de massa dos elementos e as incertezas estimadas dessas concentrações. O PMF é um modelo receptor que utiliza a análise da conservação de massa e o balanço da massa para determinar e quantificar a contribuição de cada fonte (Hu et al., 2014). O modelo é dado pela equação (equação 1):

$$
x j l=\sum_{k=1}^{p} f k l g j k+e j l
$$

onde,

- $x j l$ é concentração do elemento em dada localização,

- $\quad p$ é o número de fatores;

- $f$ é o perfil dos elementos;

- $g$ é a contribuição da massa (concentração);

- ejl é o erro estimado de cada amostra. 
A interface de entrada dos dados (Planilha de concentração dos elementos e planilha de incertezas) é mostrada na Figura 11. A planilha de incerteza pode ser obtida por duas metodologias, a calculada e a por meio de equações. Diversas equações podem ser utilizadas para o cálculo das incertezas (Norris et al., 2014). Essas equações necessitam de informações referentes à incerteza da análise e ao limite de detecção do método. Quando estes dados não estão disponíveis o método de cálculo é utilizado, neste método pode se utilizar o cálculo de $10 \%$ ou $20 \%$ das concentrações dos elementos dadas.

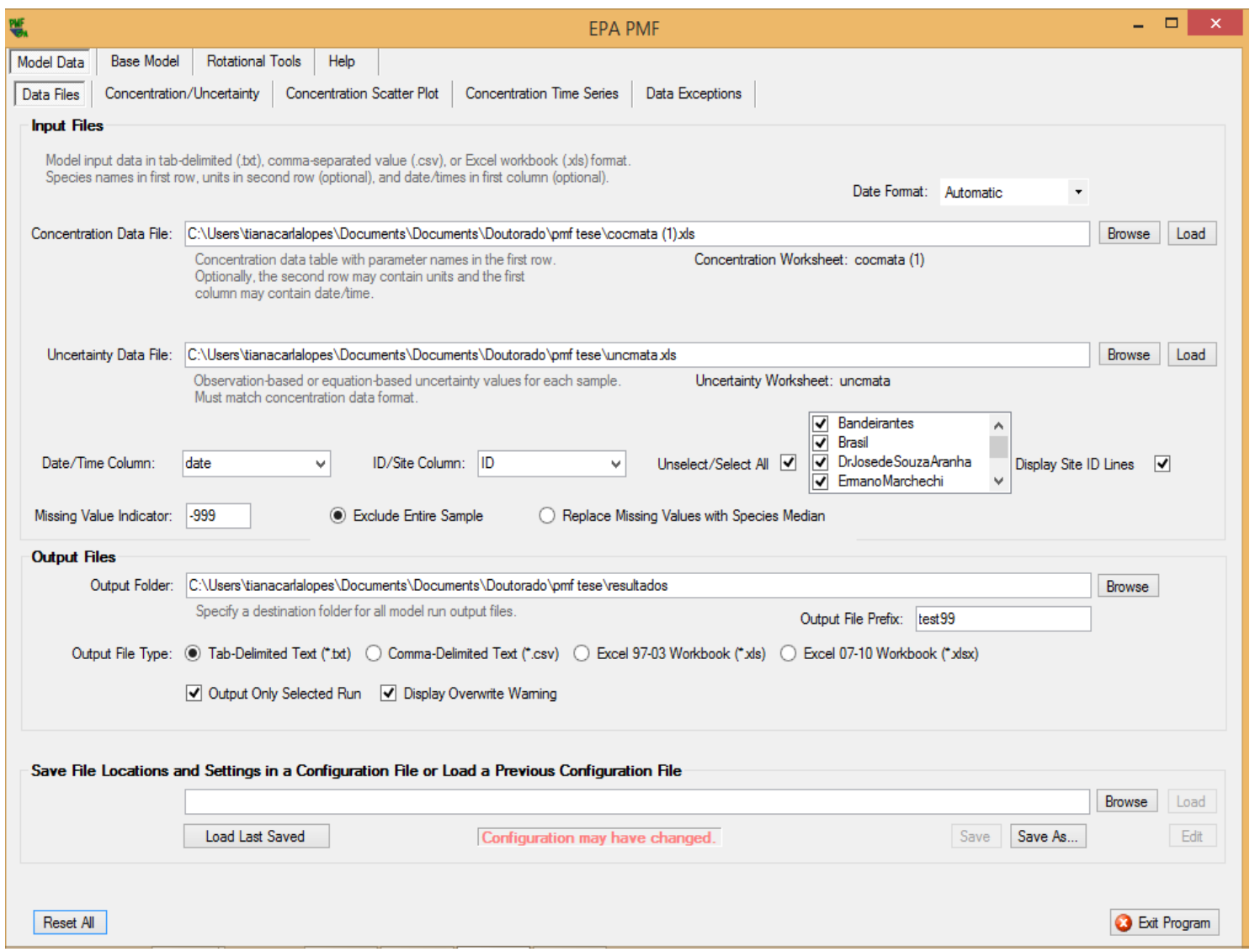

Figura 11- Interface da página de inserção das planilhas de concentração dos elementos e incertezas analíticas.

Aplicando o PMF aos resultados dos elementos determinados nas cascas de árvores podem ser classificados em "bad", "weak" e "strong” (Figura 12). Os resultados dos elementos classificados como 'bad' podem ser eliminados na interpretação dos 
dados, enquanto os elementos considerados 'weak' terão seu peso considerado menor triplicando seus valores de incerteza. Os elementos 'strong' foram incluídos nas análises sem mudanças.

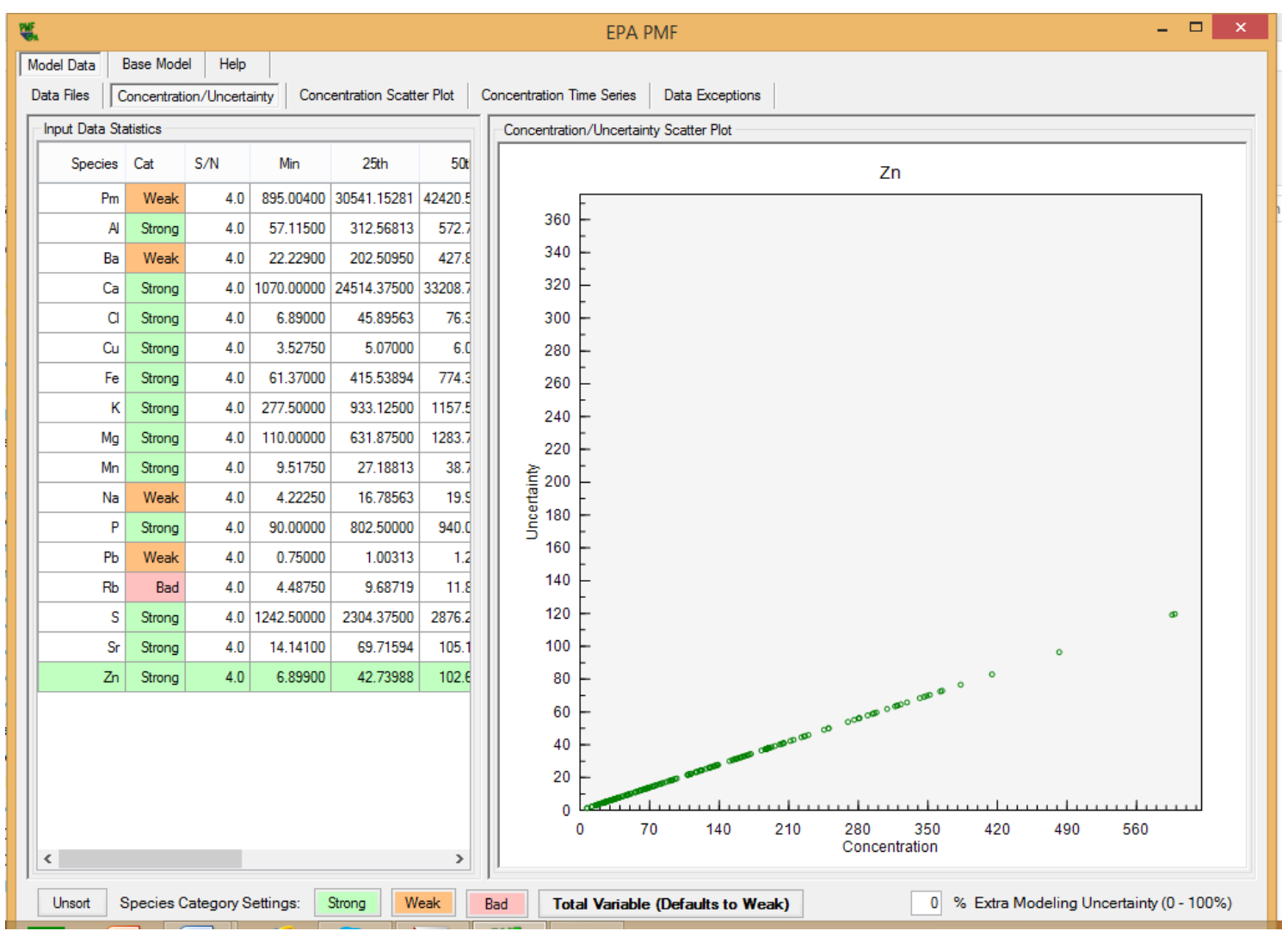

Figura 12- Classificação dos elementos (bad, weak e strong) de acordo com as incertezas e dados sobre ele.

Outliers ou os valores atípicos podem ser identificados e excluídos, baseando-se nas análises de cada espécie de acordo com o gráfico da série temporal da concentração (Figura 13), este procedimento é realizado quando existem dados durante um período de tempo. No presente estudo os dados de análises de cascas são espaciais, mas não temporais. A exclusão de dados acarreta na exclusão de um local e não apenas de um dia como nas séries temporais e esta exclusão pode comprometer os resultados. Não foram excluídos dados neste trabalho por meio da série temporal. 


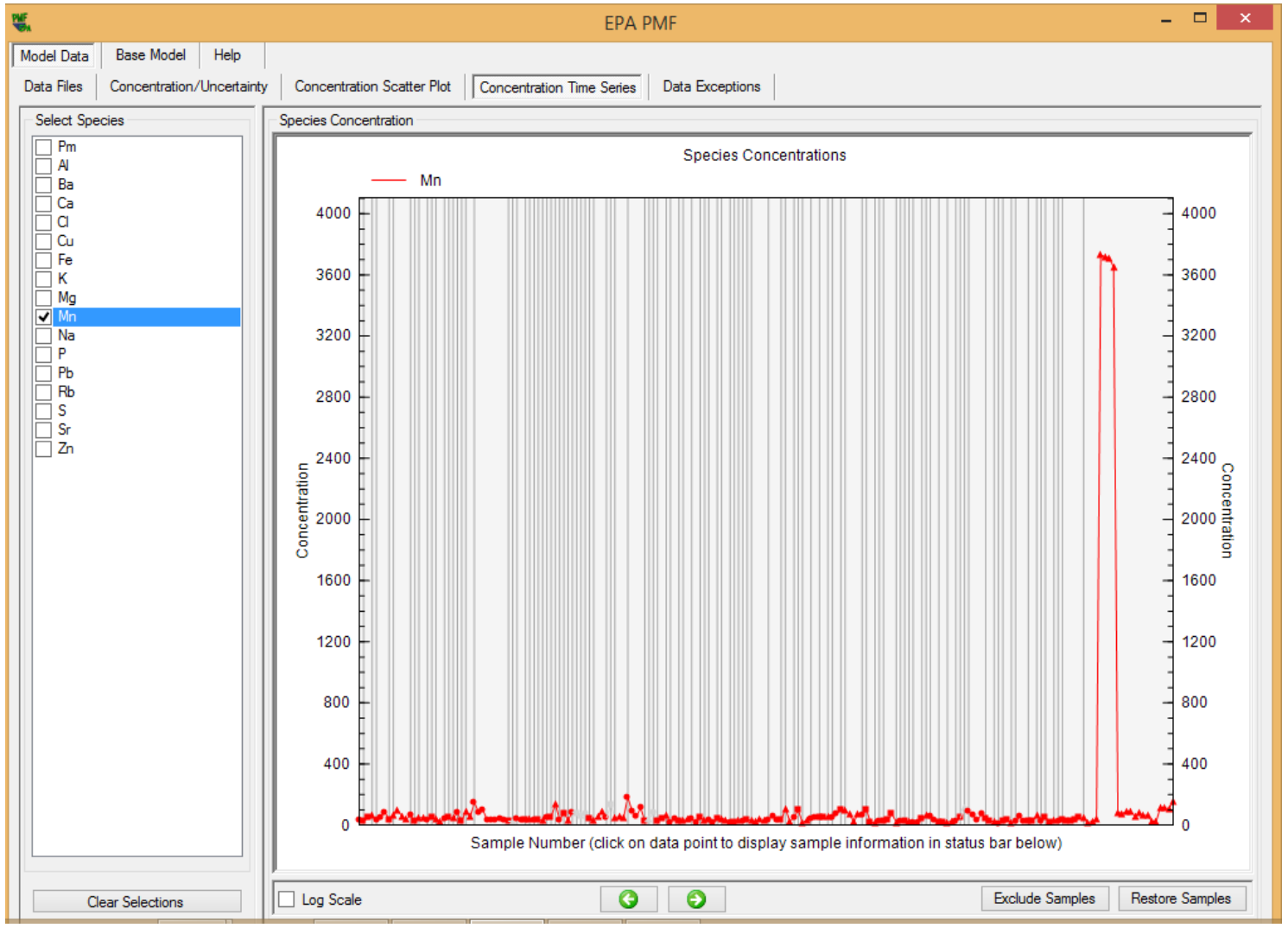

Figura 13 - Série temporal e gráfico da série temporal (time series concentration- timeseries plot). Neste trabalho a série temporal não foi utilizada.

Valores extremos podem ter grande influência nas análises dos dados já que eles podem levar a um falso fator ou fonte e distorcer o perfil dos fatores. Os valores de incertezas dos resultados analíticos de cascas de árvores foram considerados neste trabalho como sendo $20 \%$ da concentração dos elementos.

O PMF 5.0 foi aplicado diversas vezes buscando o número de fatores mais adequado. Foram utilizados de 4 a 8 fatores. Os fatores foram posteriormente nomeados de acordo com a abundância de elementos caracterizados como elementos marcadores.

\subsubsection{Analise discriminante}

Para discriminar e classificar os dados analíticos foi utilizada a técnica estatística multivariada de análise discriminante. Esta técnica foi utilizada para separar os pontos 
amostrados pelos tipos de ruas predeterminados (classificação predita segundo a emissão), e o resultado final desta classificação foi comparado com os tipos de ruas segundo a classificação dada pela companhia de engenharia de tráfego. O método utilizado foi o de Fisher (Johnson e Wichern, 2007).

\subsubsection{Geoestatistica}

O método de krigagem foi escolhido por ser a técnica geoestatística que vem sendo mais utilizada nos estudos relacionados à poluição do ar (Jerrett et al., 2001). Os mapas de distribuição das concentrações de elementos foram elaborados usando a técnica de krigagem ordinária, possibilitando a predição de valores de concentrações de elementos por meio da interpolação. Os mapas de erros também foram utilizados para determinação das incertezas nas áreas não amostradas permitindo a observação das áreas aonde a interpolação é menos confiável. 


\section{Resultados}

\subsection{Estatística descritiva}

$\mathrm{O}$ resultado do teste de normalidade Kolmogorov-Smirnov $(\mathrm{P}<0,0001)$ indicou que os dados não seguem distribuição normal. O cálculo da mediana, 1 e 3 ำ quartis e os valores máximos e mínimos são apresentados na Tabela 4.

Os elementos encontrados em concentrações mais altas foram $\mathrm{Ca}, \mathrm{S}, \mathrm{K}, \mathrm{Mg}$, e Fe nesta mesma ordem de concentração. O teste de Kruskal-Wallis demostrou que os elementos apresentam diferenças estatísticas entre os tipos de vias exceto para $\mathrm{Na}$ e $\mathrm{Rb}$.

Tabela 4 - Número de pontos amostrados, mediana das concentrações de elementos

\begin{tabular}{|c|c|c|c|c|c|c|c|c|c|c|c|c|}
\hline & \multicolumn{6}{|c|}{ Centro expandido de São Paulo } & \multicolumn{6}{|c|}{ Área controle } \\
\hline Elemento & $\begin{array}{c}\text { Pontos } \\
\text { amostra } \\
\text { dos }\end{array}$ & Mediana & $\begin{array}{l}\text { Valor } \\
\text { mínimo }\end{array}$ & $\begin{array}{c}1^{0} \\
\text { quartil }\end{array}$ & $\begin{array}{c}3^{0} \\
\text { quartil }\end{array}$ & $\begin{array}{l}\text { Valor } \\
\text { máximo }\end{array}$ & $\begin{array}{c}\text { Pontos } \\
\text { amostra } \\
\text { dos }\end{array}$ & Mediana & $\begin{array}{l}\text { Valor } \\
\text { mínimo }\end{array}$ & $\begin{array}{c}1^{0} \\
\text { quartil }\end{array}$ & $\begin{array}{c}3^{0} \\
\text { quartil }\end{array}$ & $\begin{array}{l}\text { Valor } \\
\text { máximo }\end{array}$ \\
\hline Al & 171 & 718 & 57 & 344 & 1105 & 6819 & 22 & 310 & 103 & 122 & 346 & 556 \\
\hline $\mathrm{Ba}$ & 171 & 495 & 29 & 245 & 910 & 21089 & 22 & 164 & 22 & 112 & 309 & 456 \\
\hline $\mathrm{Ca}$ & 171 & 33655 & 7558 & 26023 & 39941 & 59628 & 22 & 29775 & 1070 & 1297 & 33095 & 42230 \\
\hline $\mathrm{Cl}$ & 171 & 74 & 7 & 45 & 142 & 21769 & 22 & 102 & 17 & 67 & 248 & 10487 \\
\hline $\mathrm{Cu}$ & 171 & 6 & 4 & 5 & 8 & 28 & 22 & 5 & 4 & 4 & 5 & 5 \\
\hline $\mathrm{Fe}$ & 171 & 1016 & 61 & 435 & 1901 & 7356 & 22 & 444 & 77 & 139 & 627 & 722 \\
\hline K & 171 & 1200 & 278 & 940 & 1723 & 12473 & 22 & 1080 & 280 & 480 & 1170 & 5250 \\
\hline $\mathrm{Mg}$ & 171 & 1345 & 155 & 708 & 2108 & 4055 & 22 & 352 & 110 & 112 & 500 & 650 \\
\hline Mn & 171 & 38 & 10 & 27 & 57 & 183 & 22 & 62 & 16 & 37 & 88 & 153 \\
\hline $\mathrm{Na}$ & 171 & 20 & 4 & 17 & 23 & 127 & 22 & 21 & 5 & 15 & 25 & 30 \\
\hline $\mathbf{P}$ & 171 & 943 & 333 & 813 & 1075 & 2078 & 22 & 885 & 90 & 220 & 1067 & 1750 \\
\hline $\mathbf{R b}$ & 171 & 12 & 4 & 10 & 15 & 31 & 22 & 12 & 5 & 7 & 18 & 67 \\
\hline$S$ & 171 & 2971 & 1243 & 2470 & 3760 & 9148 & 22 & 2400 & 1590 & 2107 & 2482 & 2970 \\
\hline $\mathrm{Sr}$ & 171 & 105 & 26 & 74 & 146 & 316 & 22 & 36 & 14 & 22 & 16 & 109 \\
\hline $\mathrm{Zn}$ & 171 & 116 & 16 & 59 & 188 & 599 & 22 & 25 & 7 & 54 & 32 & 51 \\
\hline
\end{tabular}

Na Tabela 5 observamos a mediana das concentrações de elementos (em mg/kg), 1 o e 3ํ quartil, valor mínimo, valor máximo separado por classificação de vias. 


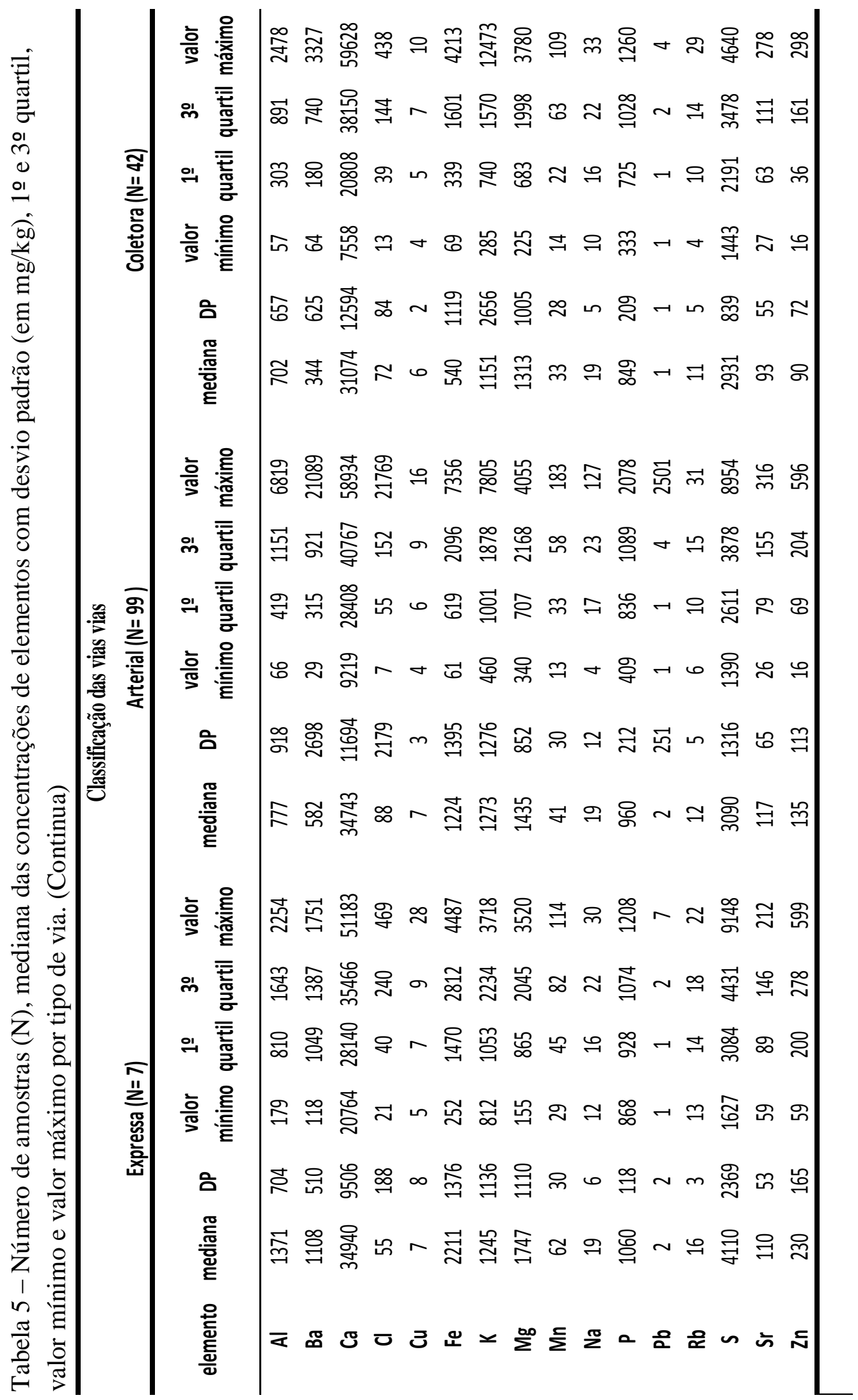




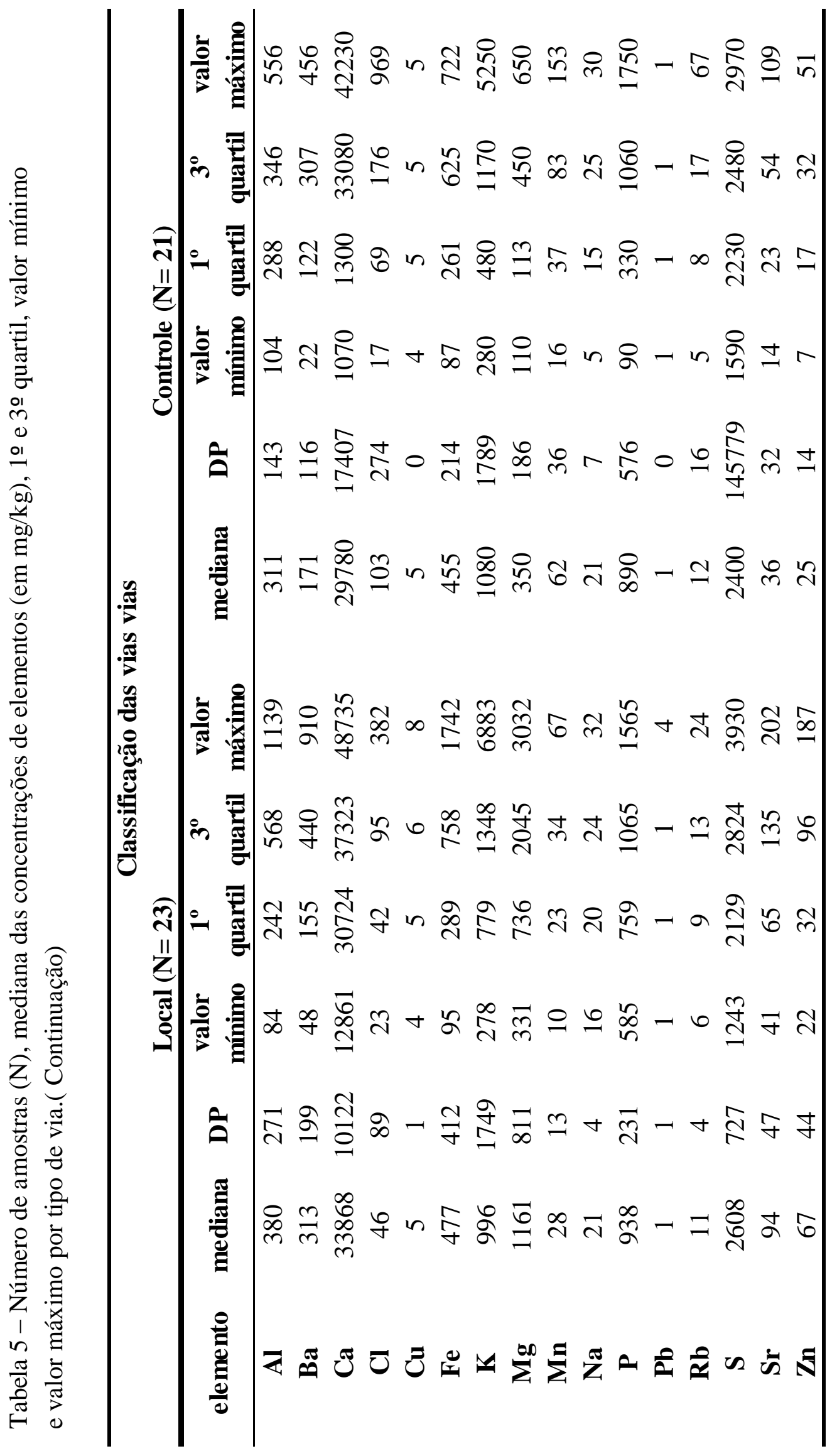


Utilizando a classificação das vias de tráfego apresentada pela Companhia de Engenharia de Tráfego e os dados da soma das concentrações elementos para cada tipo de via foi elaborado o gráfico da Figura 14.

A somatória das médias das concentrações de cada um dos elementos em cada tipo de via de acordo com a densidade de tráfego pode ser observada na figura 15.

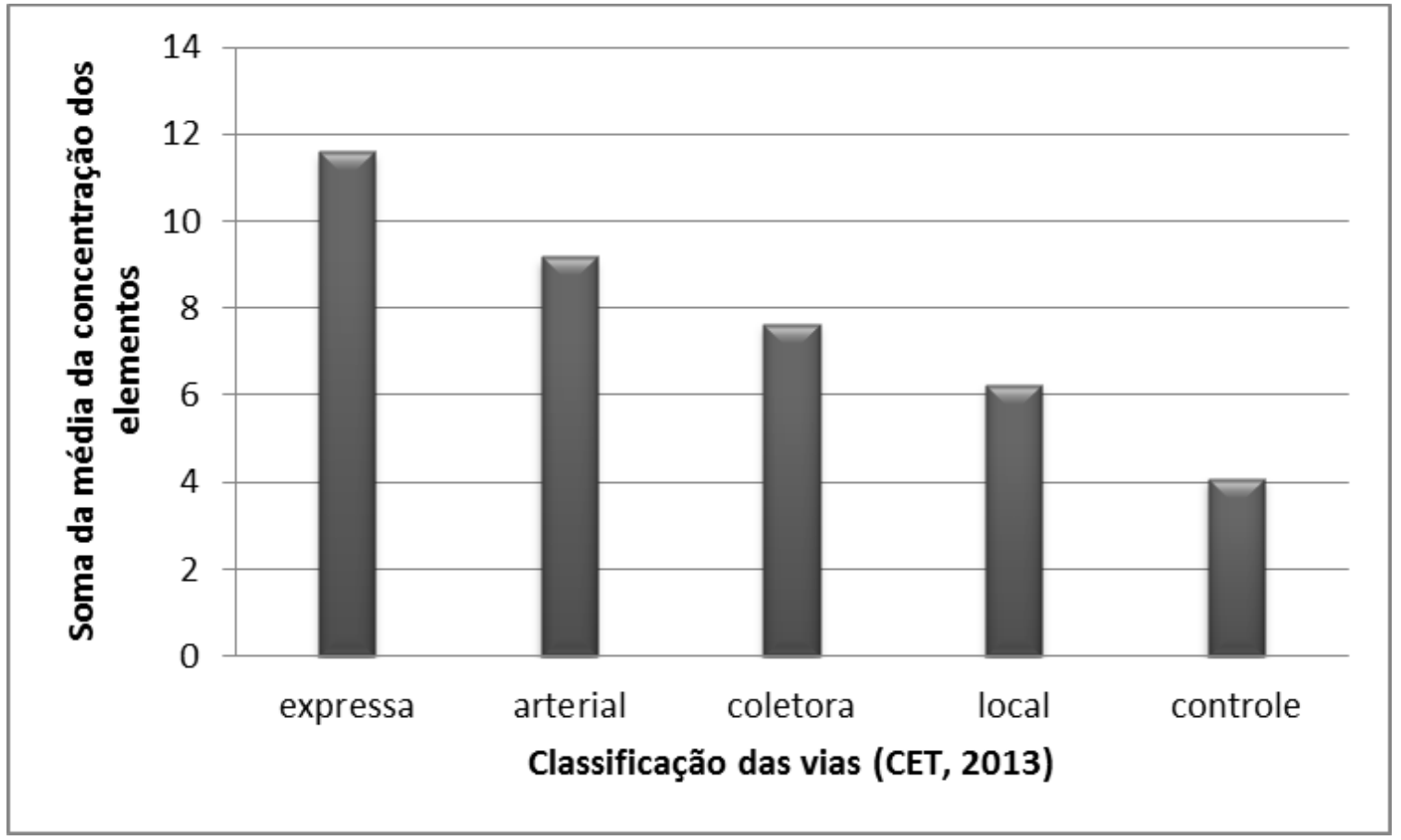

Figura 14 - Soma das médias da concentração de todos os elementos $(\mathrm{mg} / \mathrm{kg})$ em função do tipo de via e na área controle. 


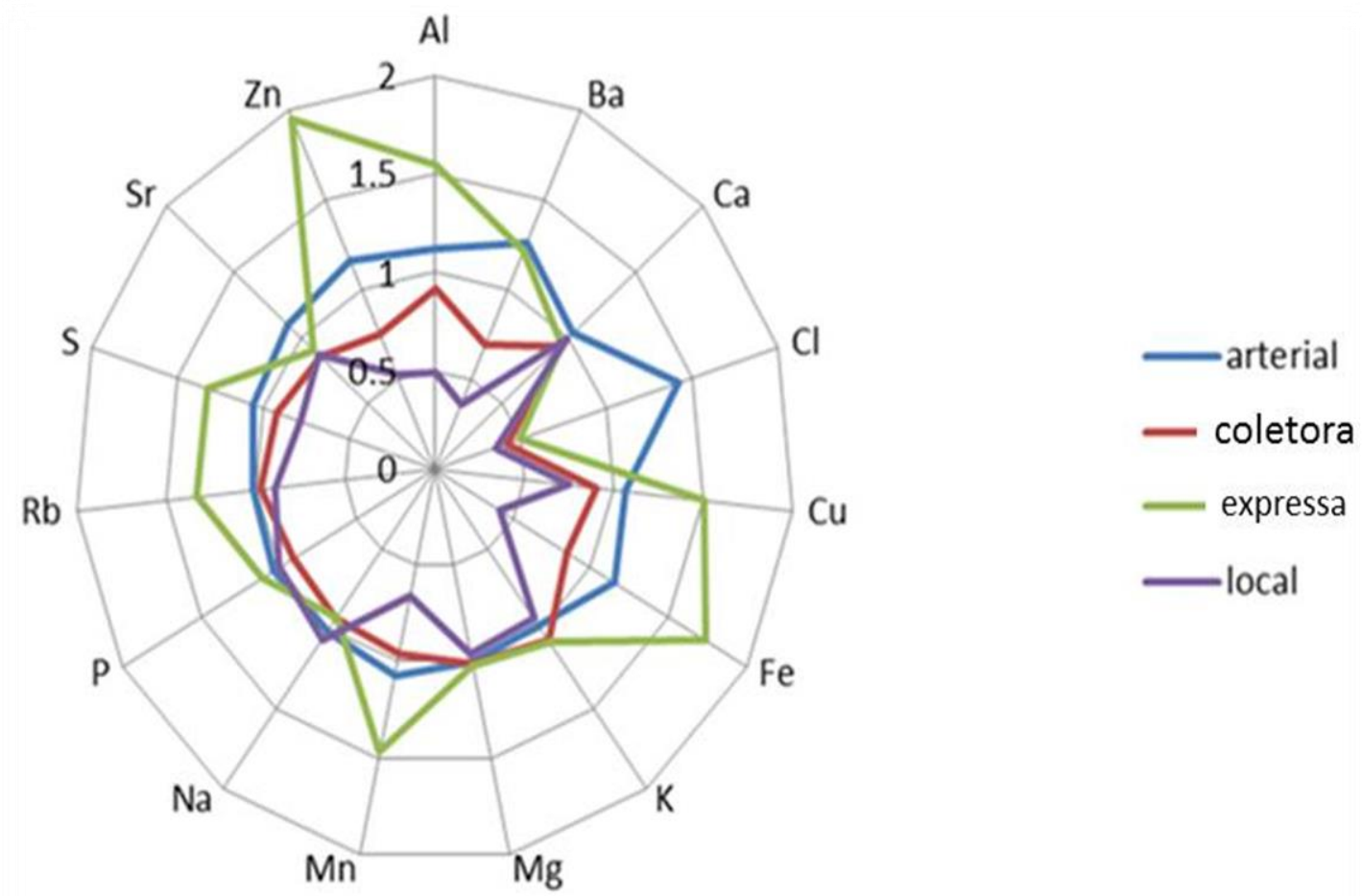

Figura 15 - Gráfico de radar mostrando a distribuição dos elementos nas diferentes vias de tráfego.

\subsubsection{Análise de componentes principais}

Na Figura 16, o Scree plot mostra que cinco componentes são suficientes para explicar a análise. A Tabela 6 apresenta os componentes da ACP onde os valores em negrito representam os elementos que compõe cada fator. De acordo com os resultados da Tabela 6 da ACP, 73,5 \% da variância podem ser explicadas pelos cinco fatores encontrados. O primeiro fator é composto de $\mathrm{Al}, \mathrm{Fe}, \mathrm{Mn}, \mathrm{Cu}$ e $\mathrm{Zn}$; ele pode ser explicado por 27,1 \% da variância. Esse fator pode indicar a origem do elemento de uma fonte de poeira da via enriquecida com elementos do solo. O segundo fator é composto por $\mathrm{Ca}$ e $\mathrm{Sr}$ e é explicado por 14,8 \% da variância. O terceiro fator é formado pelos elementos $\mathrm{Cl}$ e $\mathrm{Na}$ e é explicado por 11,6 \% da variância e esse fator pode estar relacionado origem do elemento do sal marinho conforme será discutido no Capitulo de 
Discussão. O fator 4 é formado pelos elementos K e P, explicado por $10 \%$ da variância e pode estar relacionado a fonte de queima de biomassa e o fator 5 é formado pelo elemento Mg.

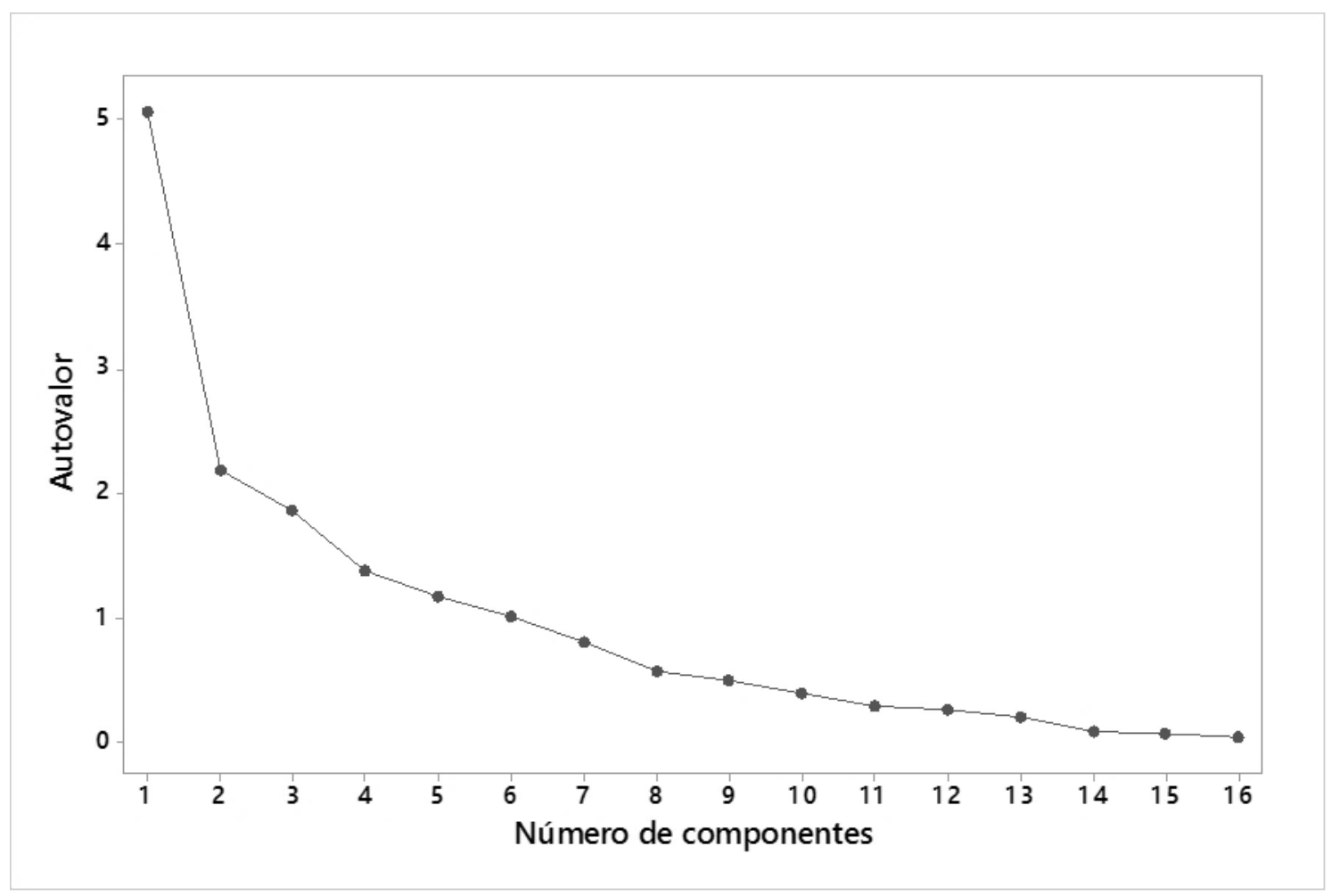

Figura 16- Gráfico Scree-Plot da análise de componentes principais 
Tabela 6 - Resultados da análise de componentes principais- Rotação ortogonal Varimax (Varimax method with Kaiser Normalization).

\begin{tabular}{cccccc}
\hline & \multicolumn{5}{c}{ Componentes } \\
\cline { 2 - 6 } $\mathrm{Al}$ & $\mathbf{0 , 8 5 3}$ & $-0,175$ & $-0,098$ & 0,048 & $-0,078$ \\
$\mathrm{Ba}$ & 0,548 & 0,004 & $-0,015$ & 0,109 & $-0,333$ \\
$\mathrm{Ca}$ & $-0,239$ & $\mathbf{0 , 9 1 5}$ & $-0,002$ & 0,027 & $-0,144$ \\
$\mathrm{Cl}$ & 0,034 & 0,008 & $\mathbf{0 , 9 3 3}$ & $-0,033$ & 0,082 \\
$\mathrm{Cu}$ & $\mathbf{0 , 7 4 1}$ & 0,138 & $-0,001$ & $-0,068$ & 0,247 \\
$\mathrm{Fe}$ & $\mathbf{0 , 9 1 8}$ & $-0,125$ & $-0,109$ & 0,067 & 0,063 \\
$\mathrm{~K}$ & 0,054 & $-0,434$ & 0,009 & $\mathbf{0 , 7 2 1}$ & 0,303 \\
$\mathrm{Mg}$ & 0,105 & $-0,067$ & $-0,027$ & 0,189 & $\mathbf{0 , 8 4 7}$ \\
$\mathrm{Mn}$ & $\mathbf{0 , 7 1 1}$ & $-0,145$ & $-0,097$ & 0,253 & 0,104 \\
$\mathrm{Na}$ & $-0,202$ & $-0,019$ & $\mathbf{0 , 9 1 2}$ & $-0,026$ & $-0,094$ \\
$\mathrm{P}$ & 0,041 & 0,355 & $-0,106$ & $\mathbf{0 , 8 1 3}$ & $-0,124$ \\
$\mathrm{Rb}$ & 0,41 & $-0,128$ & 0,044 & 0,43 & 0,175 \\
$\mathrm{~S}$ & 0,493 & 0,389 & 0,057 & $-0,136$ & 0,532 \\
$\mathrm{Sr}$ & 0,086 & $\mathbf{0 , 8 8 9}$ & $-0,007$ & $-0,013$ & 0,149 \\
$\mathrm{Zn}$ & $\mathbf{0 , 7 7 9}$ & 0,172 & 0,013 & 0,002 & 0,289 \\
Eigenvalue & 4,455 & 2,253 & 1,744 & 1,443 & 1,138 \\
\% of variance & 27,107 & 14,871 & 11,676 & 10,072 & 9,831 \\
Cumulative \% & 27,107 & 41,978 & 53,654 & 63,726 & 73,557 \\
\hline
\end{tabular}

\subsubsection{Fatorização de matriz positiva}

Os resultados da aplicação do PMF 5.0 pode ser observado na Figura 17 e na Tabela 7 a seguir. A utilização de 5 fatores (fontes) apresentou os resultados mais coerentes para a determinação do tipo de fonte de poluição atmosférica. Os números destacados na Tabela 7 são aqueles com os maiores valores encontrados no dados elemento. 


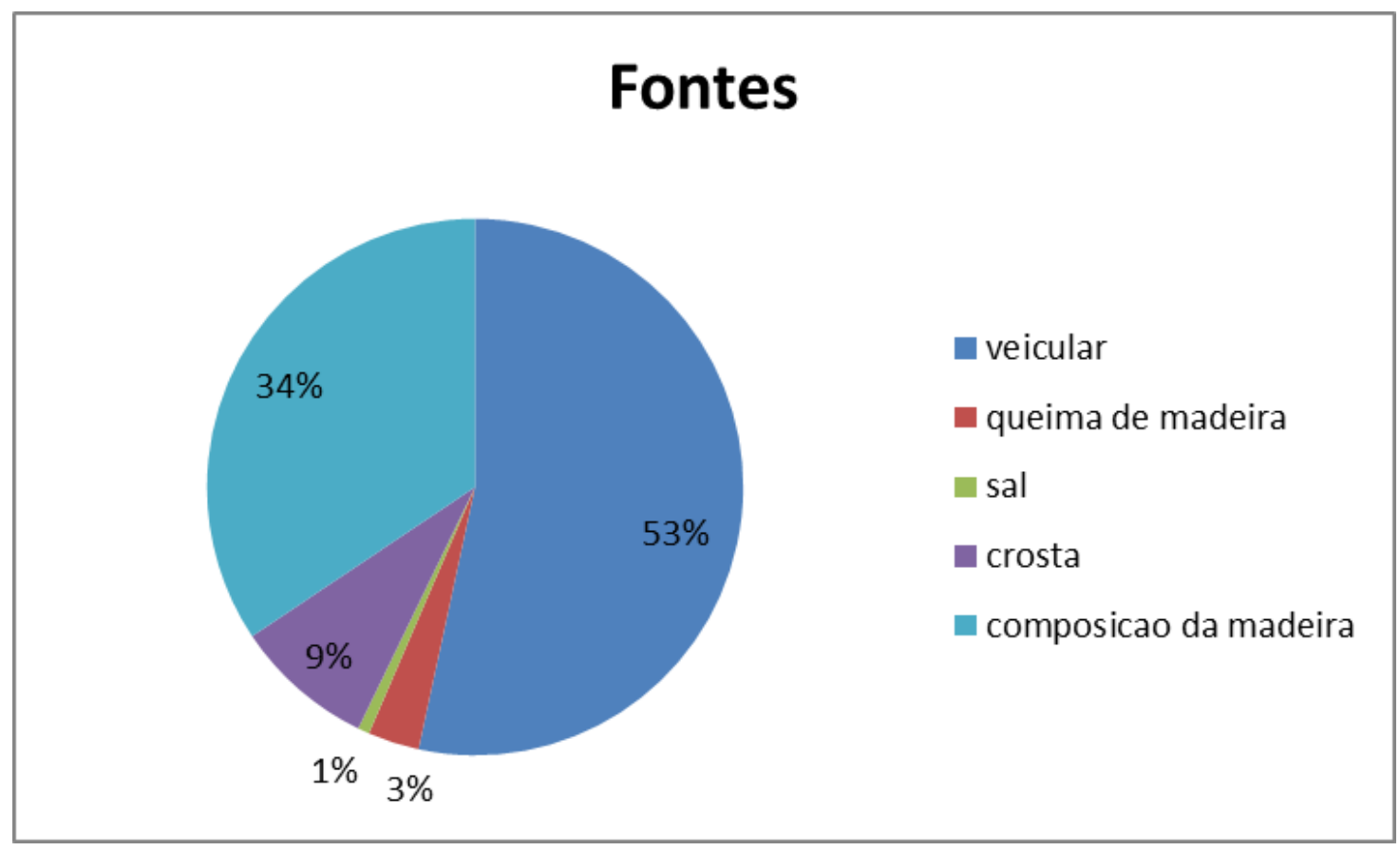

Figura 17- Composição das fontes obtidas pela aplicação da PMF.

Tabela 7-Composição das fontes segundo o resultado obtido no programa PMF.

\begin{tabular}{|c|c|c|c|c|c|}
\hline \multirow[b]{2}{*}{ Elementos } & \multicolumn{5}{|c|}{ Fontes } \\
\hline & $\begin{array}{c}\text { Sal } \\
\text { marinho }\end{array}$ & $\begin{array}{c}\text { Queima de } \\
\text { madeira }\end{array}$ & $\begin{array}{c}\text { Composição da } \\
\text { madeira }\end{array}$ & $\begin{array}{c}\text { Veiculos } \\
\text { automotores }\end{array}$ & $\begin{array}{c}\text { Elementos da } \\
\text { crosta }\end{array}$ \\
\hline MP & 0 & 0 & 2239 & 23754 & 2924,2 \\
\hline Al & 17,3 & 18,6 & 75,5 & 95 & 493,2 \\
\hline $\mathbf{B a}$ & 2,6 & 34,4 & 29,8 & 73,9 & 374 \\
\hline $\mathbf{C a}$ & 0 & 409,4 & 19735 & 9345,3 & 156,3 \\
\hline Cl & 121,6 & 0 & 9,3 & 0 & 17,3 \\
\hline $\mathbf{C u}$ & 0,5 & 0,54 & 2,1 & 1,6 & 1,45 \\
\hline $\mathbf{F e}$ & 16,3 & 33,2 & 82,1 & 153,3 & 851 \\
\hline $\mathbf{K}$ & 16,1 & 754,2 & 316,6 & 0 & 329,9 \\
\hline Mg & 0 & 458,6 & 0 & 792,7 & 0 \\
\hline Mn & 5,8 & 1,6 & 11,7 & 2,1 & 17,7 \\
\hline $\mathbf{N a}$ & 2,5 & 2,2 & 9,5 & 3,29 & 0 \\
\hline $\mathbf{P}$ & 12,9 & 108,3 & 498,7 & 149,5 & 11,6 \\
\hline $\mathbf{P b}$ & 0,1 & 0,1 & 0,42 & 0,4 & 0,4 \\
\hline $\mathbf{S}$ & 266,2 & 76,2 & 1047,3 & 891,4 & 540,2 \\
\hline $\mathbf{Z n}$ & 0 & 12,7 & 0 & 48,8 & 40 \\
\hline
\end{tabular}




\subsection{Análise discriminante}

Os resultados da aplicação da estatística de análise discriminante são apresentados na Tabela 5 juntamente com classificação oficial das vias segundo CET Tabela 8 - Classificação predita das vias da área de estudo obtida por meio da aplicação na análise discriminante ( $\mathrm{N}=$ número de vias).

\begin{tabular}{|c|c|c|c|c|c|c|c|}
\hline \multirow{10}{*}{ 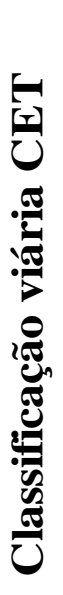 } & & & \multicolumn{5}{|c|}{ Classificação viária predita de acordo com a emissão } \\
\hline & & & Arterial & Coletora & Expressa & Local & Total \\
\hline & \multirow{4}{*}{$\mathrm{N}$} & Arterial & 35 & 21 & 19 & 24 & 99 \\
\hline & & Coletora & 11 & 15 & 3 & 13 & 42 \\
\hline & & Expressa & 4 & 1 & 1 & 1 & 7 \\
\hline & & Local & 2 & 8 & 0 & 13 & 23 \\
\hline & \multirow{4}{*}{$\%$} & Arterial & 35,4 & 21,2 & 19,2 & 24,2 & 100 \\
\hline & & Coletora & 26,2 & 35,7 & 7,1 & 31 & 100 \\
\hline & & Expressa & 57,1 & 14,3 & 14,3 & 14,3 & 100 \\
\hline & & Local & 8,7 & 34,8 & 0 & 56,5 & 100 \\
\hline
\end{tabular}

\subsection{Geoestatistica - Mapas de distribuição das concentrações de elementos nas} cascas de árvores no centro expandido de São Paulo

Os mapas de distribuição das concentrações de elementos com potenciais origens de fontes veiculares, gerados por meio da técnica de Krigagem, são mostrados nas Figuras de 18 a 43 assim como seus mapas de erro. Os mapas de apresentam os resultados de onde a interpolação não apresenta resultados adequados, as cores mais claras indicam os locais aonde a predição não está precisa. As cores mais intensas no mapa de distribuição das concentrações indicam as concentrações mais altas dos elementos. 


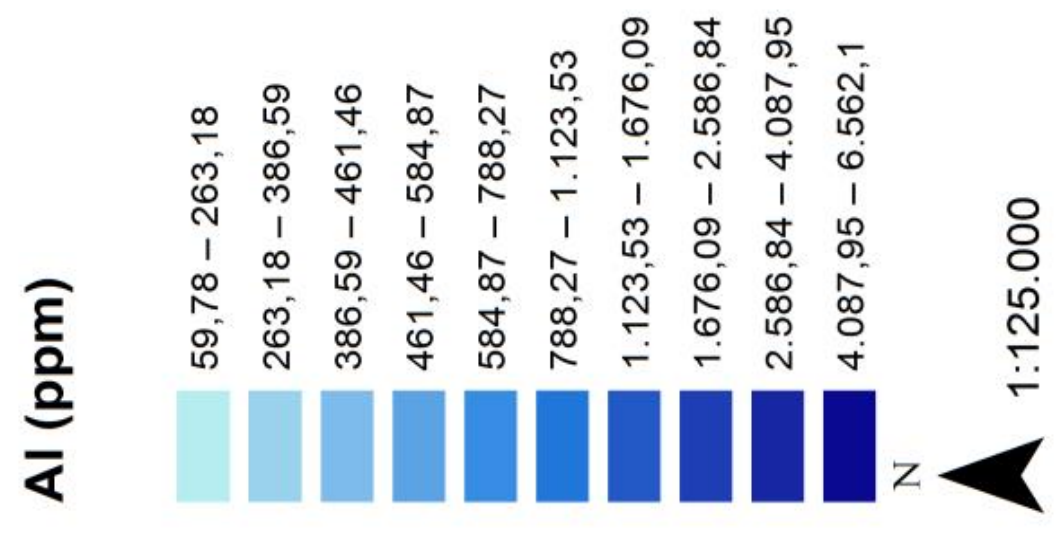

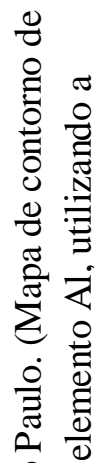

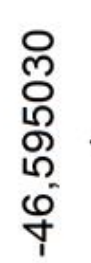

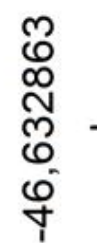

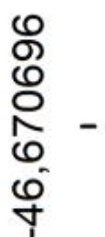

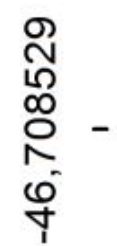

N
ल
0

$\checkmark$

i

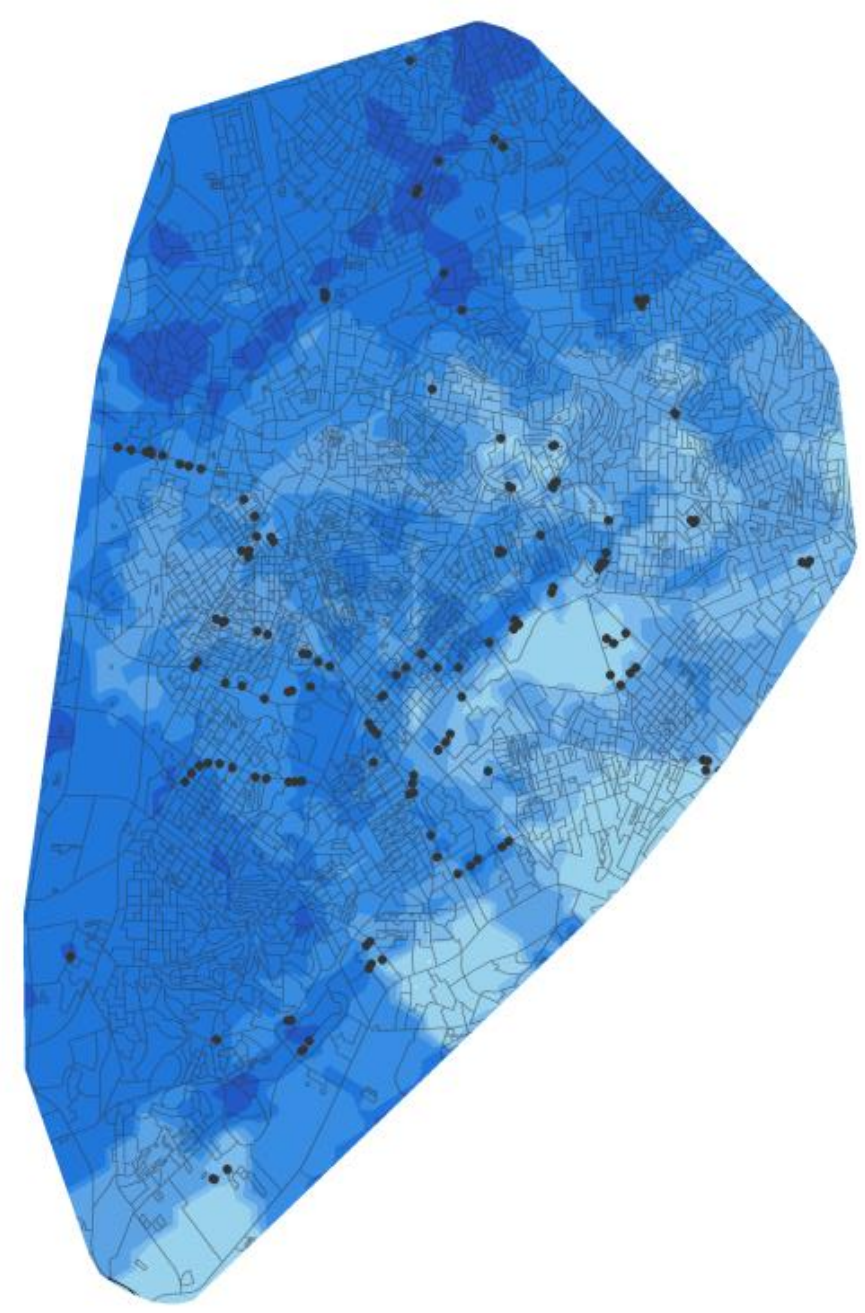

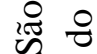

ช

을

I

这

๘

อ

8 중

:

?.

总

चे

\%ิ

兽.

트

จ

రิ

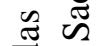

总焉

芯跣

ช

च

产 $\frac{\pi}{\infty} \frac{0}{0}$

$1 \cong \cdot \frac{\pi}{60}$

$\infty$ s 0

펼 ठ

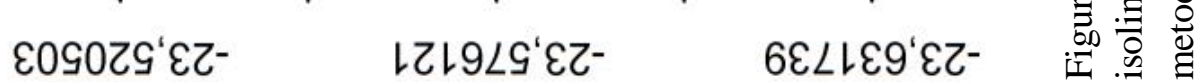




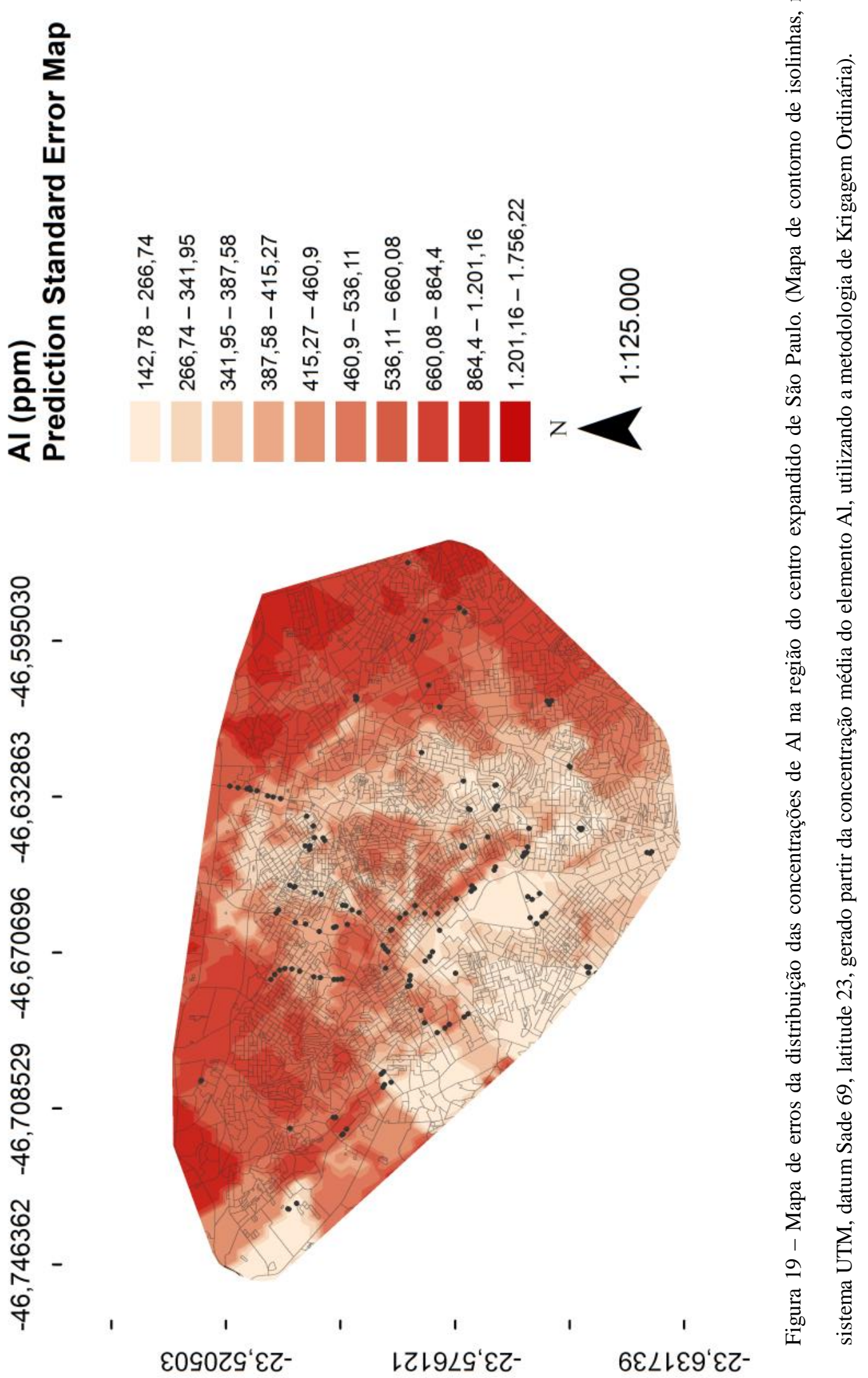




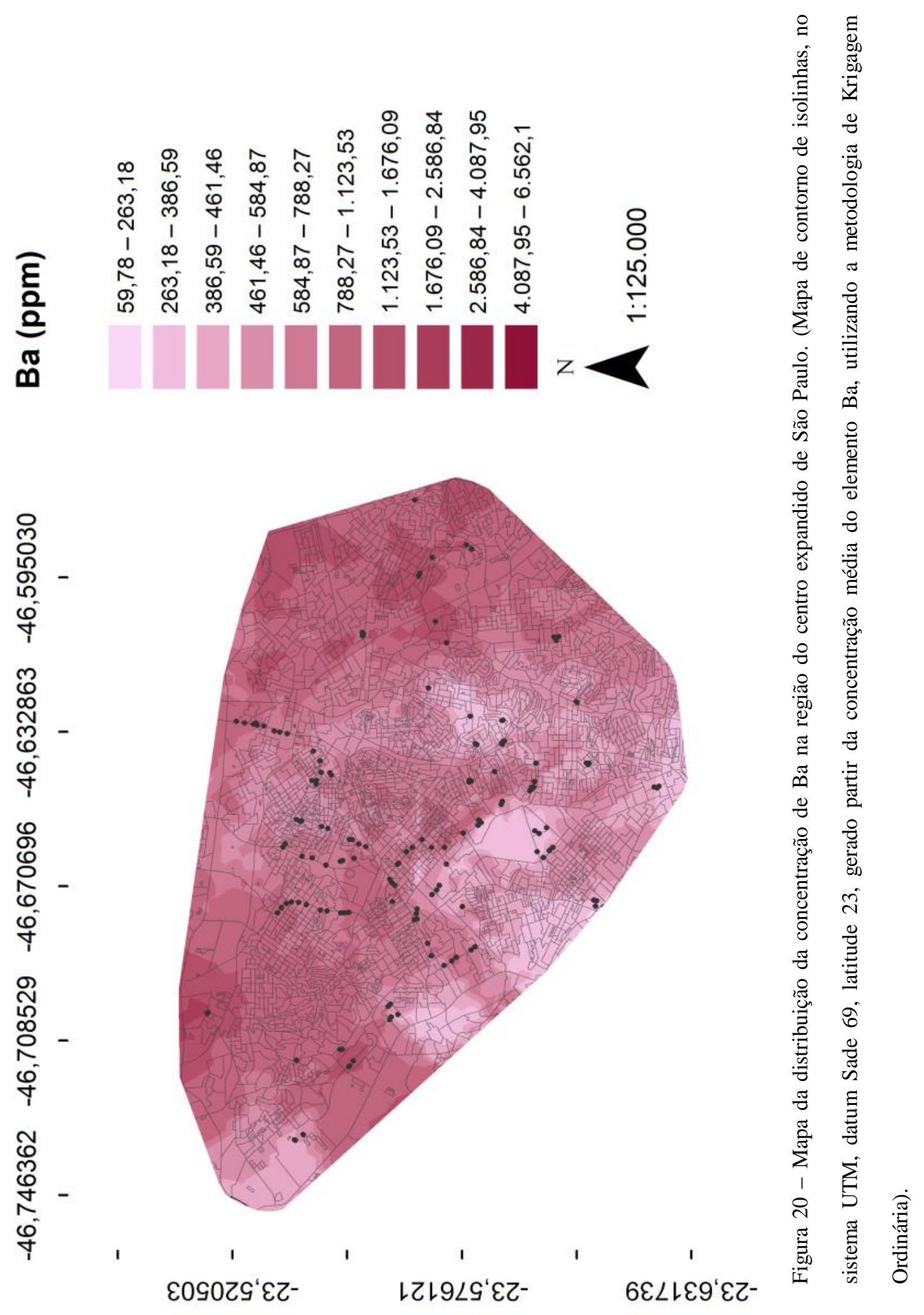




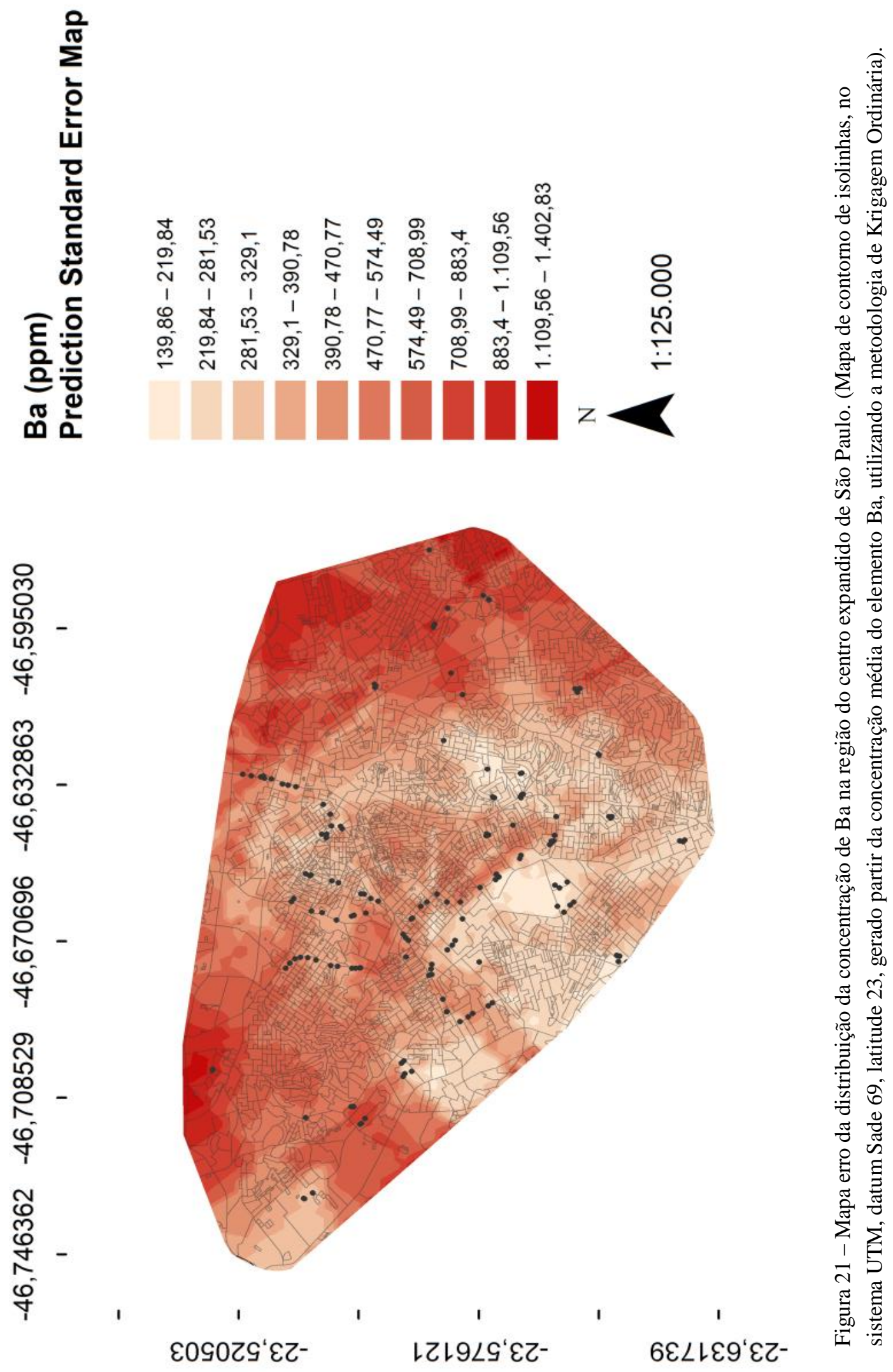




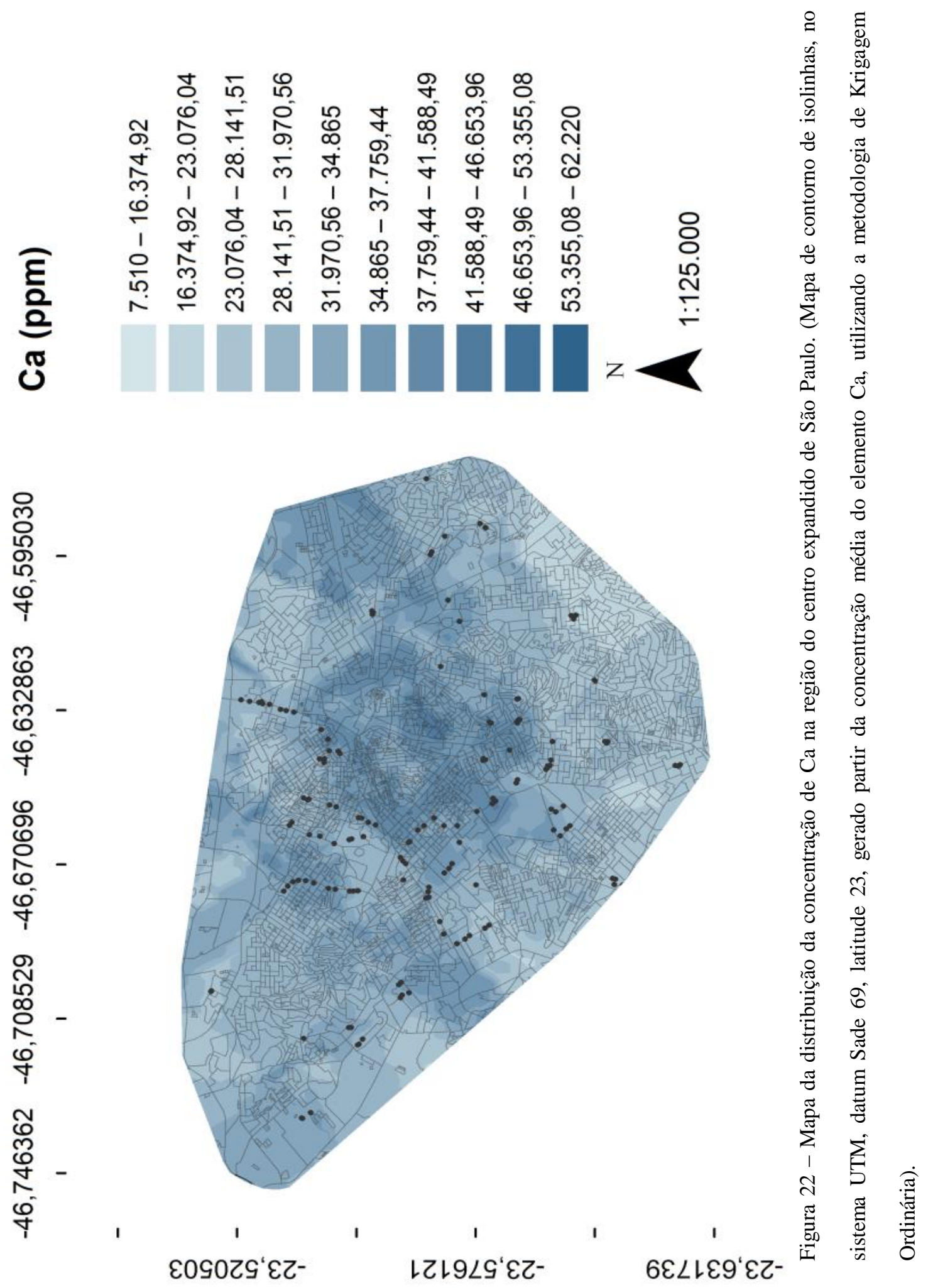




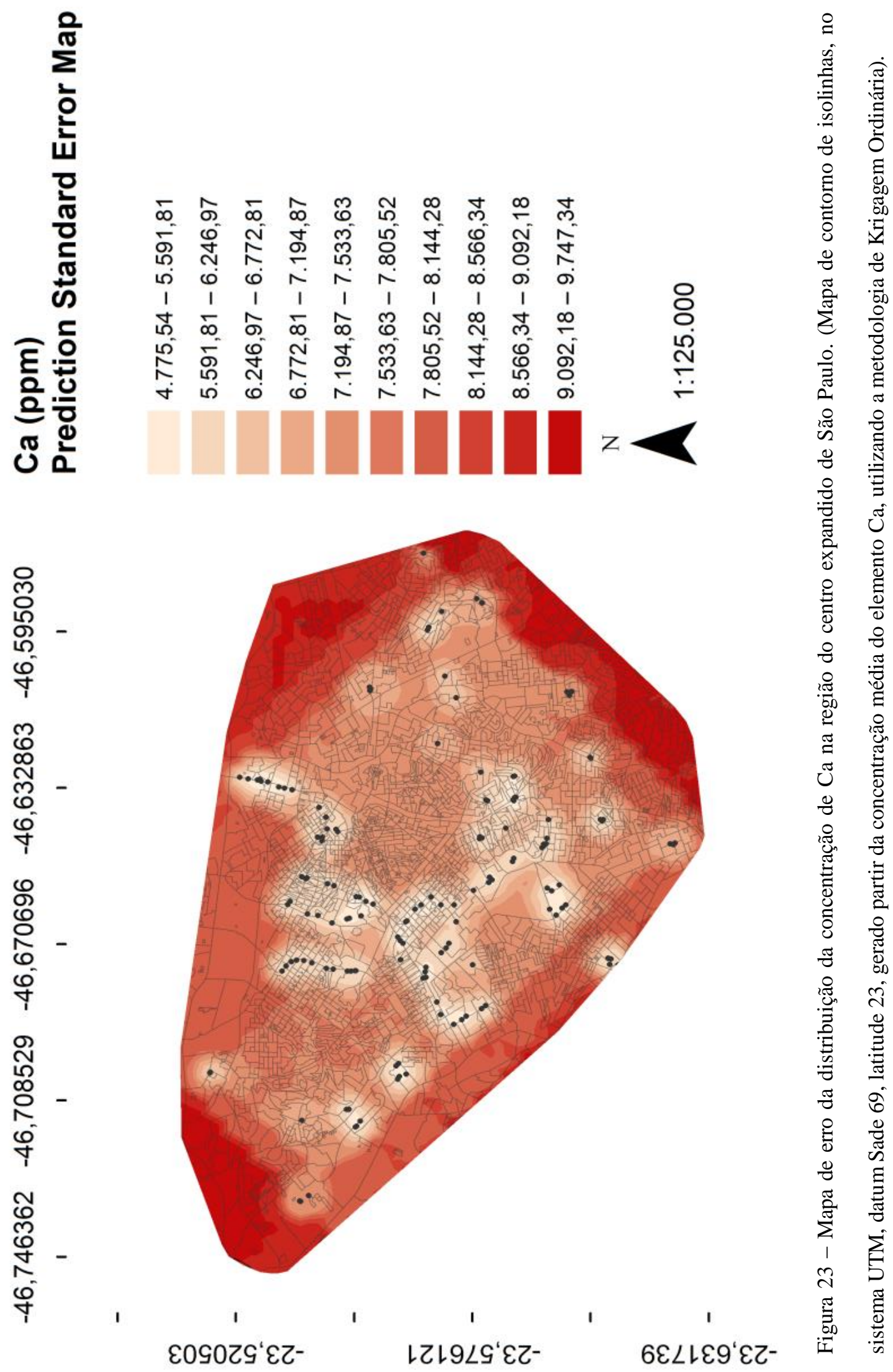




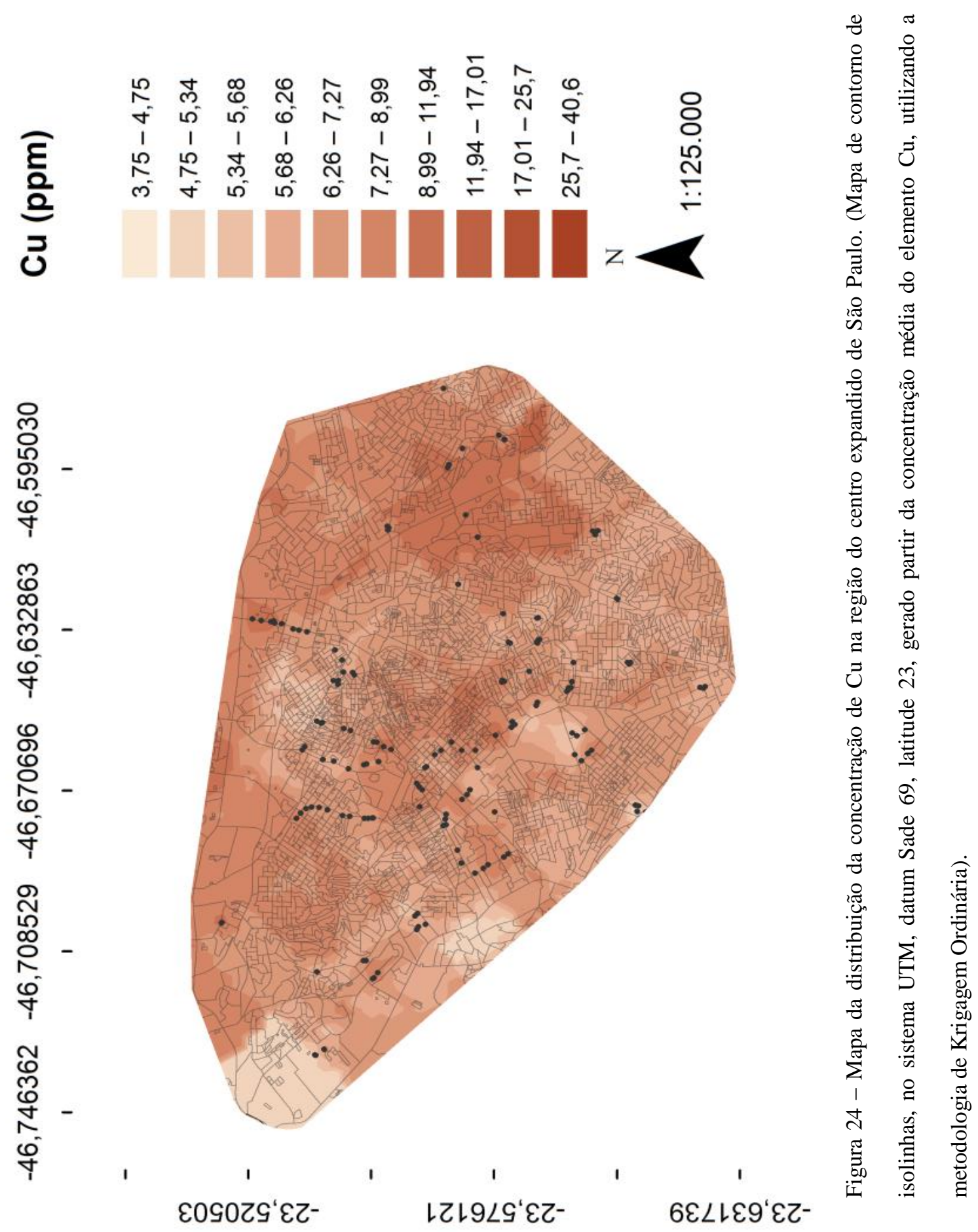




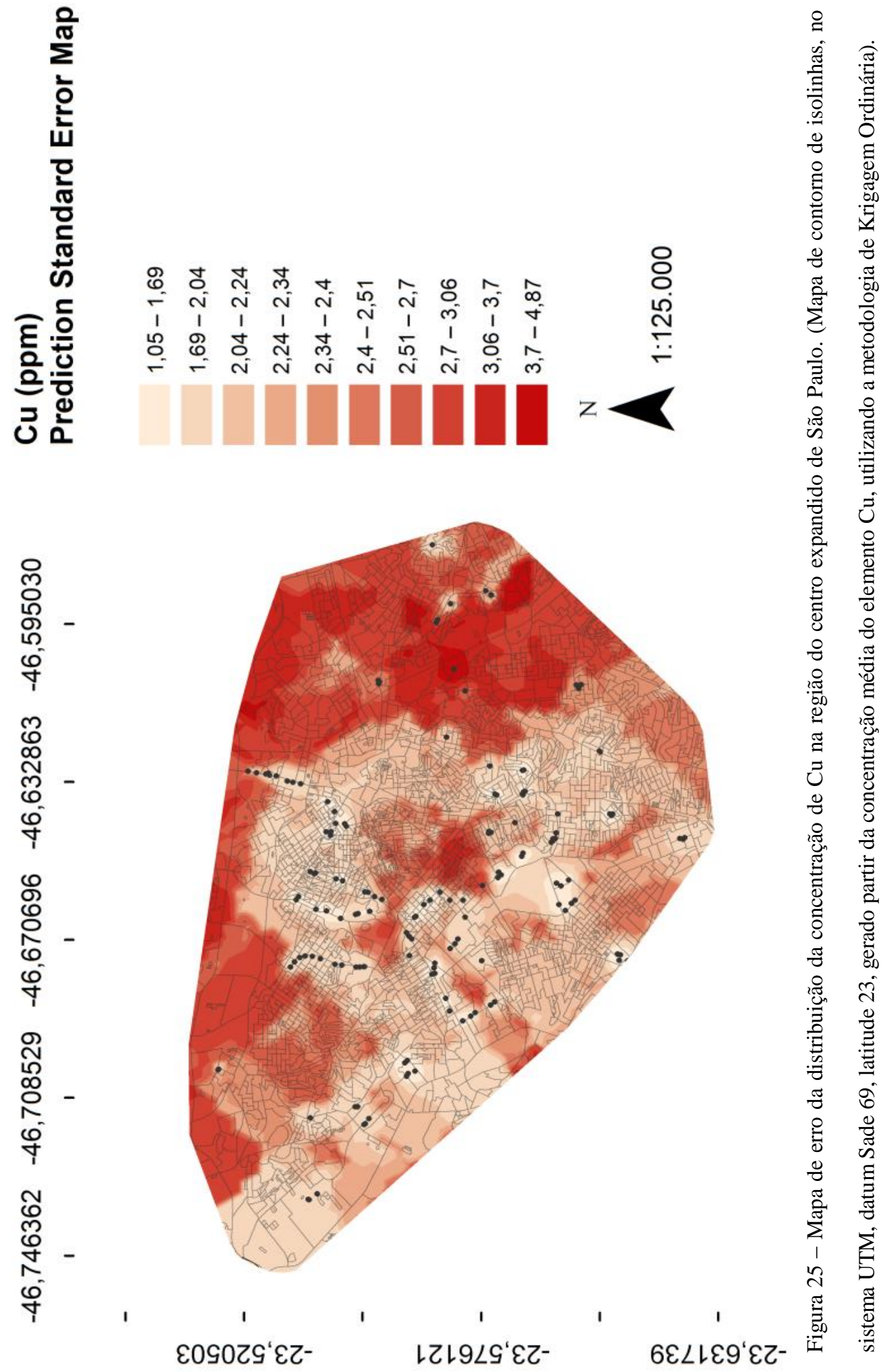




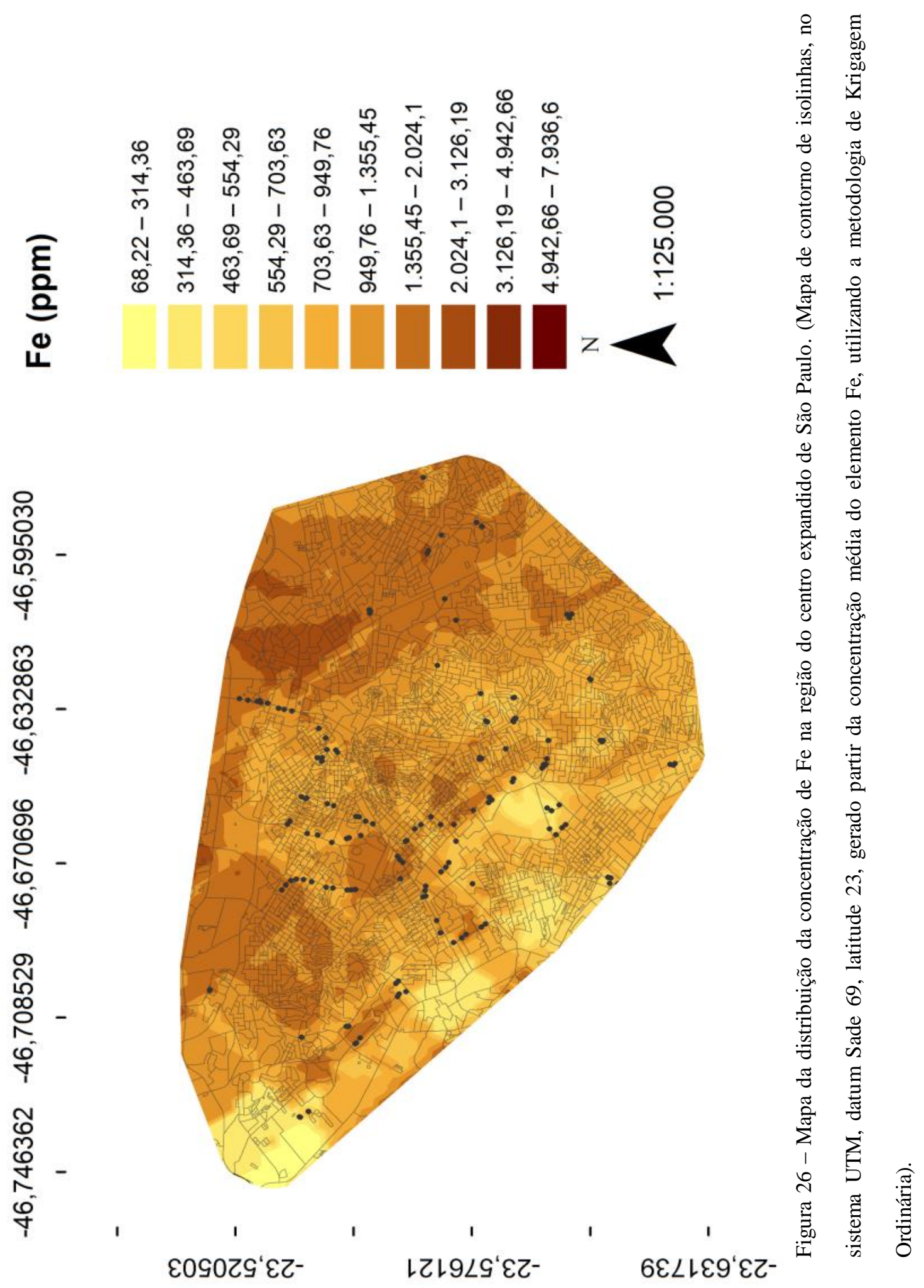




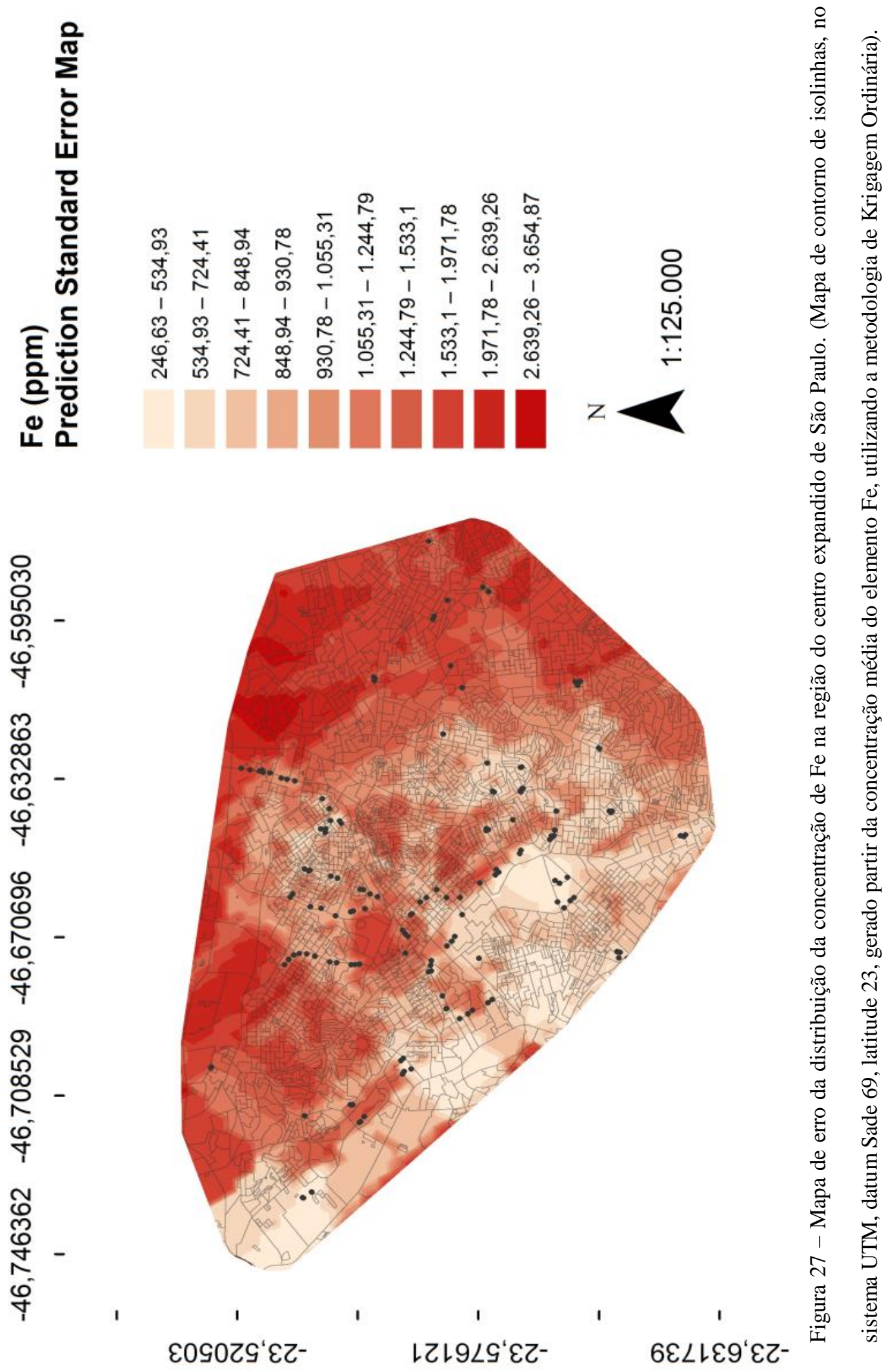




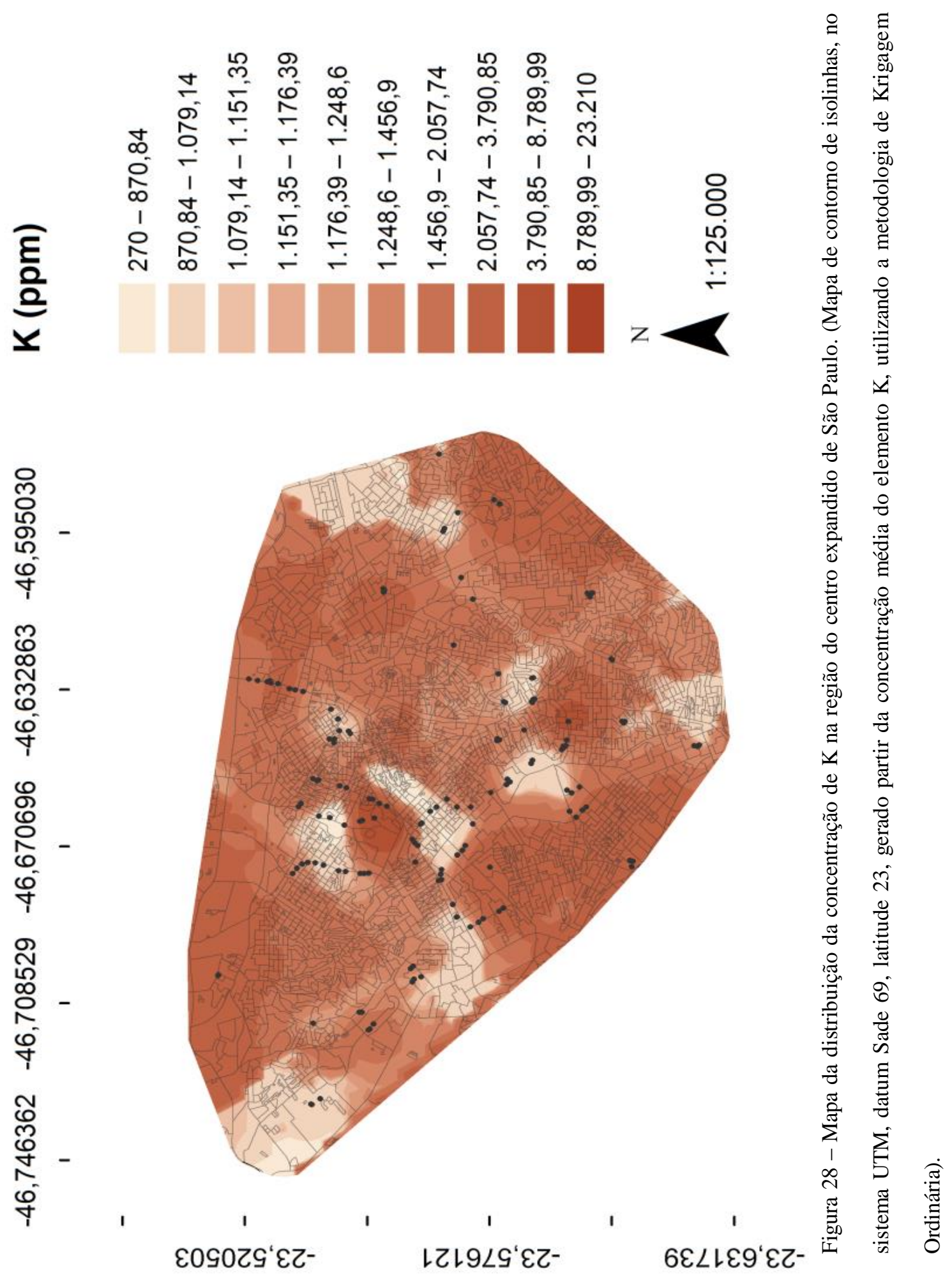




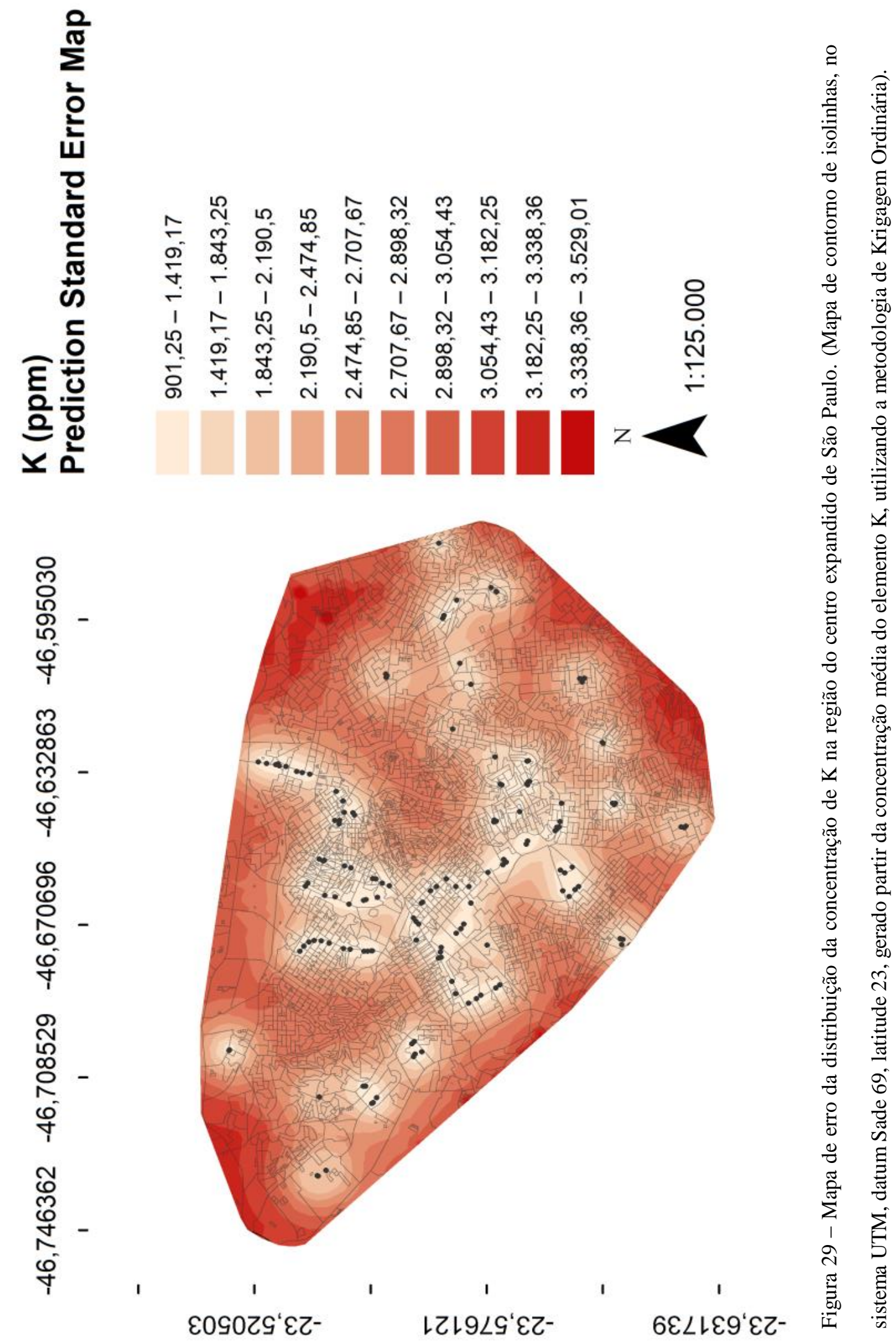




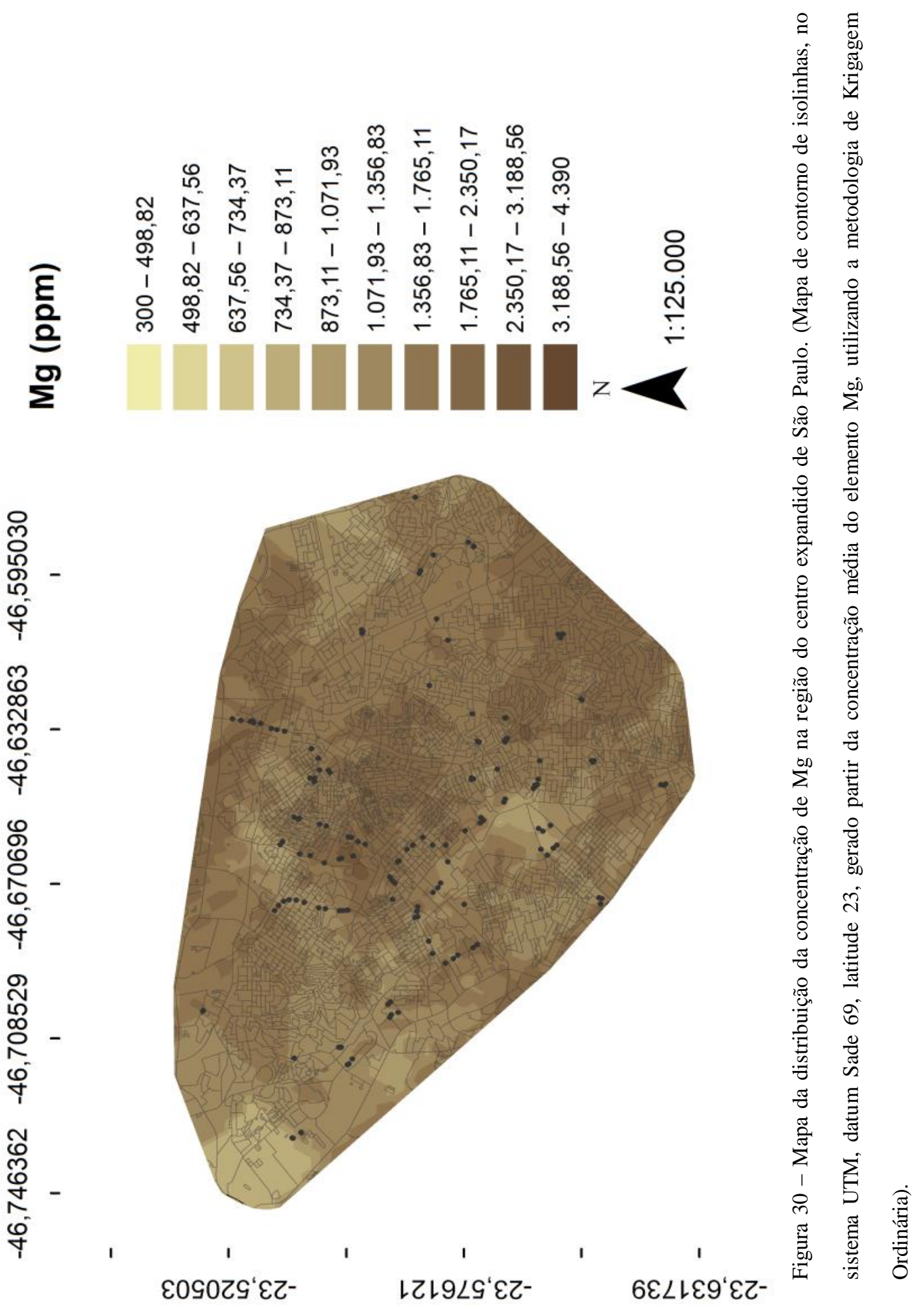




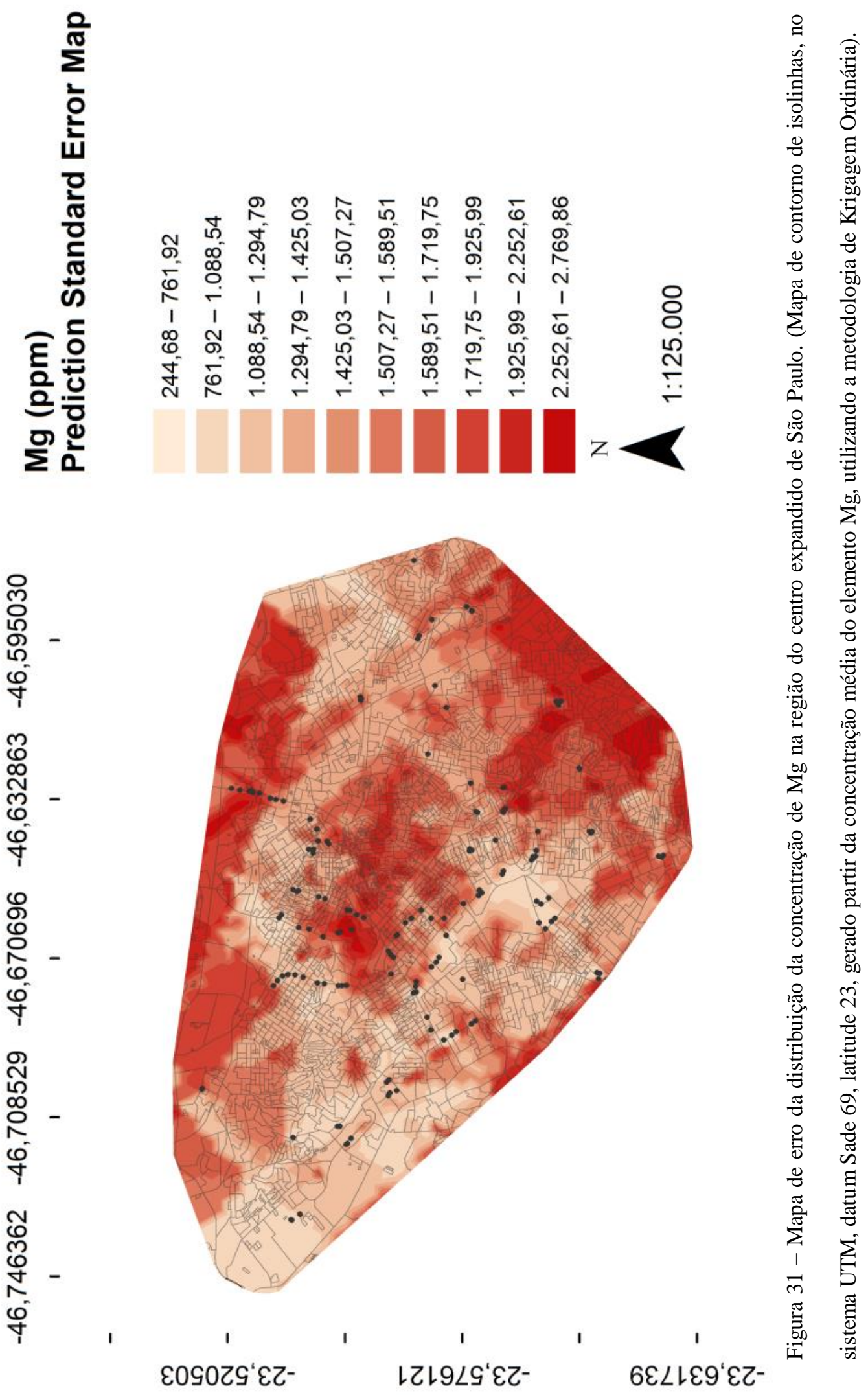




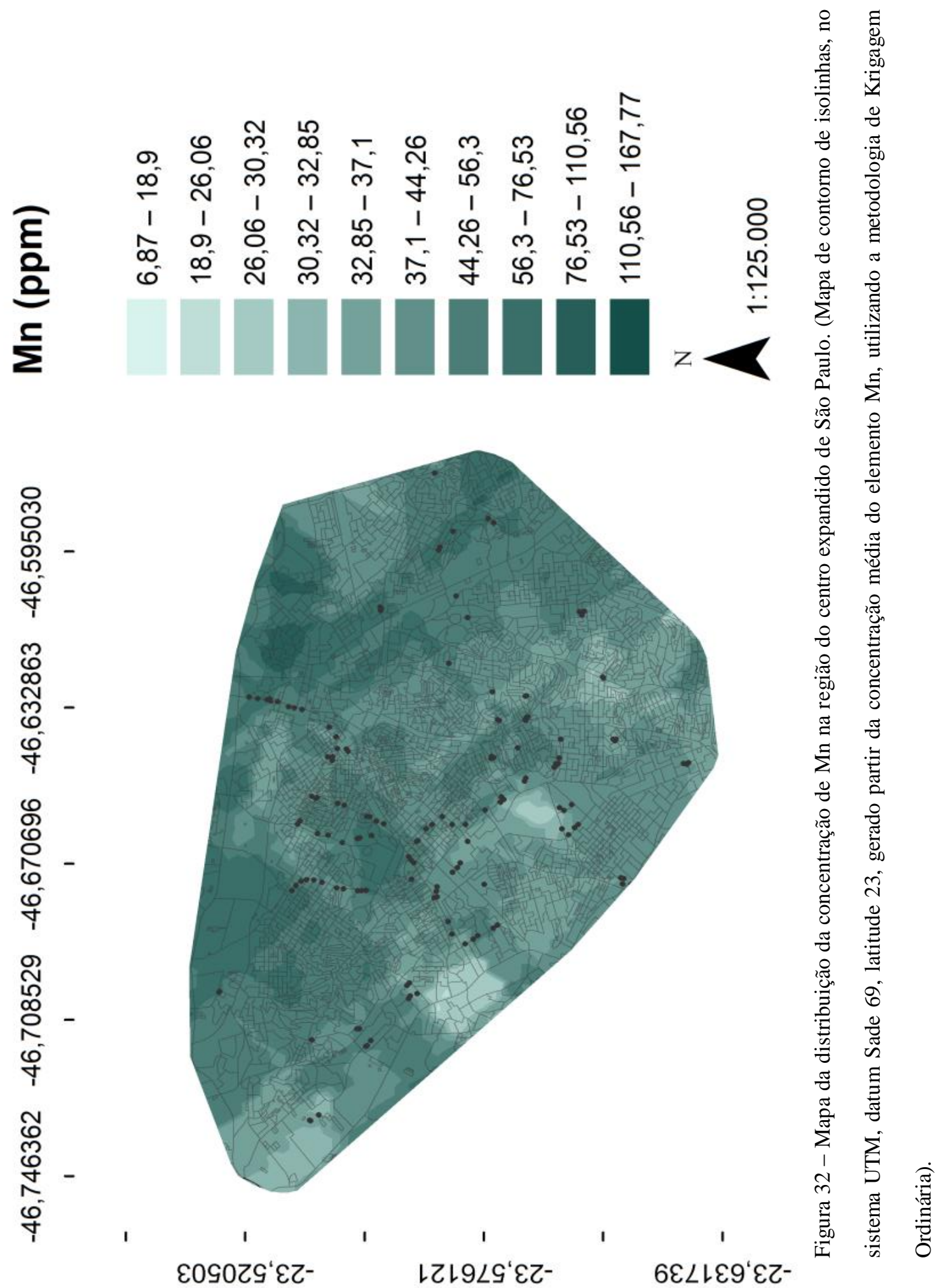




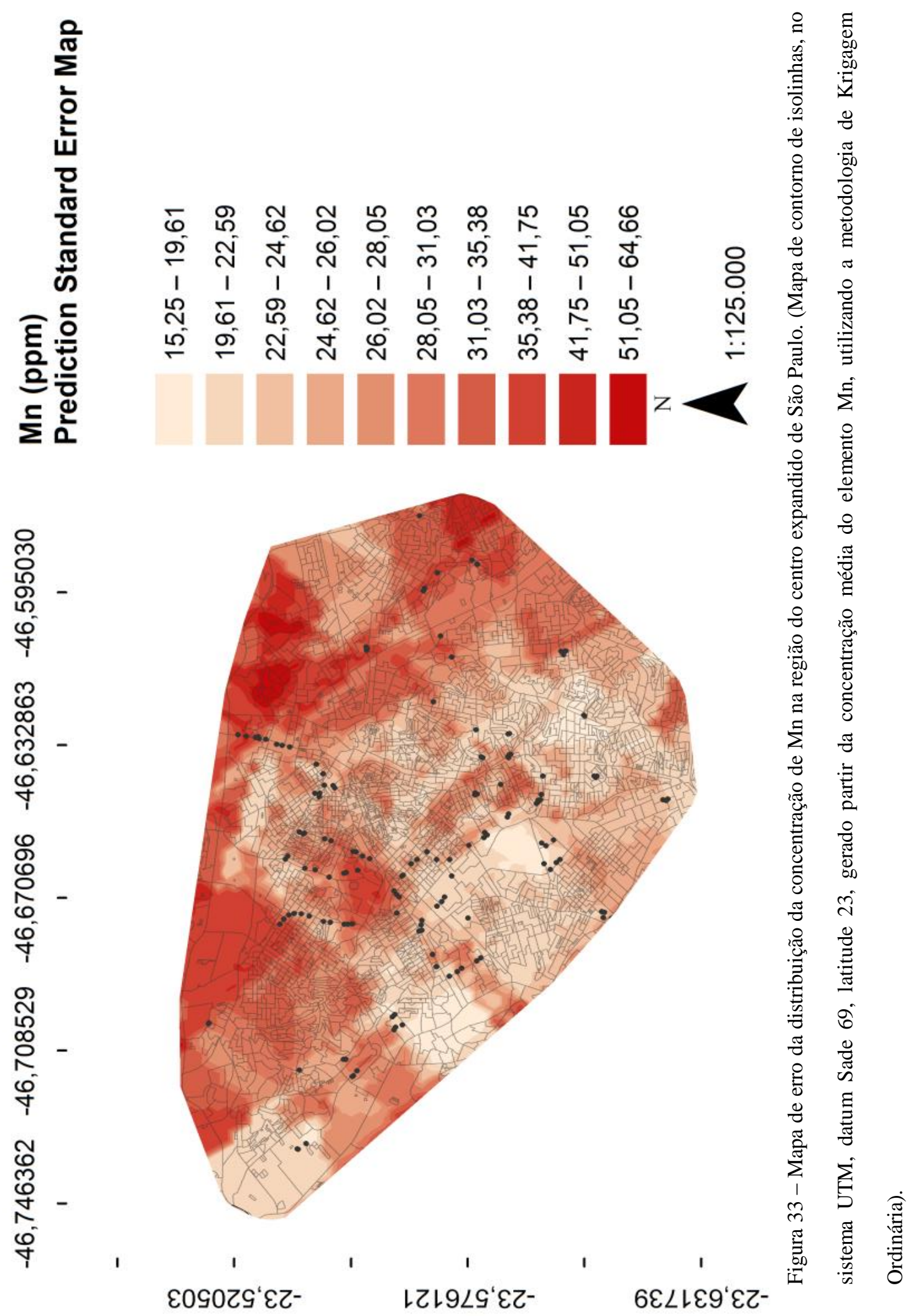




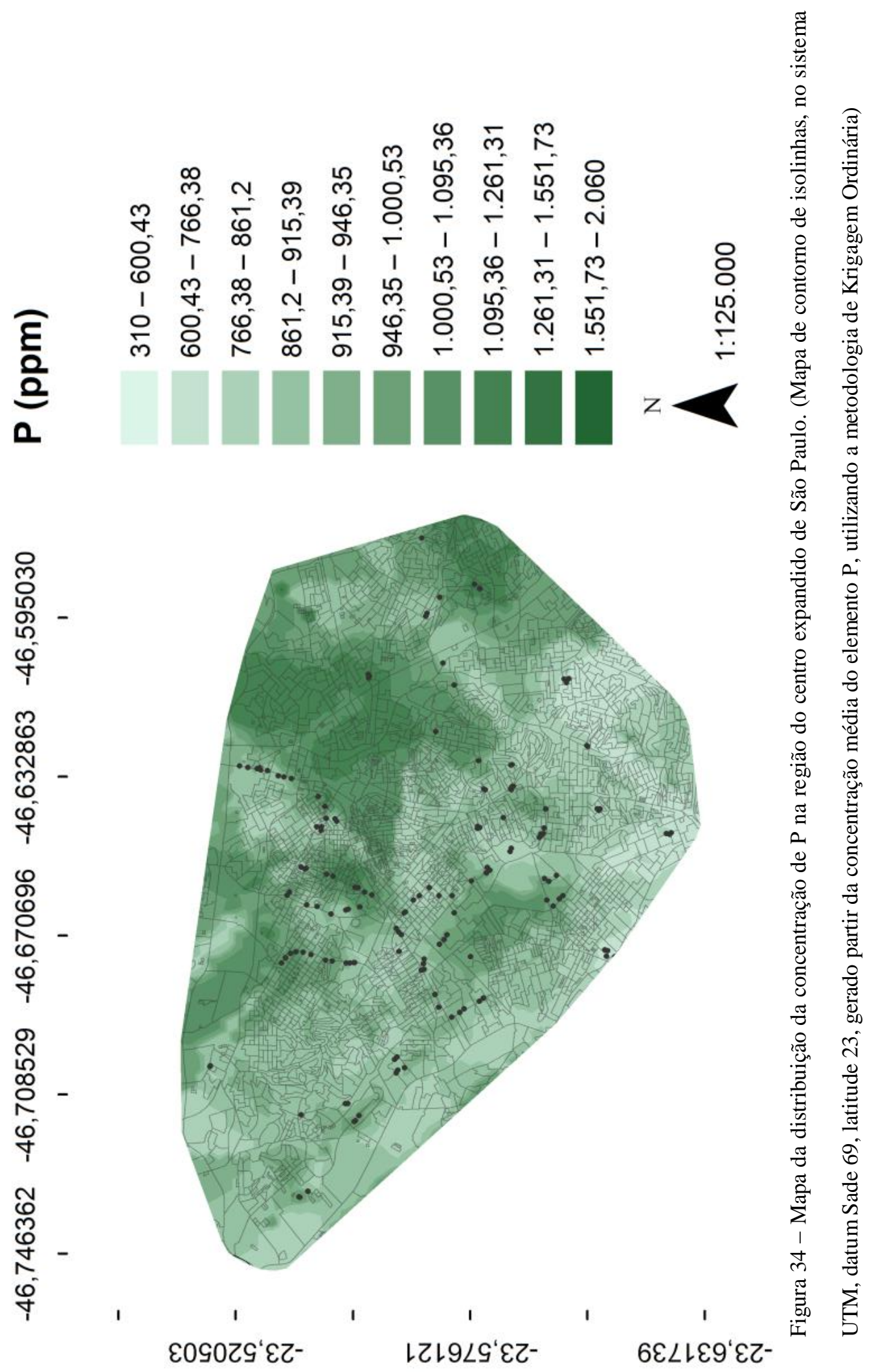




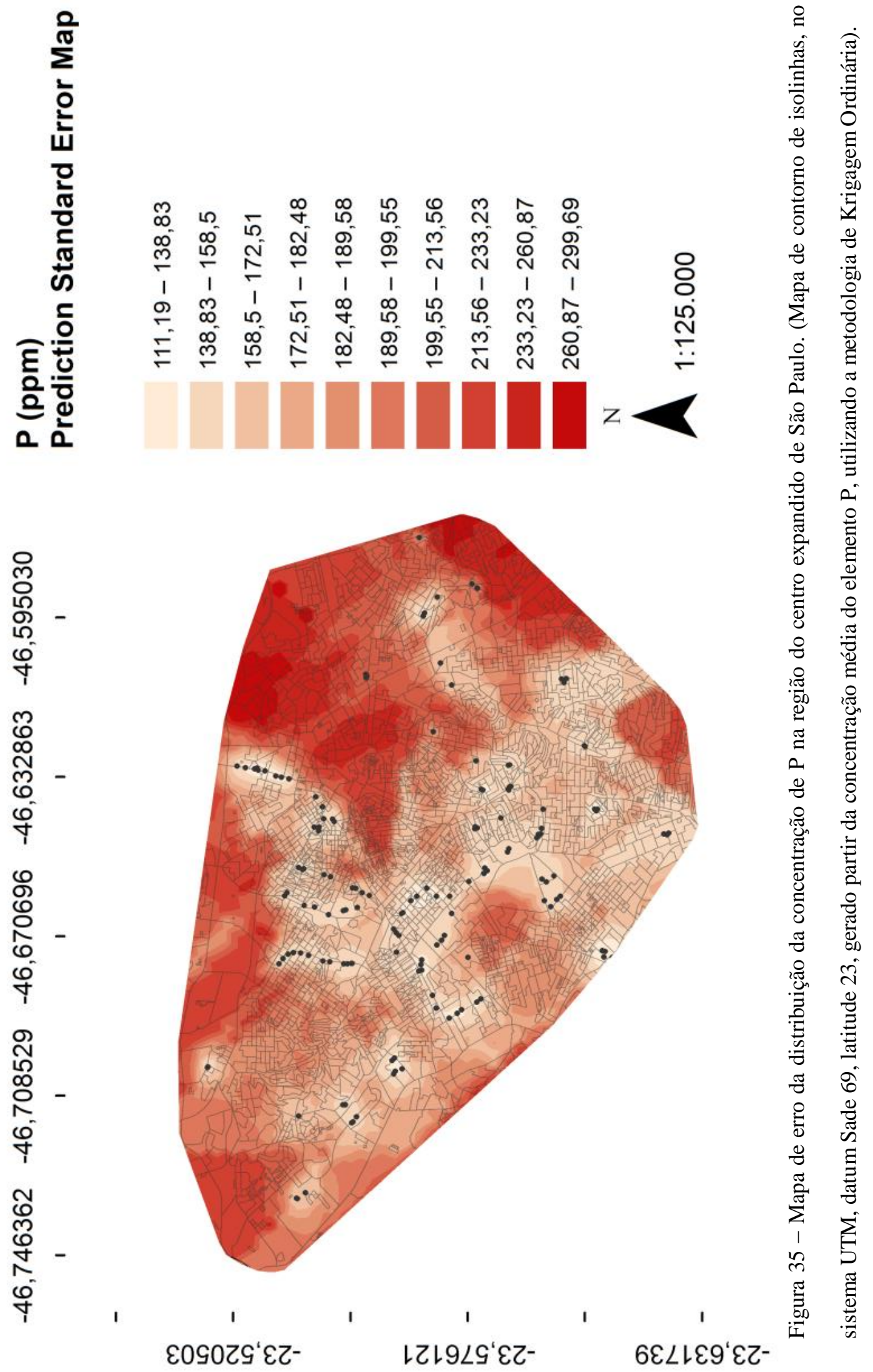




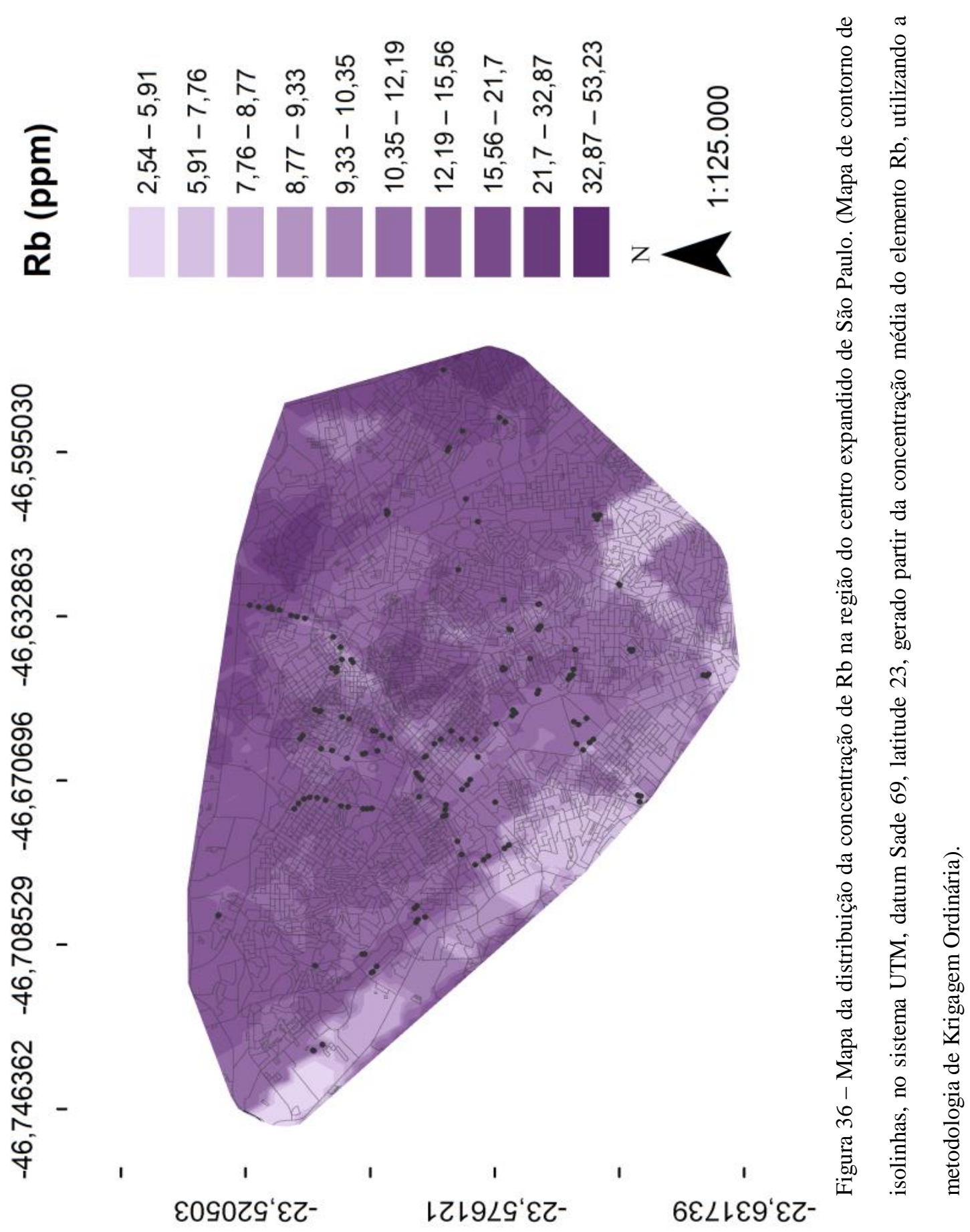




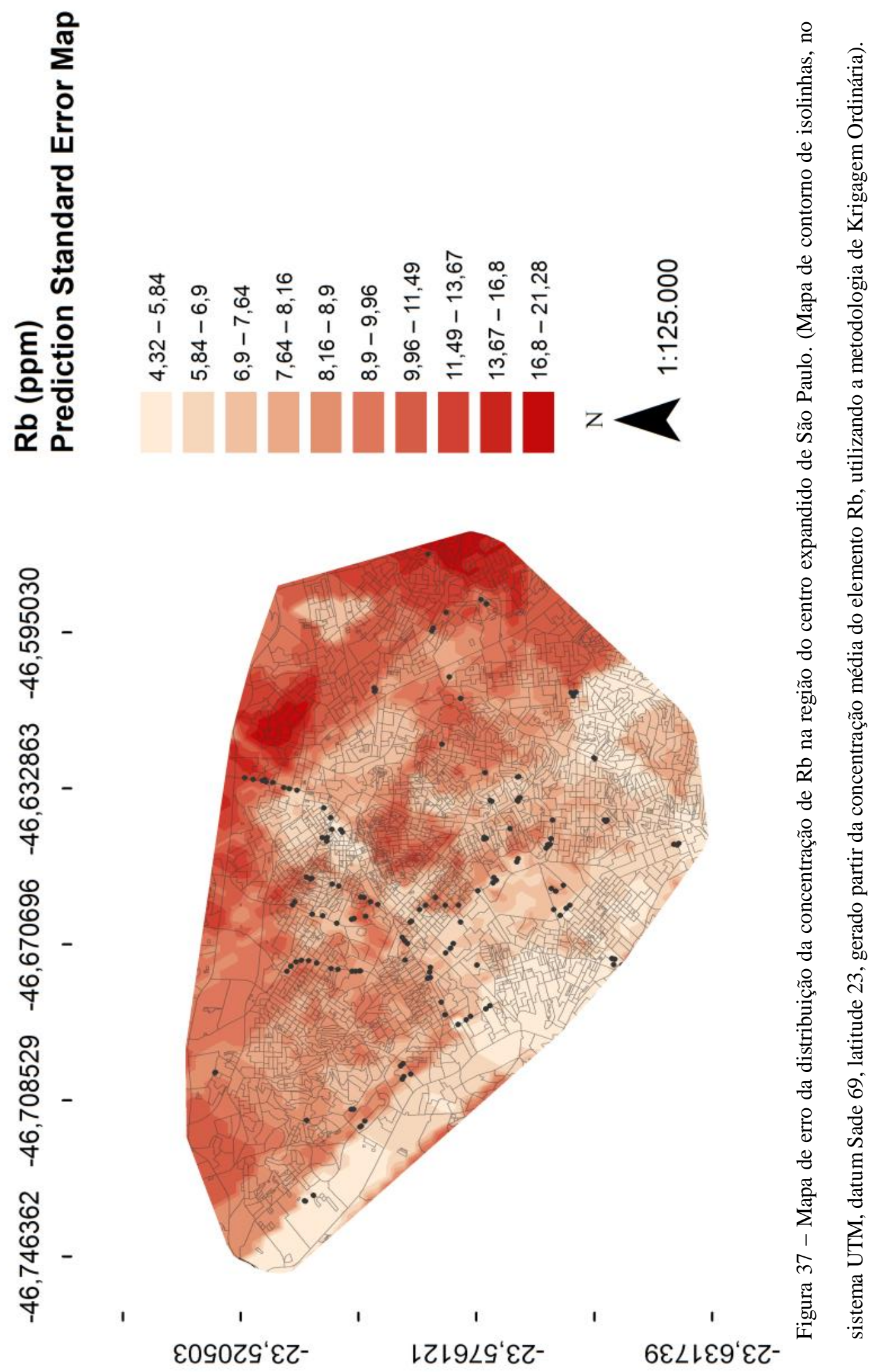




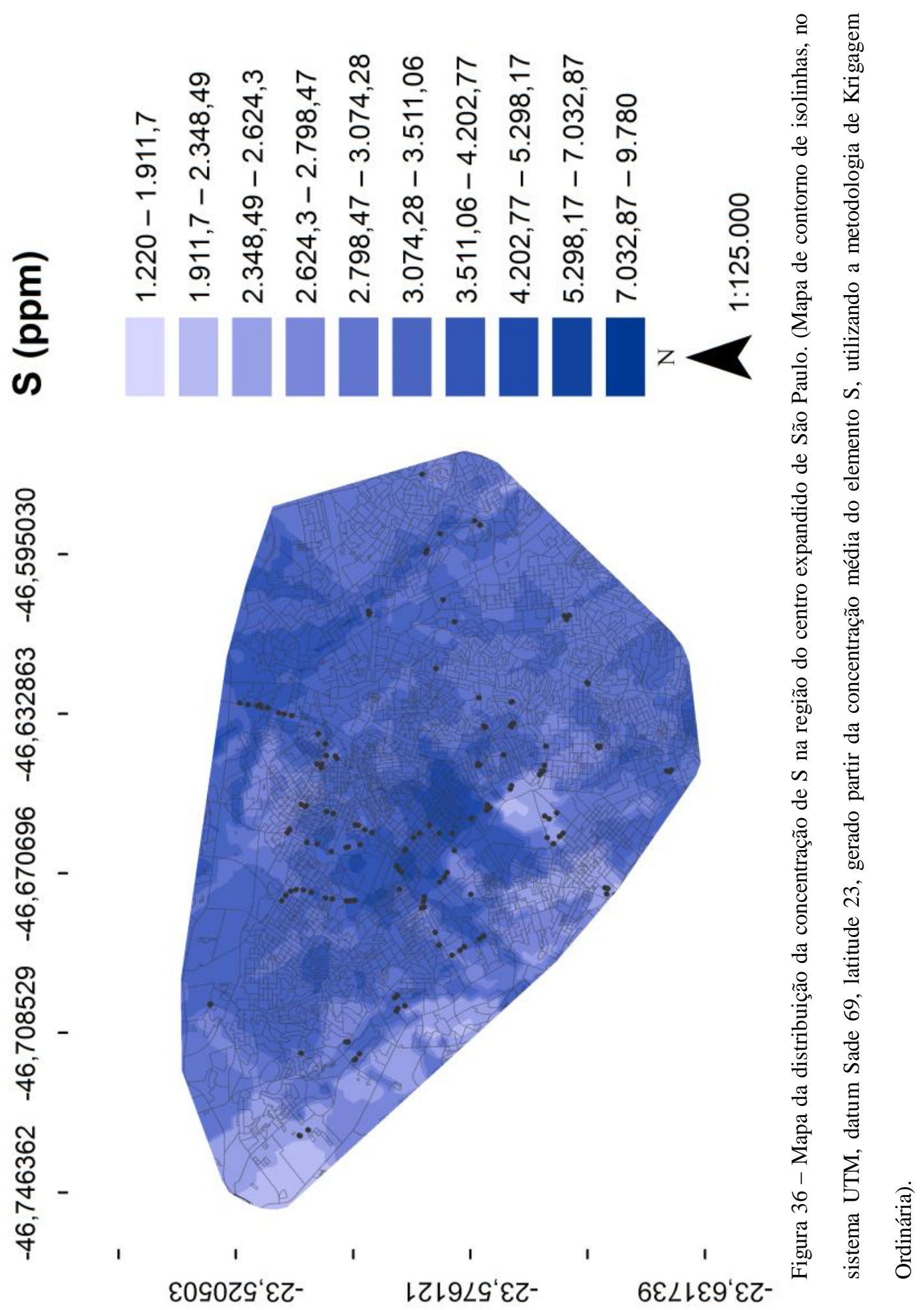




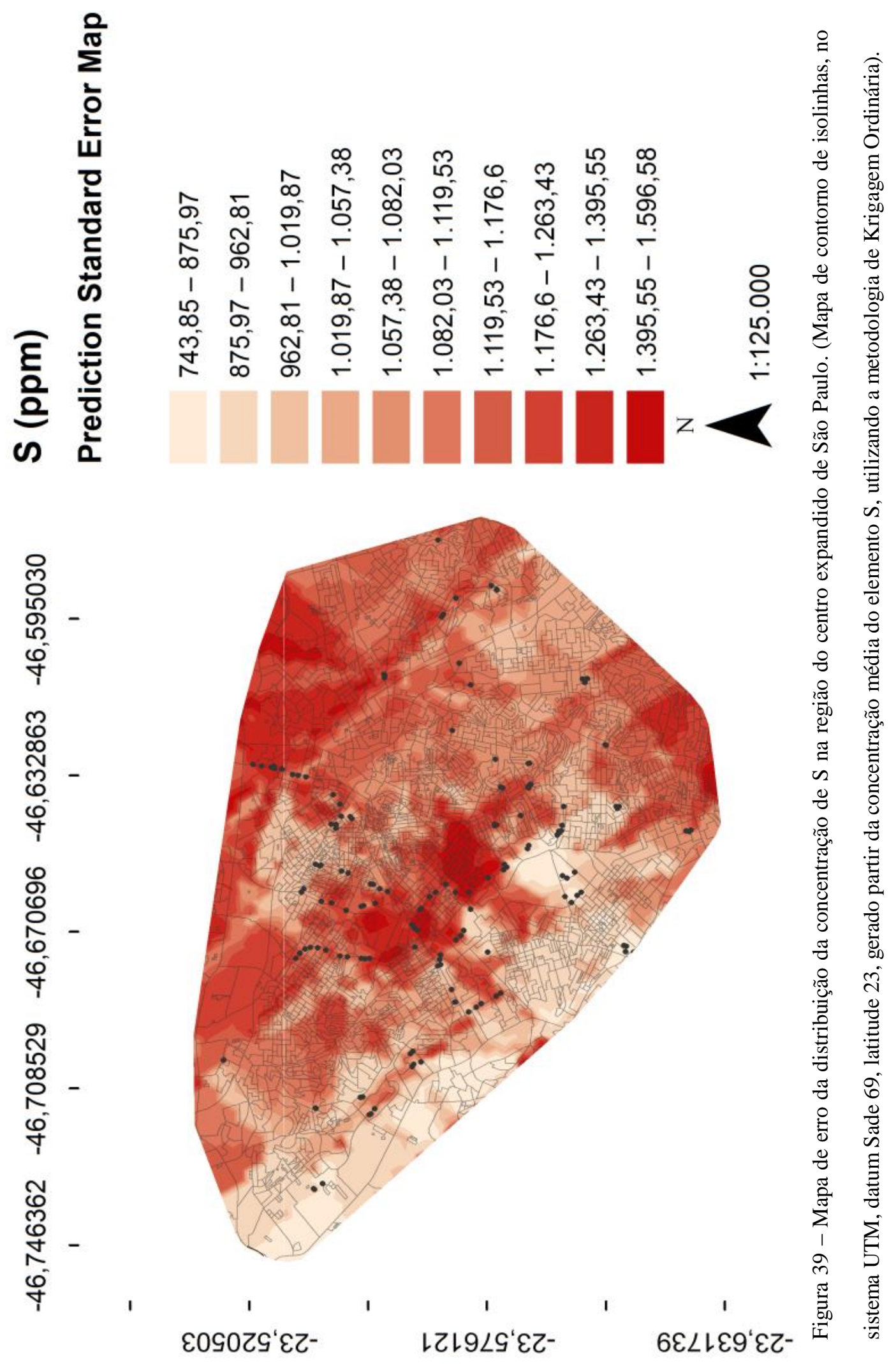




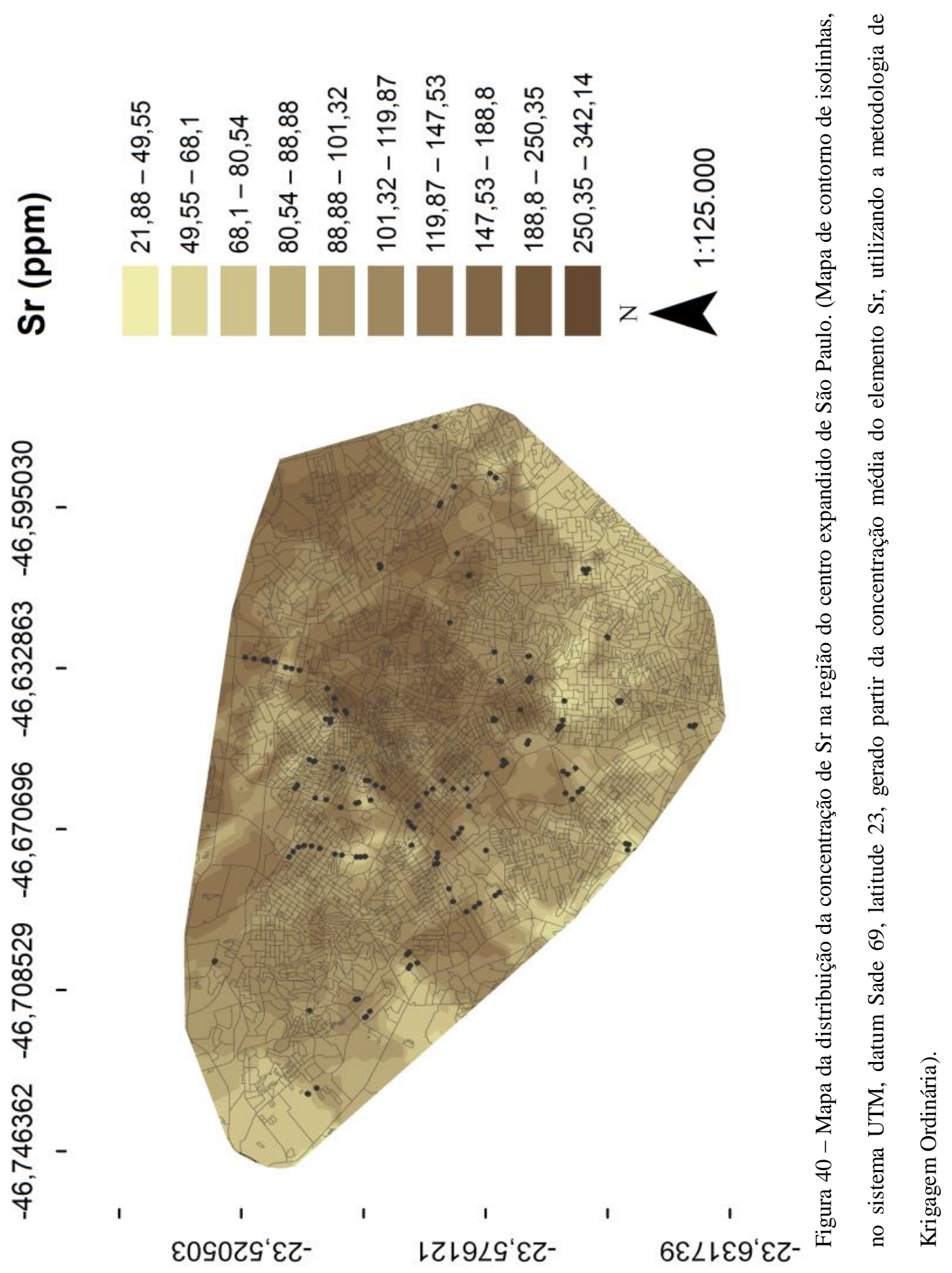




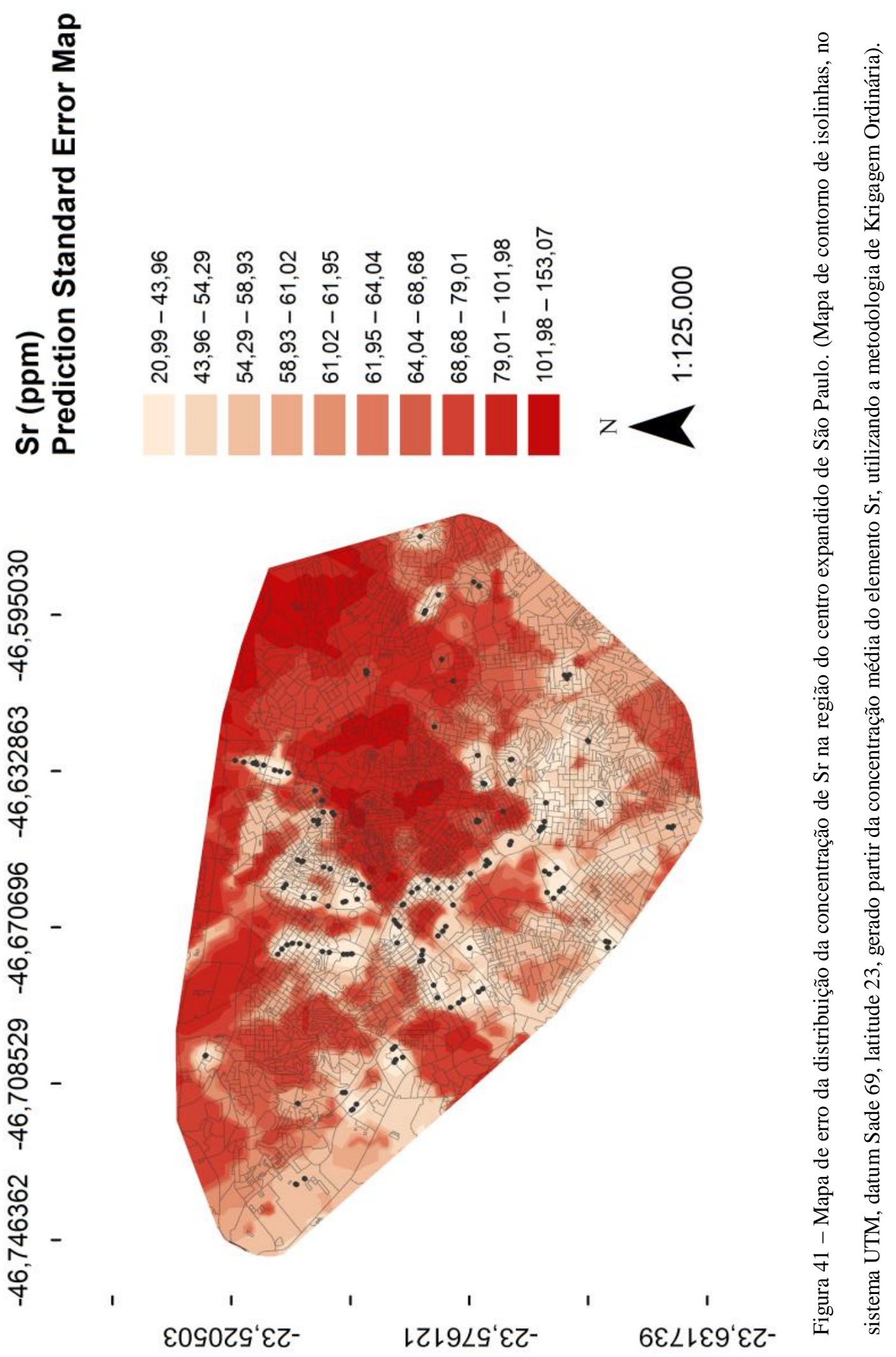




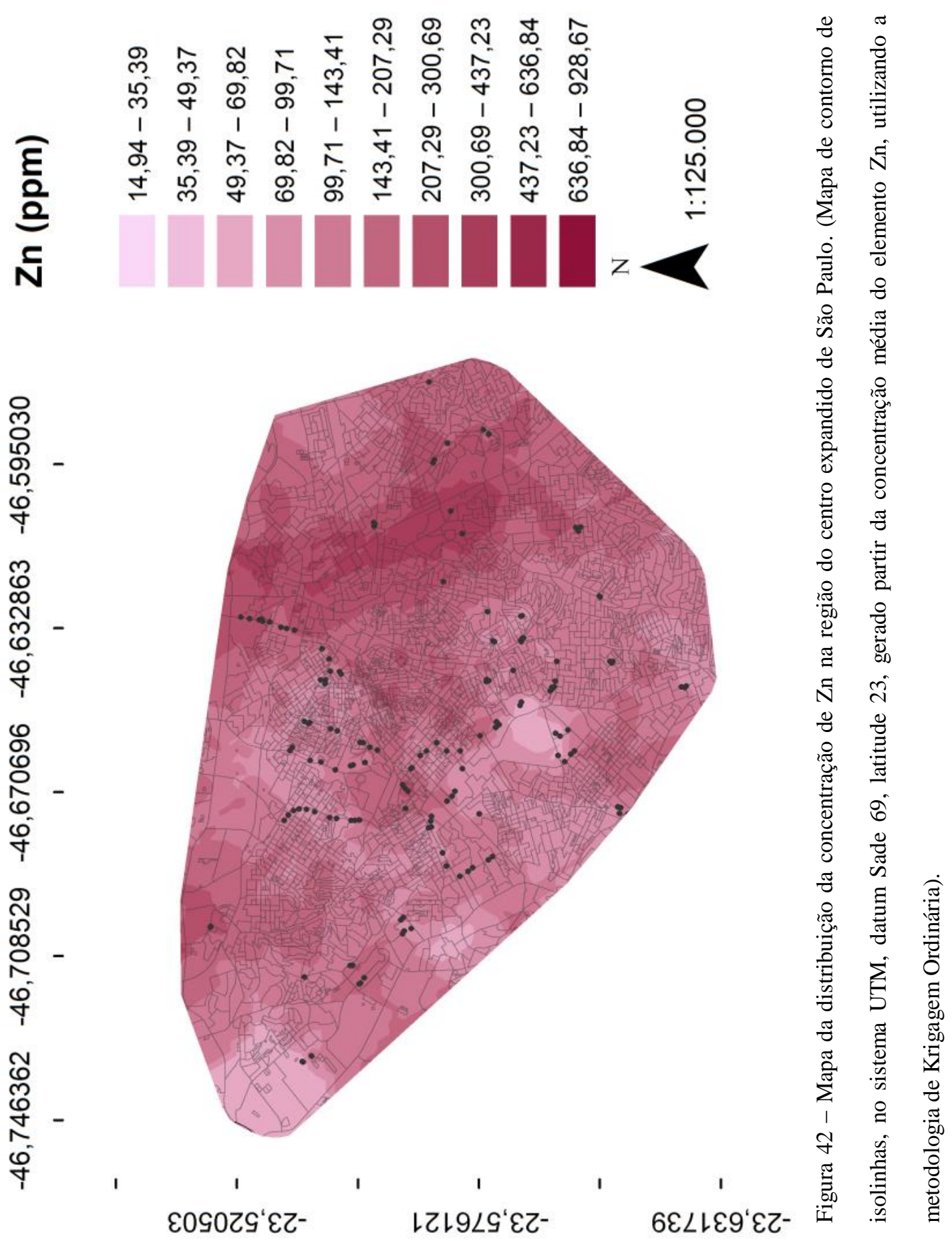




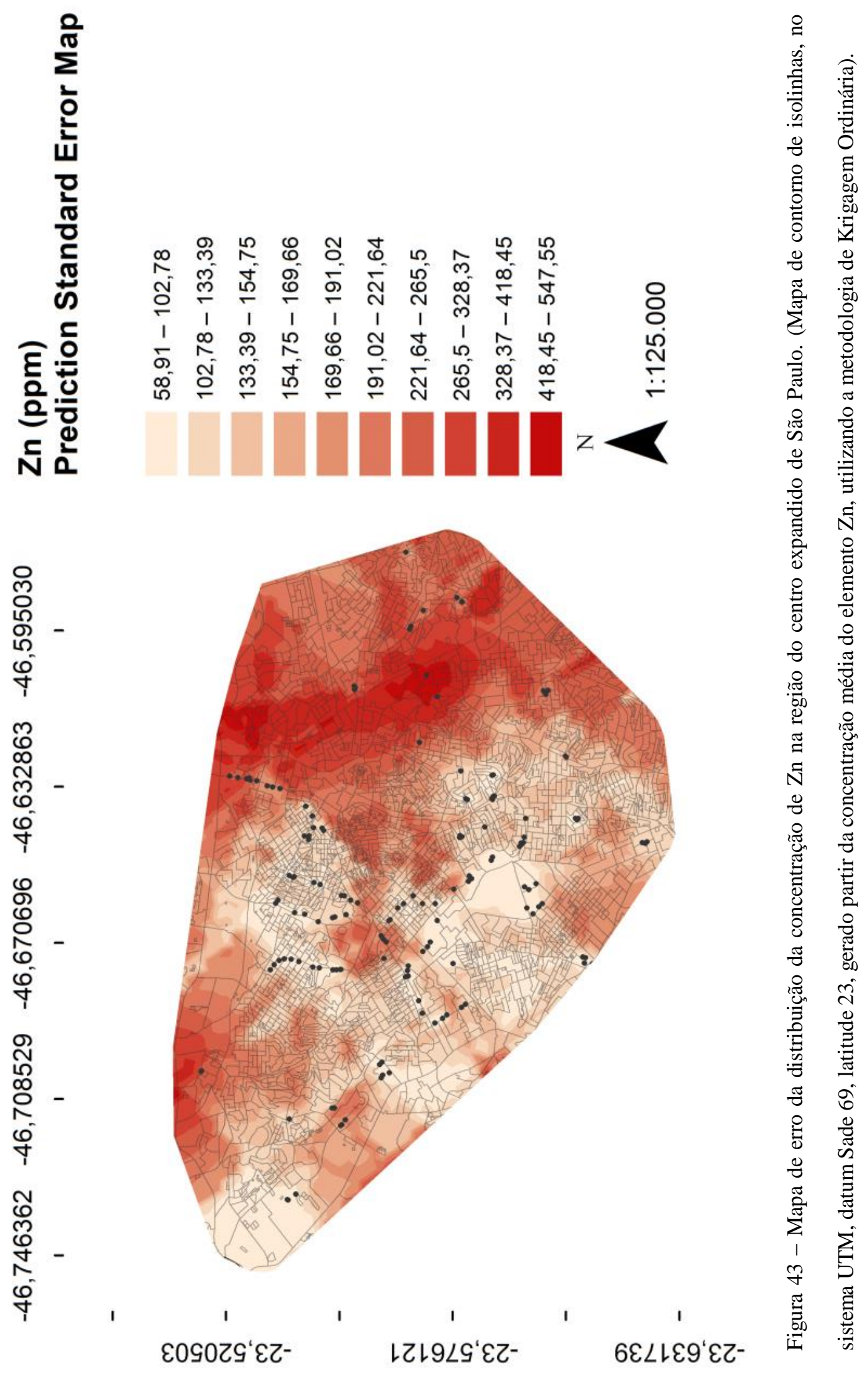




\section{Discussão}

A exposição à poluição atmosférica com diferentes concentrações e diferentes tipos de poluente é responsável por variados efeitos na saúde humana. A determinação da composição e concentração dos poluentes em microescala espacial irá permitir uma melhor compreensão desses efeitos.

A fonte de poluição que apresentou a maior representatividade neste estudo foi a veicular. Os elementos $(\mathrm{Ca}, \mathrm{S}, \mathrm{Mg}, \mathrm{Fe})$ encontrados em maior concentração podem ser considerados marcadores de tráfego. Quando foram determinadas as fontes de poluição atmosférica por meio da análise de componentes principais, observou-se que o componente que representava as fontes veiculares é responsável por aproximadamente $50 \%$ da fonte de poluição atmosférica na região estudada. Também foi possível diferenciar a origem da emissão veicular pelo tipo de elemento emitido, demonstrando que as emissões veiculares são resultantes principalmente do desgaste de peças dos veículos, bem como da queima de combustível, óleo e outros gases provenientes do escapamento.

Os resultados encontrados demonstraram que existem diferenças de emissão de poluentes atmosféricos conforme o tipo de via de tráfego. Essas diferenças podem ser tanto em relação à concentração quanto ao tipo dos elementos. Ainda foi possível observar que o biomonitoramento utilizando as cascas de árvore foi capaz de identificar variações no padrão de tráfego veicular.

Apesar de nossos resultados verificarem a contaminação do ar da região em micro e macroescala, conseguindo separar os tipos de tráfego, a estrapolação direta para os níveis de poluentes dispersos na atmosfera deve ser considerada com cautela. A concentração dos elementos encontrados nas cascas de árvore é consequência de um 
período de acumulação maior, na grandeza de anos, enquanto em filtros geralmente são resultado da amostragem de 24 horas.

Também deve ser considerado que o acúmulo desses elementos nas plantas pode decorrer não só da exposição aos poluentes da atmosfera como da soma destes adicionados aos elementos provenientes do solo, absorvidos pela raiz. Tais interferências não foram consideradas pela metodologia empregada neste estudo. Entretanto acreditamos que o resultado obtido com esta metodologia pode ser considerado como representativo da contaminação atmosférica. Isso porque, em nosso estudo, os elementos encontrados em maior concentração na área estudada foram o Ca, $\mathrm{S}, \mathrm{K}, \mathrm{Mg}, \mathrm{Fe}$, o que também foi verificado por Tositti et al. (2014) em um estudo utilizando filtros de quartzo na cidade de Bologna, Itália. Quando comparados os dois estudos, podemos observar um padrão na distribuição dos elementos encontrados em casca de árvore e nos filtros de quartz do estudo referido.

Esses elementos também estão presentes em altas quantidades na crosta terrestre, porém podem ser elementos considerados marcadores de tráfego veicular em razão da ressuspensão da poeira das vias, a qual contém elementos da emissão veicular enriquecidos com elementos provenientes da crosta terrestre. Schauer et al. (2006) relataram que a poeira da via possui elementos vindos da emissão ocasionada por desgaste de peças ( $\mathrm{Fe}$ ) e lançamento do escapamento ( $\mathrm{S}, \mathrm{Ca}, \mathrm{Mg})$.

Faggi et al. (2011), em um estudo de biomonitoramento com cascas de árvores nas cidades de Montevidéu e Buenos Aires, encontraram concentrações dos elementos na mesma ordem de grandeza que os resultados verificados neste estudo para vias de tráfego pesado e avenidas.

A análise das diferentes classificações das vias de tráfego mostrou que existe uma hierarquia da emissão dos elementos. As vias consideradas expressas possuem 
maiores concentrações dos elementos que as vias locais, observando-se a seguinte sequência: expressa $>$ arterial $>$ coletora $>$ local $>$ controle (Tabela 5, Figuras 14 e 15).

Segundo Apeagyei et al. (2011), os elementos podem ser diferenciados em cada via. No estudo na cidade de Boston, os elementos $\mathrm{Fe}, \mathrm{Ba}, \mathrm{Cu}$ e $\mathrm{Mo}$ apresentaram concentrações similares em todos os tipos de via. Nesse estudo, os elementos $\mathrm{Rb}$ e $\mathrm{Na}$ não apresentaram diferenças estatísticas significativas nos diversos tipos de classificação de vias de tráfego. No presente estudo, $\mathrm{Zn}$ e $\mathrm{Cu}$ apresentaram maiores concentrações nas vias de tráfego expresso. Apeagyei et al. (2011) também encontraram altas concentrações de Zn em áreas com tráfego mais pesado.

A emissão gerada pelo escapamento também pode conter diferentes elementos de acordo com o combustível utilizado. Estudos sobre a composição de combustíveis brasileiros mostram que a emissão de diesel utilizado no Brasil é composta predominantemente pelo $\mathrm{Ca}, \mathrm{Mg}$, Fe e Al (Loyola et al. , 2009). De acordo com a literatura e os resultados deste estudo é possível afirmar que apesar da pequena frota de veículos a diesel eles são responsáveis por emissões consideráveis de poluição atmosférica.

De acordo com os resultados da análise de componentes principais (Tabela 6), foram encontrados cinco grupos, os quais explicam 73,5\% dos dados, a saber: grupo 1 $(\mathrm{Al}, \mathrm{Fe}, \mathrm{Mn}, \mathrm{Cu}, \mathrm{Zn})$, grupo $2(\mathrm{Ca}, \mathrm{Sr})$, grupo $3(\mathrm{Cl}, \mathrm{Na})$, grupo $4(\mathrm{~K}, \mathrm{P})$ e grupo 5 ( Mg ). O grupo 1 explica 27,1 \% da variância. O tráfego veicular é a principal fonte emissora desses elementos, que estão relacionados principalmente à ressuspensão de poeira ( $\mathrm{Al}, \mathrm{Fe}, \mathrm{Cu})$ e elementos de desgaste de peças veiculares ( $\mathrm{Cu}$ e $\mathrm{Zn}$ ) (Wang et al., 2006). A análise de fatores não foi capaz de separar o grupo de emissões veiculares em desgaste de peças e ressuspensão da via e tão pouco distinguir a frota. O grupo 5 é explicado por $9,83 \%$ da variância dos dados e o elemento que o compõe $(\mathrm{Mg})$ está 
relacionado às emissões pelo escapamento veicular (queima de combustível, uso de aditivos e óleo lubrificante) $\mathrm{O}$ grupo 3 explica-se como aerossol marítimo; apesar de a cidade de São Paulo não se encontrar na região costeira, este aerossol é capaz de ser transportado em pequenas distâncias. A cidade de São Paulo encontra-se a aproximadamente $60 \mathrm{~km}$ da costa.

O grupo 4 pode ser identificado como queima de madeira. A emissão de $\mathrm{K}$, segundo dados de literatura, pode ser explicada pela queima de madeira (Thurston et al., 2011). A área amostrada possui diversas pizzarias e churrascarias que utilizam madeira para o cozimento, apontando que as cozinhas estão entre as potenciais fontes.

O grupo 2 pode ser explicado pela composição do cimento, tanto na pavimentação de vias e calçadas quanto em obras. A região amostrada possuía diversas construções e obras em andamento. Yeung et al. (2003) sugerem em seu estudo em Hong Kong que Ca e Sr são provenientes do material de pavimentação.

O programa da EPA, PMF 5.0, encontrou resultados similares à ACP, porém com algumas diferenças na composição das fontes. O PMF 5.0 foi desenvolvido para determinar as fontes poluidoras e ainda é pouco utilizado em estudos de biomonitoramento. O melhor resultado obtido pelo PMF 5.0 apresentou 5 fontes de poluição atmosférica (Tabela7 e Figura 17): aerossol marítimo $(\mathrm{Cl})$, crosta terrestre (Al, $\mathrm{Ba}, \mathrm{Mn})$, queima de biomassa $(\mathrm{K})$, composição da madeira (Ca, Na, P, S) e tráfego veicular ( $\mathrm{Fe}, \mathrm{Mg}, \mathrm{Pb}, \mathrm{Zn}$ ). Diferentemente da $\mathrm{ACP}$, ele foi capaz de separar os elementos da crosta e o tráfego, além de encontrar um componente relacionado com a composição da casca de árvore. Sen et al. (2010) constataram que, em cascas de Quercus cerris, os elementos em maior quantidade eram $\mathrm{Na}, \mathrm{Ca}, \mathrm{P}$ e K.

Os mapas de dispersão da concentração dos poluentes (Figuras 18 até 43) permitem a identificação das regiões da cidade com maior volume de tráfego, e a 
análise individual dos elementos possibilita a separação das áreas mais impactadas por veículos pesados e por veículos leves.

As maiores concentrações do $\mathrm{Al}$ são encontradas nas áreas com maior circulação de veículos pesados e próximas às vias expressas.

Os elementos $\mathrm{Cu}$ e $\mathrm{Zn}$ possuem concentrações elevadas principalmente na via expressa que é utilizada predominantemente por caminhões. A distribuição da concentração do Fe está localizada em áreas que possuem uma alta densidade de fluxo veicular tanto de veículos leves quanto pesados, assim como o Mn.

A dispersão do elemento $\mathrm{S}$ (enxofre) está relacionada aos corredores de ônibus indicando que a principal fonte de emissão veicular desse elemento é a frota de ônibus e o combustível utilizado.

Quando comparados o mapa de concentrações e o mapa de erros, é possível observar as áreas onde a interpolação dos dados é considerada fraca.

Os mapas também apontaram que locais como parques e outras áreas verdes geralmente possuem concentrações mais baixas de alguns elementos, principalmente aqueles que possuem partículas maiores. Esse fato pode ser explicado pela deposição desses elementos em razão do impacto e da sedimentação. A vegetação nessas áreas é responsável por fazer o papel de barreira (Irga et al. 2015, Pugh et al. 2012, Escobedo et al. 2011).

O material particulado mais grosso pode ser removido da atmosfera por meio de sedimentação ao encontrar barreiras como a vegetação (Irga et al. 2015).

As áreas centrais da cidade também mostram as maiores concentrações quando analisadas pelo mapa, regiões estas com alto tráfego veicular e algumas com as maiores taxas de tráfego de veículos pesados. 
A análise discriminante mostrou que as vias podem ser classificadas segundo a emissão dos veículos diferentemente da classificação oficial dos órgãos governamentais, mostrando que, para estudos de emissões veiculares, é mais importante determinar a concentração de elementos nas vias do que predizer as concentrações conforme o tipo de via. Os 99 pontos classificados como ruas arteriais tornaram-se 35 ruas arteriais, 21 coletoras arteriais, 19 arteriais expressas e 24 arteriais locais. Fatores, tais como praças, obstáculos verticais, canteiros centrais com árvores, garagens e estacionamentos podem alterar a caracterização local em termos de concentração de elementos e, consequentemente, o perfil de local de exposição. Em nosso estudo, a análise de cascas de árvore coletadas próximo de garagens em ruas de tráfego de baixa densidade mostrou características de emissão semelhante àquelas encontradas em ruas com alta densidade de tráfego. Por outro lado, amostras de cascas de árvore localizadas em praças e canteiros centrais com árvores em vias de alta densidade de tráfego veicular mostraram emissão característica das ruas com baixa densidade de tráfego.

Esses resultados encontrados demonstram a relevância do uso de cascas de árvore como um monitor passivo de distribuição de poluentes do ar. Geralmente, a urbanização nos países em desenvolvimento ocorre sem planejamento da ocupação do solo e sem considerar o impacto disso sobre a saúde dos residentes. Portanto, a utilização de metodologias simples e sensíveis, capazes de identificar a distribuição de poluição do ar em pequena escala espacial, pode desempenhar um papel importante para melhorar o planejamento de urbanização.

Comparando-se os resultados das concentrações de elementos poluentes encontrados nas cascas de árvore em relação à exposição das pessoas a tais poluentes, observou-se que as pessoas que estão em vias de tráfego com alta densidade e alto fluxo de veículos estão mais expostas aos poluentes que aquelas presentes em outras vias. 
Também foi possível concluir que pessoas que vivem em vias de baixo fluxo e densidade de veículos nas quais houver algum obstáculo próximo que aumente o desgaste de peças e a emissão pelo escapamento do veículo, como faróis, ladeiras, lombadas, entre outros, podem estar sujeitas aos poluentes. Verificou-se que a presença de áreas verdes, como praças e canteiros, em locais de alto tráfego pode diminuir as concentrações de poluentes nas árvores amostradas.

Comparando-se os resultados das concentrações de elementos poluentes encontrados nas cascas de árvore em relação à exposição das pessoas a tais poluentes, observou-se que as pessoas que estão em vias de tráfego com alta densidade e alto fluxo de veículos estão mais expostas aos poluentes que aquelas presentes em outras vias.

Também foi possível concluir que pessoas que vivem em vias de baixo fluxo e densidade de veículos nas quais houver algum obstáculo próximo que aumente o desgaste de peças e a emissão pelo escapamento do veículo, como faróis, ladeiras, lombadas, entre outros, podem estar sujeitas aos poluentes. Verificou-se que a presença de áreas verdes, como praças e canteiros, em locais de alto tráfego pode diminuir as concentrações de poluentes nas árvores amostradas.

A distribuição irregular das árvores na cidade assim como a falta de árvores pode ser considerada uma limitação deste trabalho. Outra limitação observada é em relação à técnica de EDXRF quando utilizada para a análise de casca de árvore já que alguns elementos apresentam concentrações abaixo do limite de detecção do método. 


\section{Conclusões}

A técnica de biomonitoramento utilizando cascas de árvore permitiu determinar quais os tipos de vias pela análise dos elementos químicos emitidos. A análise da determinação do tipo de frota veicular predominante na área não apresentou resultados satisfatórios.

Essa técnica possibilita criar uma distribuição espacial dos poluentes em microescala, fornecendo um conjunto de dados mais precisos para serem utilizados em estudos epidemiológicos.

Os resultados permitiram identificar áreas com maior abundancia de elementos químicos e indicar as possíveis fontes de poluição atmosférica utilizando a técnica de biomonitoramento. Foi possível também obter uma classificação das vias de acordo com a emissão de poluentes. 


\section{Referências Bibliográficas}

Allaby M, Park C (Eds.). Dictionary of Environment and Conservation. Oxford University Press; 2013.

Apeagyei E, Bank MS, Spengler JD. Distribution of heavy metals in road dust along an urban-rural gradient in Massachusetts.Atmospheric Environment. 2011:45(13): 23102323.

Arbex MA, Santos US, Martins LC, Saldiva PHN, Pereira LA, Braga ALF . A poluição do ar e o sistema respiratório. Jornal Brasileiro Pneumologia. 2012; 38 (5): 643-655.

Assunção JV. Controle ambiental do ar. In: Philippi Jr. A; Roméro Ma., BRUNA GC, editors. Curso de gestão ambiental. Barueri: Manole, 2004. 4, 101-154.

Austin E, Coull BA, Zanobetti A, Koutrakis P . A framework to spatially cluster air pollution monitoring sites in US based on the PM 2.5 composition. Environment International. 2013; 59, 244-254.

Bargagli R. Trace elements in terrestrial plants. An ecophysiological approach to biomonitoring and biorecovery. New York : Springer; 1998.

Bell ML, Morgenstern RD, Harrington W. Quantifying the human health benefits of air pollution policies: review of recent studies and new directions in accountability research. Environmental Science \& Policy. 2011;14 (4): 357-368.

Bereitschaft, B, Debbage, K .Urban form, air pollution, and CO2 emissions in large US metropolitan areas. The Professional Geographer. 2013;65 (4): 612-635.

Bona IAT, Sarkis JES, Salvador VLR, Soares ALR, Klamt SC. Análise arqueométrica de cerâmica Tupiguarani da região central do Estado do Rio Grande do Sul, Brasil, usando fluorescência de raios X por dispersão de energia (EDXRF). Química Nova. 2007; 30 (4): 785-90.

Brasil. Lei No 9.503, de 23 de Setembro de 1997. Código de Trânsito Brasileiro. Diário Oficial da União 24 set 1997. p.21201.

Bravo MA, Son J, de Freitas CU, Gouveia N, Bell ML . Air pollution and mortality in São Paulo, Brazil: Effects of multiple pollutants and analysis of susceptible populations. Journal of Exposure Science and Environmental Epidemiology. 2015.( doi:10.1038/jes.2014.90).

Carneiro MFH, Ribeiro FQ, Fernandes-Filho FN, Lobo DJA, Barbosa F, Rhoden CR, Mauad T, Saldiva PHN, Carvalho-Oliveira R. Pollen abortion rates, nitrogen dioxide by passive diffusive tubes and bioaccumulation in tree barks are effective in the characterization of air pollution. Environmental and Experimental Botany, 2011; 72 (2): 272-277. 
Catinon M, Ayrault S, Clocchiatti R, Boudouma O, Asta J, Tissut M, Ravanel P. The anthropogenic atmospheric elements fraction: a new interpretation of elemental deposits on tree barks. Atmospheric Environment. 2009; 43 (5): 1124-1130.

Companhia Ambiental do Estado de São Paulo (CETESB), (2009). São Paulo (Estado). Evolução das Concentrações de Chumbo na Atmosfera da Região Metropolitana de São Paulo. Disponível em:<http://www. http://ar.cetesb.sp.gov.br/publicacoes-relatorios/ >. Acesso em 30 out. 2014.

Companhia Ambiental do Estado de São Paulo (CETESB), (2013). São Paulo (Estado). Secretaria do meio ambiente. Companhia Ambiental do Estado de São Paulo (CETESB). Relatório da qualidade do ar 2012. Disponível em: <http://www.cetesb.sp.gov.br/ar/qualidade-do-ar/31-publicacoes-e-relatorios>.

Acesso: 30 mar. 2015.

Companhia Ambiental do Estado de São Paulo (CETESB), (2014). São Paulo (Estado). Emissões Veiculares no Estado de São Paulo 2013 (CETESB). Disponível em:<http://www.cetesb.sp.gov.br >. Acesso em 30 out. 2014.

Companhia Ambiental do Estado de São Paulo (CETESB), (2015). São Paulo (Estado). Emissões Veiculares no Estado de São Paulo 2014 (CETESB). Disponível em:<http://www.cetesb.sp.gov.br >. Acesso em 30 jun. 2015.

Companhia Ambiental do Estado de São Paulo (CETESB), (2015). São Paulo (Estado). Secretaria do meio ambiente. Companhia Ambiental do Estado de São Paulo (CETESB). Disponível em:<http://www. http://veicular.cetesb.sp.gov.br/proconve/>.

Companhia de Engenharia de Tráfego (CET), 2013. Desempenho do Sistema Viário Principal - Volume e Velocidade - 2012. Disponível em: http://www.cetsp.com.br/sobre-a-cet/relatorios-corporativos.aspx. Acesso em 25 mar. 2014.

Companhia de Engenharia de Tráfego (CET), 2013. Rodizio Municipal. Disponível em: http://www.cetsp.com.br/consultas/rodizio-municipal/como-funciona.aspx. . Acesso em 25 mar. 2015.

Conselho Nacional do Meio Ambiente - CONAMA. Resolução n ${ }^{\circ}$ 03, de 28 de junho de 1990. Dispõe sobre padrões de qualidade do ar, previstos no PRONAR. Disponível em: http://www.mma.gov.br/port/conama/legiabre.cfm?codlegi=100. Acesso: 4 abr. 2015.

Dai L, Zanobetti A, Koutrakis P, Schwartz JD . Associations of fine particulate matter species with mortality in the United States: A multicity time-series analysis. Environmental Health Perspectives. 2014;

(http://dx.doi.org/10.1289/ehp.1307568).

Departamento Estadual de Trânsito (DETRAN). Frota de veículos. Disponível em: http://www.detran.sp.gov.br/frota.asp. Acesso em 25 out. 2013. 
Dos Santos Cruz LP, Campos, VP. Amostragem passiva de poluentes atmosféricos. Aplicação ao SO2. Quimica Nova. 2002; 25 (3): 406-411.

Ebisu K, Bell ML .Airborne PM 2.5 Chemical Components and Low Birth Weight in the Northeastern and Mid-Atlantic Regions of the United States. Environmental Health Perspectives. 2012; 120 (2): 1746-1752.

EPA, Estados Unidos. Environmental Protection Agency. Master list of compounds emitted by mobile source. Washington (2006). Disponível em http://www.epa.gov/otaq/toxics.htm. Acesso em 15 set. 2013.

EPA, Estados Unidos. Environmental Protection Agency. Chemical Speciation Network (CSN). Disponivel em http://www.epa.gov/ttnamti1/speciepg.html. Acesso em 25/4/2015).

Ericsson E. Variability in urban driving patterns. Transportation Research Part D: Transport and Environment. 2000; 5 (5): 337-354.

Escobedo, FJ, Kroeger T, Wagner, JE. Urban forests and pollution mitigation: Analyzing ecosystem services and disservices. Environmental pollution. 2011; 159 (8): 2078-2087.

Faggi AM, Fujiwara F ,Anido C, Perelman, PE. Use of tree bark for comparing environmental pollution in different sites from Buenos Aires and Montevideo. $J$ Environmental Monitoring and Assessment. 2011; 178, 237-245.

Ferreira MI, Domingos M, Gomes HAG, Saldiva PHN, Assunção JV. Evaluation of mutagenic potential of contaminated atmosphere at Ibirapuera Park, São Paulo - SP, Brazil, using the Tradescantia stamen-hair assay, Environmental Pollution. 2007; 145 (1): 219-224.

Figueiredo AMG, Nogueira CA, Saiki M, Milian FM, Domingos M. Assessment of atmospheric metallic pollution in the metropolitan region of São Paulo, Brazil, employing Tillandsia usneoides L. as biomonitor. Environmental Pollution. 2007; 145 (1): 279-292.

Guarnieri M, Balmes JR . Outdoor air pollution and asthma. The Lancet. 2014; 383(9928): 1581-1592.

Guéguen F, Stille P, Geagea Ml, Boutin R. Atmospheric pollution in an urban environment by tree bark biomonitoring-Part I: Trace element analysis. Chemosphere. 2012; 86 (10): 1013-1019.

Habermann M, Gouveia N. Application of land use regression to predict the concentration of inhalable particular matter in São Paulo city, Brazil. Engenharia Sanitaria e Ambiental. 2012; 17 (2):155-162.

Health Effects Institute (HEI). Panel on the Health Effects of Traffic-Related Air Pollution. (2010) Traffic-related Air Pollution: A Critical Review of the Literature on 
Emissions, Exposure, and Health Effects (No. 17). Health Effects Institute, Boston Massachusetts .

Hu J, Zhang H, Chen S, Ying Q, Wiedinmyer C, Vandenberghe F, Kleeman MJ. Identifying $\mathrm{PM}_{2.5}$ and $\mathrm{PM}_{0.1}$ sources for epidemiological studies in California. Environmental Science \& Technology. 2014; 48 (9): 4980-4990.

Instituto Brasileiro de Geografia e Estatística (IBGE). Censo 2010. [Citado em 25 de jul de 2012] Disponível em: http://www.censo2010.ibge.gov.br.

Irga PJ, Burchett MD, Torpy F R. Does urban forestry have a quantitative effect on ambient air quality in an urban environment?. Atmospheric Environment. 2015; 120: 173-181.

Jerrett M, Burnett RT, Kanaroglou PS, Eyles J, Finkelstein N, Brook JR, Giovis C. A GIS F environmental justice analysis of particulate air pollution in Hamilton, Canada. Environment and Planning A. 2001; 33: 955-973.

Johnson R A, Wichern D W. Applied multivariate statistical analysis .6ed.Uper Saddle River. Ed. Pearson Prentice Hall, 2007. 773p.

Kabata-Pendias A. Trace elements in soils and plants. 4ed. Boca Raton: CRC Press; 2011.520p.

Kampa M, Castanas E. Human health effects of air pollution. Environmental Pollution. 2008; 151 (2): 362-367.

Kenneth W, Warner CF. Air pollution: its origin and control. New York, Harper and Row Publishers, 1981. 526p.

Laschober C, Limbeck A, Rendl J, Puxbaum H. Particulate emissions from on-road vehicles in the Kaisermühlen-tunnel (Vienna, Austria). Atmospheric Environment, 2004; 38 (14): 2187-2195.

Lepage ES, (coord.) Manual de preservação de madeiras. São Paulo, IPT/SICCT, 1986. $708 \mathrm{p}$.

Lepeule J, Laden F, Dockery DW, Schwartz JD. Chronic exposure to fine particles and mortality: an extended follow-up of the Harvard Six Cities study from 1974 to 2009. Environmental Health Perspectives. 2012; 120: 965-970.

Lippmann M . Semi-continuous speciation analyses for ambient air particulate matter: an urgent need for health effects studies. Journal of Exposure Science and Environmental Epidemiology. 2009; 19 (3): 235-247.

Lodenius M. Biomonitoring of air borne metal pollution. Air Pollution XXII, 183, 75. Edited By: J.W.S. Longhurst, University of the West of England, UK; C.A. Brebbia, Wessex Institute of Technology, UK; 2014. 
Loyola J, Arbilla G, Quiterio S L, Escaleira V, Bellido A V. Concentration of airbone trace metals in a bus station with a high heavy-duty diesel fraction. Journal of the Brazilian Chemical Society. 2009; 20, (7): 1343-1350.

Lötschert W, Köhm HJ. Characteristics of tree bark as an indicator in high-immission areas. Oecologia. 1978; 37 (1): 121-132.

Maher BA, Moore C, Matzka J. Spatial variation in vehicle-derived metal pollution identified by magnetic and elemental analysis of roadside tree leaves. Atmospheric Environment. 2007; 42 (1): 364-373.

Markert, BA, Breure, AM, Zechmeister, HG. Definitions, strategies and principles for bioindication/biomonitoring of the environment.Trace Metals and other Contaminants in the Environment. 2003; $6: 3-39$.

Martins, APG Cascas de árvores como biomonitores da poluição atmosférica de origem veicular em parques urbanos da cidade de São Paulo. 2009. [Tese]. São Paulo: Faculdade de Medicina, Universidade de São Paulo, 2009.

Maynard D, Coull BA, Gryparis A, Schwartz J. Mortality risk associated with shortterm exposure to traffic particles and sulfates. Environmental Health Perspectives. 2007; 115 (5): 751-755.

Mills NL, Donaldson K, Hadoke PW, Boon NA, MacNee W, Cassee F R, Newby DE . Adverse cardiovascular effects of air pollution. Nature Clinical Practice Cardiovascular Medicine. 2009; 6 (1): 36-44.

Narewski U, Werner G, Schulz H, Vogt C. Application of laser ablation inductively coupled mass spectrometry (LA-ICP-MS) for the determination of major, minor, and trace elements in bark samples. Fresenius' Journal of Analytical Chemistry. 2000; 366 (2):167-170.

Nel A. Air pollution-related illness: effects of particles. Science. 2005; 308 (5723): 804-806.

Norris G, Duvall R., Wade K., Brown, S., Bai.S. EPA positive matrix factorization (PMF) 5.0 fundamentals \& u ser guide. US Environmental Protection Agency, Washington, DC. 2014.124p.

Nylander W. Les lichens Du Jardin du Luxembourg. Paris: Bulletin de la Societé Botanique de France 13:364, 1886 apud Wolterbeek B, Sarmento S, Verburg T. Is there a future for biomonitoring of elemental air pollution? A review focused on a largerscaled health-related (epidemiological) context. Journal of Radioanalytical and Nuclear Chemistry. 2010; 286: 195-210.

Olowoyo JO, Van Heerden E, Fischer JL. Investigating Jacaranda mimosifolia tree as biomonitor of atmospheric trace metals. Environmental Monitoring and Assessment. 2010; 164 (1-4): 435-443. 
OMS (Organização Mundial de Saúde) Regional Office for Europe, OECD (2015). Economic cost of the health impact of air pollution in Europe: Clean air, health and wealth. Copenhagen: WHO Regional Office for Europe.

OMS (Organização Mundial de Saúde). (2012) 7 million premature deaths annually linked to air pollution Disponível em:

http://www.who.int/mediacentre/news/releases/2014/air-pollution/en/. Acessado em $10 / 08 / 2015$.

Pacheco AM, Freitas MC, Barros LI, Figueira R. Investigating tree bark as an airpollution biomonitor by means of neutron activation analysis. Journal of Radioanalytical and Nuclear Chemistry. 2001; 249 (2): 327-331.

Pandian S, Gokhale S, Ghoshal AK. Evaluating effects of traffic and vehicle characteristics on vehicular emissions near traffic intersections. Transportation Research Part D: Transport and Environment. 2009; 14 (3): 180-196.

Perelman P, Faggi A, Castro M, Carretero EM. Pollution trends using bark of morusalba in the cities of Buenos Aires and Mendoza (Argentina). Revista Arvore. 2010; 34 (3): 505-511.

Pope III CA, Ezzati M, Dockery DW.Fine-particulate air pollution and life expectancy in the United States.The New England Journal of Medicine.2009;360 (4):376 - 386.

Powell, RL. The use of vascular plants as "field" biomonitors. In: Lower WR, Gorsuch JW, Hughes J. Plants for environmental studies. Plants for environmental studies. Boca Raton: CRC Press; 1997. p. 335-365.

Pugh TA, MacKenzie AR, Whyatt,JD, Hewitt CN. Effectiveness of green infrastructure for improvement of air quality in urban street canyons. Environmental science \& technology. 2012; 46 (14): 7692-7699.

Richardson DHS, Shore M, Hartree R, Richardson RM. The use of X-ray fluorescence spectrometry for the analysis of plants, especially lichens, employed in biological monitoring. Science of the Total Environment. 1995; 176 (1): 97-105.

Ritcher HG, Mazzoni-Viveiros, SC; Alves ES; Luchi AE; Costa CG. Padronização de critérios para a descrição anatômica da casca: lista de características e glossário de termos. IF. Serie Registros, 1996; 161-25.

Samara C, Voutsa D. Size distribution of airborne particulate matter and associated heavy metals in the roadside environment. Chemosphere. 2005; 59 (8):1197-1206.

Sant'Anna SMR, Esposito MP, Domingos M, Souza SR. Suitability of Nicotiana tabacum 'Bel W3' for biomonitoring ozone in São Paulo, Brazil, Environmental Pollution. 2008; 151 (2): 389-394.

Santos APM, Segura-Muñoz SI, Nadal M, Schuhmacher M, Domingo JL, Martinez CA, Takayanagui AMM. Traffic-related air pollution biomonitoring with Tradescantia 
pallida (Rose) Hunt. cv. purpurea Boom in Brazil. Environmental Monitoring and Assessment. 2015; 187 (2): 1-10.

São Paulo (Estado). Leis etc. Decreto n. 59113 de 23 de abril de 2013. Estabelece novos padrões de qualidade do ar e dá providências correlatas. Disponível em: http://www.al.sp.gov.br/repositorio/legislacao/decreto/2013/decreto-59113-23.

04.2013.html. Acesso: $1^{\circ}$ abr. 2015.

Sawidis T, Breuste J, Mitrovic M, Pavlovic P, Tsigaridas K. Trees as bioindicator of heavy metal pollution in three European cities. Environmental Pollution. 2011; 159 (12): 3560-3570.

Schauer JJ, Lough GC, Shafer MM, Christensen WF, Arndt MF, Deminter JT, Park JS. Characterization of metals emitted from motor vehicles. Research Report. Health Effects Institute. 2006; 133: 1-88.

Schelle E, Rawlins BG, Lark RM, Webster R, Staton I, McLeod C W. Mapping aerial metal deposition in metropolitan areas from tree bark: a case study in Sheffield, England. Environmental Pollution. 2008; 155, (1): 164-173.

Şen A, Miranda I, Santos S, Graça J, Pereira H. (2010). The chemical composition of cork and phloem in the rhytidome of Quercuscerris bark. Industrial Crops and Products. 2010; 31, (2): 417-422.

Senhou A, Chouak A, Cherkaoui R, Lferde M, Elyahyaoui A, El Khoukhi T, Bouhakhla M, Embarchek K, Gaudry A, Ayrauld S, Piccot D. Comparison of 14 MeV-NAA, k 0NAA and ED-XRF for air pollution biomonitoring. Journal of Radioanalytical and Nuclear Chemistry. 2002; 253 (2): 247-252.

Silva MF. Emissão de metais por veículos automotores e seus efeitos à saúde pública. [Dissertação]. São Paulo: Faculdade de Saúde Pública da Universidade de São Paulo; 2007.

Spangenberg A, Hofmann F, Kirchner M. Determining the agricultural ammonia immission using bark biomonitoring: comparison with passive sampler measurements. Journal of Environmental Monitoring. 2002; 4 (6): 865-869.

Su JG, Apte JS, Lipsitt J, Garcia-Gonzales DA, Beckerman BS, de Nazelle A, Texcalac-Sangrador JL, Jerrett M. Populations potentially exposed to traffic-related air pollution in seven world cities. Environment International. 2015; 78: 82-89.

Thurston GD, Ito K, Lall R. A Source apportionment of U.S. fine particulate matter air pollution. Atmospheric Environment. 2011; 45(24):3924-3936.

Toledo GIFM, Nardocci AC. Análise do uso de dados modelados de tráfego para avaliação da exposição à poluição veicular: um estudo de caso. Revista de Ciências Ambientais, 2013; 6 (2): 19-34. 
Toledo GIFM. Avaliação da exposição da população à poluição relacionada ao trafego no município de São Paulo. [Tese]. São Paulo: Faculdade de Saúde Pública da Universidade de São Paulo; 2010.

Tositti L, Brattich E, Masiol M, Baldacci D, Ceccato D, Parmeggiani S, Straquadanio M, Zappoli S. (2014). Source apportionment of particulate matter in a large city of southeastern Po Valley (Bologna, Italy). Environmental Science and Pollution Research. 2014; 21 (2): 872-890.

Upreti DK, Divakar PK,Shukla,V, Bajpai, R. Recent Advances in Lichenology. Springer, India; 2015.

Vasconcellos PC, Souza DZ, Ávila SG, Araújo MP, Naoto E, Nascimento KH, Cavalcante FS, Dos Santos M. and Smichowski P, Behrentz E. Comparative study of the atmospheric chemical composition of three South American cities. Atmospheric Environment. 2011; 45 (32): 5770-5777.

Wang X, Bi X, Sheng G, Fu J. (2006). Chemical composition and sources of PM10 and PM2. 5 aerosols in Guangzhou, China. Environmental Monitoring and Assessment. 2006; 119 (1-3): 425-439.

Wolterbeek B, Sarmento S, Verburg T. Is there a future for biomonitoring of elemental air pollution? A review focused on a larger-scaled health-related (epidemiological) context. Journal of Radioanalytical and Nuclear Chemistry. 2010; 286 (1):195-210.

Yeung ZLL, Kwok RCW, Yu KN. Determination of multi-element profiles of street dust using energy dispersive X-ray fluorescence (EDXRF). Applied Radiation and Isotopes. 2003; 58 (3): 339-346.

Zanobetti A, Austin E, Coull BA, Schwartz J, Koutrakis P . Health effects of multipollutant profiles. Environment International. 2014; 71: 13-19.

Zhao Y, Wang Q, Yang L, Li Z, Satake K, Tsunoda KI. Alternative normalization method of atmospheric polycyclic aromatic hydrocarbons pollution level recorded by tree bark. Environmental Science \& Technology. 2006; 40 (19): 5853-5859. 